\title{
Experimental and numerical studies of reinforced concrete columns confined by circular steel tubes exposed to fire
}

\author{
Faqi Liu ${ }^{\mathrm{a}, \mathrm{b}}$, Yuyin Wang ${ }^{\mathrm{a}, \mathrm{b}}$, Leroy Gardner ${ }^{\mathrm{c}}$, Amit H. Varma ${ }^{\mathrm{d}}$
}

${ }^{a}$ Key Lab of Structures Dynamic Behavior and Control (Harbin Institute of Technology), Ministry of Education, Heilongjiang, Harbin, 150090, China

${ }^{b}$ Key Lab of Smart Prevention and Mitigation of Civil Engineering Disasters of the Ministry of Industry and Information Technology, Harbin Institute of Technology, Harbin, 150090, China

${ }^{c}$ Department of Civil and Environmental Engineering, South Kensington Campus, Imperial College London, SW7 2AZ, UK

${ }^{d}$ School of Civil Engineering, Purdue University, West Lafayette, IN 47907, USA

\section{Abstract:}

Reinforced concrete columns confined by steel tubes, also known as steel tube confined reinforced concrete (STCRC) columns, are a kind of composite column in which the outer steel tube acts predominantly as hoop reinforcement. This is achieved by the provision of breaks to the longitudinal continuity of the steel tube. The compressive behavior and seismic performance of STCRC columns have been extensively studied in the past few decades. However, knowledge of the fire behavior of STCRC columns is very limited. Hence, experimental and numerical studies to investigate the response of STCRC columns under combined thermal (fire) and structural loading are presented herein. Four full-scale STCRC columns and one concrete-filled steel tubular (CFST) column were first axially loaded and then subjected to the ISO 834 standard fire until failure. The measured furnace temperatures, specimen temperatures, axial displacement versus time curves and fire resistance of the columns are presented and discussed. A nonlinear finite element model, employing a sequentially coupled thermal-stress analysis, was then developed in ABAQUS and validated against recent fire tests on STCRC columns and concrete-filled steel tubular (CFST) columns reported in the literature. Following extensive parametric studies, a simplified method is proposed for predicting the temperatures of the steel tube, the reinforcing bars and the concrete. Design rules are then proposed for predicting the load-bearing capacity of STCRC columns exposed to the ISO 834 standard fire, 
which are consistent with the design method for STCRC columns at ambient temperature.

Key words: experiments, fire resistance, finite element, steel tube confined reinforced concrete, temperature, design method 


\section{Introduction}

2 Steel tube confined reinforced concrete (STCRC) columns are composite columns where the outer

3 steel tube serves principally as hoop reinforcement. This is achieved by breaking the longitudinal

4 continuity of the steel tube (i.e. introducing gaps). In this arrangement, the confinement effect to the

5 concrete occurs from the onset of loading and can be maximized, which greatly enhances the

6 strength and ductility of the concrete. Local buckling of the steel tube in STCRC columns is

7 generally prevented or at least delayed compared to that in concrete-filled steel tubular (CFST)

8 columns, since no vertical load is directly applied to the tube; this allows much thinner steel tubes to

9 be used in STCRC columns than in CFST columns. In order to prevent load being applied to the tube

10 directly, the steel tube is usually terminated at the beam to column connections, rather than being

11 continuous. STCRC column to reinforced concrete beam connections are therefore similar to

12 connections in reinforced concrete structures, and can be designed and constructed following

13 established methods for conventional reinforced concrete.

14 Numerous studies have been conducted to date on the compressive behavior and seismic 15 performance of this kind of column (Tommi et al. 1985a, 1985b; Sakino et al. 1985; Aboutaha et al. 16 1998, 1999; Sun and Sakino 2000; Sun and Fukuhara 2005; Han et al. 2005a, 2009; Liu and Zhou 17 2010; Liu et al. 2015; Wang et al. 2015; Zhou et al. 2016; Wang and Liu 2017). However, the 18 behavior of circular STCRC columns at elevated temperatures has received less attention. Hence, the

19 fire and post-fire behavior of STCRC columns is the focus of ongoing research by the authors. The 20 post-fire response of STCRC columns, including their cross-sectional behavior, buckling behavior 21 and behavior under combined compression and bending, were experimentally and numerically 22 studied by the authors and presented by Liu et al. (2014), Yang et al. (2015) and Liu et al. (2016), 23 respectively. The present paper focuses on the performance of STCRC columns subjected to standard 24 fire conditions, in order to evaluate the fundamental behavior of these columns in fire and to obtain essential information to underpin their fire safety design. STCRC columns resemble to CFST

26 columns in appearance, and research methods of fire performance of CFST columns can be referred

27 to. To date, extensive studies on fire performance of CFST columns have been conducted, especially 28 by research groups led by Lie and Kodur (Lie and Chabot 1992; Chabot and Lie 1992; Lie 1994; Lie 
29 and Kodur 1996; Kodur and Lie 1996; Kodur 1999; Schaumann et al. 2009) and Han (Han et al. 30 2003a; 2003b; 2003c; 2005b; Yang et al. 2008; Han et al. 2012). Amongst them, constitutive model 31 for the confined core concrete under/after elevated temperatures with the "confinement factor" as an 32 essential variable (Han 2007; Yang et al 2008) was established, which provides an essential base for 33 the investigations of full-range fire exposed concrete-filled steel tubular columns. From the above 34 research onwards, the research on fire performance of CFST columns has been further continued 35 (Ding and Wang 2008; Espinos et al. 2010; Espinos et al. 2011; Hong and Varma 2009; Ibáñez et al. 36 2013; Tao et al. 2012, 2016; Neuenschwander et al. 2017a; Xiong and Liew 2016; Yang et al. 2013a, 37 2013b; Yu et al. 2018).

38 Fire tests were first conducted to investigate the behavior of circular STCRC columns subjected to 39 the ISO 834 standard fire. Five full-scale specimens, including four STCRC columns and one CFST 40 column, were tested to failure under combined thermal and structural loading. The furnace and 41 specimen temperatures, the axial deformation versus time curves, the fire resistance and the failure 42 modes of the specimens were all recorded during the tests. Following testing, an advanced finite 43 element (FE) model was developed using the program ABAQUS, utilizing a sequentially coupled 44 thermal-stress analysis, to investigate the fire performance of circular STCRC columns. The FE 45 model incorporates key features, such as the thermal resistance at the steel tube and concrete 46 interface, the variation of the Poisson's ratio of concrete at elevated temperatures and the variation of 47 the bi-axial compressive strength to uniaxial compressive strength ratio of concrete at elevated 48 temperatures. The FE model was validated against the fire test results presented herein on the 49 STCRC columns, as well as existing tests on CFST columns (Lie and Chabot 1992; Chabot and Lie 50 1992; Espinos et al. 2015). Following validation of the model, the influence of key parameters on the 51 cross-sectional temperature development are identified, and simplified methods are proposed for 52 predicting the temperatures of the outer steel tube, inner concrete and reinforcing bars. A design 53 method for evaluating the load-bearing capacity of STCRC columns exposed to fire is then presented, 54 which can be employed to predict the fire resistance of STCRC columns. 


\section{Experimental program}

\section{General information}

57 In the experimental program, five full-scale specimens, including four circular steel tube confined reinforced concrete (STCRC) columns and one concrete-filled steel tubular (CFST) column, were tested to failure under the ISO 834 standard fire conditions (1999). Plain concrete-filled steel tubular columns are usually used in practice in China and hence a plain CFST column was employed herein for comparison purposes. The influence of three parameters on the fire behavior of these columns was investigated: load ratio $(n=0.25,0.33,0.42)$, frequency of breaks to the longitudinal continuity of the steel tube (case (a) and case (b), which are defined below) and type of specimen (STCRC or CFST). Table 1 summarizes the details of the specimens, where $D$ is the cross-sectional diameter, $t_{\mathrm{s}}$ is the wall thickness of the steel tube, $L$ is the length of the specimens, $\alpha_{\mathrm{s}}$ is the steel tube to concrete area ratio, $\alpha_{\mathrm{b}}$ is the reinforcement ratio, $N_{\mathrm{f}}$ is the applied axial load and $n$ is the load ratio $\left(n=N_{\mathrm{f}} / N_{\mathrm{u}}\right.$, where $N_{\mathrm{u}}$ is the ultimate capacity of the specimen before fire exposure determined by FE analysis). In order to prevent the vertical load from being directly applied to the steel tube of the STCRC columns, two strips were cut from the steel tubes, introducing $30 \mathrm{~mm}$ wide gaps (as shown in Fig.1). However, axial load may be transferred to the steel tube via the friction and bond between the steel tube and the concrete in practice. To investigate the degree and influence of the axial load transferred to the steel tube, the frequency of breaks to the longitudinal continuity of the steel tube was varied, considering two cases: case (a) and case (b). For case (a), the central fire-exposed portion of the steel tube was continuous, as shown in Fig.1(a). For case (b), the exposed portion of the steel tube was divided into three equal parts (see Fig.1(b)), thereby breaking the longitudinal continuity more frequently and decreasing the possible vertical load borne by the steel tube. The steel tube in the CFST column was continuous along the whole length and subjected to axial loading as well. For each column, the fire-exposed length was approximately $3000 \mathrm{~mm}$. All specimens had an outer diameter of $300 \mathrm{~mm}$ and a length of $3810 \mathrm{~mm}$. The steel tube to concrete area ratio and the

80 reinforcement ratio of the STCRC columns were about $3.38 \%$ and $3.68 \%$, respectively. The total

81 steel ratio (i.e. tube plus reinforcement) of the STCRC columns was $7.06 \%$, which is similar to that of the CFST column (7.58\%). 


\section{Material properties}

84 The properties of the steel tube were obtained by means of tensile coupon testing, conducted in accordance with ISO 6892-1 (2009). The measured yield strength $f_{\mathrm{sy}}$, ultimate tensile strength $f_{\mathrm{su}}$,

86 elastic modulus $E_{\mathrm{s}}$ and Poisson's ratio $v_{\mathrm{s}}$ of the structural steel at ambient temperature are presented

87 in Table 2. Hot-rolled ribbed bars and hot-rolled plain bars were used for the longitudinal reinforcing

88 bars and stirrups, respectively. The properties of the reinforcing bars obtained from tensile coupon

89 tests are given in Table 3 , where $d_{\mathrm{b}}$ is the diameter, $f_{\text {by }}$ is the yield strength, $f_{\text {bu }}$ is the ultimate tensile

90 strength and $E_{\mathrm{b}}$ is the elastic modulus.

91 Ready-mixed concrete was used to fill the steel tubes. Concrete cubes $(150 \mathrm{~mm} \times 150 \mathrm{~mm} \times 150 \mathrm{~mm})$

92 and concrete prisms $(150 \mathrm{~mm} \times 150 \mathrm{~mm} \times 300 \mathrm{~mm})$ were cast during the preparation of the

93 specimens and wrapped in aluminum foil to simulate the closed environment that the concrete

94 experiences in the steel tubes. The cube and prism specimens were cured, together with the columns,

95 in the testing laboratory. The concrete cube strength and elastic modulus were tested at 28 days after

96 pouring and on the test day of the first specimen; the results are given in Table 4.

\section{$97 \quad$ Fabrication of specimens}

98 The steel tubes were produced by seam welding cold-formed steel sheets, and the ends of the 99 members were machined flat and parallel. The reinforcing cages were fabricated by tying eight 100 longitudinal reinforcing bars with stirrups at intervals of $200 \mathrm{~mm}$, and were placed inside the steel 101 tubes. The concrete cover from the edge of the concrete to the perimeter of the reinforcing bars was 102 around $25 \mathrm{~mm}$. Two $20 \mathrm{~mm}$ thick end plates, each with four stiffening ribs, were welded to the ends 103 of the steel tube to ensure the end sections remained plane during testing. The geometrical center of 104 the steel tube coincided with that of the end plates to attain concentric loading conditions.

105 For the CFST column, two semi-circular holes, with a diameter of $20 \mathrm{~mm}$, were drilled at each end 106 of the steel tube to provide vent holes for water vapor produced during the test. The water vapor in 107 the STCRC columns could be released via the gaps, and thus vent holes were not provided.

108 Holes of $30 \mathrm{~mm}$ diameter were drilled at the mid-height and near the ends of the specimens for the 109 installation of thermocouples, as shown in Fig.1. Type K (chromel/alumel) thermocouples, with a 110 diameter of $1 \mathrm{~mm}$, were installed to measure the temperatures at different locations across the section. 
111 The resulting gaps were filled with high-strength non-shrinkage grout. The layout of the

112 thermocouples is depicted in Fig.2.

\section{Test setup and procedure}

114 The specimens were tested in a custom-built furnace for testing structural members under combined

115 thermal and structural loading conditions, at Harbin Institute of Technology. The loading capacity is 116300 tonnes. The furnace has a $4.9 \mathrm{~m} \times 2.6 \mathrm{~m}$ floor area and a height of $4.05 \mathrm{~m}$. The interior surfaces

117 of the furnace chamber are lined with ceramic fiber materials that efficiently transfer heat to the test

118 specimens. Eight platinum-rhodium thermocouples were installed at different locations within the

119 furnace to measure the air temperature. The furnace temperature can be automatically controlled to 120 follow programed air temperature-time curves. A special camera, which can endure high 121 temperatures by utilizing both air cooling and water cooling, was mounted at the mid-height of the 122 chamber to capture the response of the specimens during testing. The specimens were fixed at the 123 bottom end and pinned at the top end. Concentric load was applied to the specimens around 30 mins 124 prior to the ignition of the fire and then held constant. The column is $3770 \mathrm{~mm}$ in length and only $1253000 \mathrm{~mm}$ was exposed to fire directly. The portion of the column length outside the furnace was 210 $126 \mathrm{~mm}$. A general view of test setup is shown in Fig.3.

127 The ambient temperatures ranged from $20{ }^{\circ} \mathrm{C}$ to $24{ }^{\circ} \mathrm{C}$ before the tests. The furnace temperatures 128 were increased following the ISO 834 standard fire curve. The furnace and specimen temperatures 129 and the axial displacement versus time curves of the specimens were monitored and recorded during 130 the tests. The failure criteria specified in ISO 834 (1999) were adopted in this study - when the axial 131 deformation reached $0.01 L \mathrm{~mm}$ or the rate of axial deformation reached $0.003 \mathrm{~L} \mathrm{~mm} / \mathrm{min}$, where $L$ is 132 the length of the specimens in $\mathrm{mm}$, the specimens were considered to have failed and the tests were 133 terminated.

\section{Test results}

135 The deformed STCRC and CFST columns after testing are presented in Fig.4. The STCRC columns 136 failed by global buckling, accompanied by local buckling (Fig.4(f)). The CFST column failed with 137 no significant lateral deformation, but clear evidence of local buckling of the steel tube (Fig.4(e) and 138 (g)). There is no obvious lateral deformation for specimen STCRC-1 because the supply of gas was 
139 exhausted when the column was close to failure and the lateral deformation recovered as the axial

140 load was removed. A typical specimen after removal of the steel tube is shown in Fig.5. Despite 141 some crushing of the concrete, the inner concrete remained essentially intact, which may be 142 attributed to the presence of the outer steel tube.

143 The temperatures in the furnace were uniform and followed the ISO 834 standard fire curve 144 accurately, as shown in Fig.6, in which T1 to T8 are the measured temperatures from the eight 145 thermocouples in the furnace during the testing of specimen STCRC-1. The average furnace 146 temperatures of all tests agreed well with the ISO 834 standard fire curve, and the deviation of the 147 average furnace temperature from the ISO 834 standard temperature curve was within the limits 148 specified in ISO 834 (1999) (see Fig.7), confirming the reproducibility and robustness of the furnace.

149 The temperatures of corresponding thermocouples at different heights, e.g. thermocouple 2 and 8 , are 150 very close, as depicted in Fig.8, confirming the uniformity of temperature along the longitudinal 151 direction of the specimens and further confirming the uniformity of temperature in the furnace. 152 Thermocouple 6 failed during testing, after which no results were available. There are some 153 discrepancies of temperature in the steel tube (Fig.8(a)), which may be attributed to the sensitivity of 154 the thermocouples to flames or the influence of the insulation materials positioned to ensure 155 thermocouples will not be subjected to flame directly.

156 The measured temperatures of the specimens through the cross-sections during the tests are 157 presented in Fig.9. The rate of increase in temperature of the steel tube decreases with increasing 158 time, similar to the ISO-834 standard fire curve. Take specimen STCRC-1 for example - the 159 temperature of the steel tube reached $320^{\circ} \mathrm{C}, 471{ }^{\circ} \mathrm{C}, 688{ }^{\circ} \mathrm{C}$ and $880{ }^{\circ} \mathrm{C}$ after heating times of 10 $160 \mathrm{~min}, 20 \mathrm{~min}, 40 \mathrm{~min}$ and $80 \mathrm{~min}$, respectively. The deeper the location of the thermocouples within 161 the concrete, the lower the temperature that was achieved, and the longer it took for the onset of 162 rising temperatures. Considering specimen STCRC-1, the temperatures began to rise for the 163 thermocouples with a distance of $50 \mathrm{~mm}, 100 \mathrm{~mm}$ and $150 \mathrm{~mm}$ from the steel tube, from about $5 \mathrm{~min}$, $16415 \mathrm{~min}$ and $20 \mathrm{~min}$ after ignition, respectively. This delay in temperature rise is due to the high 165 thermal capacity of the concrete and the insulation effect of the surrounding material. Owing to moisture evaporation and migration, the temperature of the concrete remained essentially constant 
167 for some time at around $100{ }^{\circ} \mathrm{C}$, after which the temperature continued to increase.

168 The measured axial displacement versus time curves are presented in Fig.10, in which positive and 169 negative values correspond to expansion and contraction, respectively. The axial displacement 170 velocity versus time curves are also depicted in Fig.10. The axial displacement versus time curves 171 may be seen to exhibit three stages: (i) expansion; (ii) stable shortening and (iii) rapid shortening. 172 These three stages were also observed in fire tests on square and rectangular CFST columns (Yang et 173 al. 2013a; 2013b). The fire resistances of the columns were determined according to the criteria 174 specified in ISO 834 (1999) and are indicated in Fig.10. Specimen STCRC-1 was not tested to failure, 175 but it was close to failure by the end of the test, as can be observed from the displacement versus 176 time curve in Fig.10(a). Therefore, the time at the end of the test was taken as the approximate fire 177 resistance of specimen STCRC-1 in subsequent analysis.

\section{Discussion of results}

179 The influence of load ratio on the axial displacement versus time curves and fire resistance of the 180 columns is depicted in Fig.11 (a). The expansion stage may be seen to reduce with increasing load 181 ratio, with even no expansion arising in the case of high load levels. The maximum expansion was $1821.8 \mathrm{~mm}$ and $0.6 \mathrm{~mm}$ for specimens with a load ratio of 0.25 and 0.33 , respectively, while the 183 corresponding duration of expansion was $88 \mathrm{~min}$ and $47 \mathrm{~min}$, respectively. However, only shortening 184 occurred for the specimen with a load ratio of 0.42 . The expansion depends predominantly on the 185 temperature and the length of the specimen, whereas the shortening is dominated by the load ratio 186 and the temperature, hence the observed decrease in the expansion stage with increasing load ratio. 187 The load ratio significantly influenced the fire resistance of the STCRC columns. In this study, the 188 fire resistances were $116.5 \mathrm{~min}, 82.5 \mathrm{~min}$ and $50 \mathrm{~min}$ for the specimens with load ratios of $0.25,0.33$ 189 and 0.42 , respectively, decreasing by $29.2 \%$ and $57.1 \%$ for the specimens with the load ratios of 0.33 190 and 0.42 respectively relative to the specimen with the load ratio of 0.25 .

191 The frequency of the breaks to the longitudinal continuity of the members had limited influence on

192 the deformation and fire resistance of the STCRC columns, as shown in Fig.11 (b). This can be 193 explained as follows: (1) The high temperature deteriorates the bond stress between the steel tube 194 and concrete, and hence the axial load transferred to the steel tube through the bond stress decreases. 
195 (2) The temperature of the steel tube rises more rapidly than that of concrete, causing degradation of

196 the mechanical properties and lateral thermal expansion of the steel tube, rendering the confinement

197 afforded by the steel tube to the concrete relatively insignificant for columns in fire. In spite of this,

198 the steel tube is effective in preventing spalling and retaining the integrity of the concrete.

199 The development of the deformation of the STCRC columns generally follows that of the CFST 200 column shown in Fig.11 (c). However, the STCRC columns possessed much higher fire resistance 201 than the CFST column with the same load level $(n=0.42)$, achieving over double the fire exposure 202 time at failure. The greatly improved fire performance of the STCRC columns is primarily due to the 203 thermal protection afforded to the embedded steel, which plays an important load-bearing role with 204 increasing temperature, in contrast to the outer steel tube in CFST columns that is directly exposed to 205 the fire.

206 Although not explicitly investigated in the present study, the fire resistance of STCRC columns 207 relative to reinforced concrete (RC) columns has been examined in previous research (Liu et al., 208 2017). It was found that STCRC columns have lower fire resistance than RC columns, with greater 209 differences observed at higher load levels. The lower fire performance of the STCRC columns relates 210 principally to the high load-bearing capacities at room temperature that benefit from the confinement 211 afforded to the concrete being eliminated by the rapid deteriorations of the material properties and 212 hence loss of confinement ability of the outer tube in fire.

\section{Development of the FE model}

214 A finite element (FE) model was developed employing a sequentially coupled thermal-stress analysis, 215 whereby a heat transfer analysis was first conducted, and then the thermal results were imported into 216 a subsequent stress analysis.

\section{Heat transfer analysis}

218 The steel tube, reinforcing bars and concrete were modelled with 4-node shell elements (DS4), 219 2-node truss elements (DC1D2) and 8-node continuum solid elements (DC3D8), respectively. The 220 ambient temperature was set at $20{ }^{\circ} \mathrm{C}$ and the temperature was increased following the ISO 834 221 (1999) standard fire curve. Recognizing the symmetry of the geometry and boundary conditions, a 222 quarter of the column was modelled, as shown in Fig.12. 
223 In the analysis, the heat is transferred from the fire to the outer steel tube via convection and 224 radiation, and then into the columns by means of conduction. The convective heat transfer coefficient 225 and the resultant emissivity were taken as $25 \mathrm{~W} /\left(\mathrm{m}^{2} \mathrm{~K}\right)$ and 0.5 , respectively (Ding and Wang 2008; 226 Yang et al. 2013a, 2013b; Liu et al. 2014). The thermal resistance, arising from air gaps between the 227 steel tube and the concrete, was taken into account with a constant value of $0.01\left(\mathrm{~m}^{2} \mathrm{~K}\right) / \mathrm{W}$ (Ding and 228 Wang 2008; Lv et al. 2011), which was found to provide accurate predictions (Liu et al.2014; Yang et 229 al.2015).

230 The density, thermal conductivity and specific heat of the materials are required for the heat transfer 231 analysis. The thermal models recommended by Lie et al. (1994), which have been successfully used 232 by Hong and Varma (2009) and Yang et al. (2013a; 2013b) to simulate CFST columns, were 233 employed in this study, since the cross-section of STCRC columns resembles that of CFST columns. 234 Han and his research group conducted numerous studies on CFST structures exposed to fire using 235 these thermal models, including circular, square and rectangular CFST columns during and after fire 236 exposure (Han et al. 2003a; 2003b; 2003c; 2005b; Yang et al. 2008; Song et al. 2010a), beam to 237 column connections (Tan et al. 2012; Song et al. 2010b) and frames (Han et al. 2012) exposed to fire, 238 confirming the robustness of the thermal models. The thermal models provided in Eurocode 4 have 239 also been successfully employed for the simulation of CFST columns by many researchers 240 (Schaumann et al. 2009; Ding and Wang 2008; Espinos et al. 2010; Ibañez et al. 2013; Imani et al. 241 2015; Neuenschwander et al. 2017a), with good predictions obtained. These models would also be 242 expected to be suitable for the simulation of STCRC columns exposed to fire. Moisture evaporation 243 and migration affect the temperature development of the concrete; reasonable temperature 244 predictions can generally be obtained by taking the moisture evaporation into account but ignoring 245 the moisture migration. Different values of moisture content have been adopted by different 246 researchers, ranging from about $4 \%$ to $10 \%$ by weight, as summarised by Tao and Ghannam (2012).

247 Tao and Ghannam (2012) proposed an equation for calculating the moisture content of the concrete 248 in CFST columns based on the mix proportions; a value of 5\% by weight was recommended if the 249 mix proportions of the concrete are not detailed. The moisture content of the concrete in the STCRC 250 columns was assumed to be $5 \%$ by weight herein. 


\section{Stress analysis}

\section{Elements, interactions and initial imperfections}

253 Following the heat transfer analysis, nonlinear stress analysis was conducted, allowing the behavior 254 of STCRC columns to be investigated under combined thermal and structural loading. In order to 255 ensure that the thermal results could be read into the stress analysis model efficiently and accurately, 256 the same finite element mesh was employed for both models, but the heat transfer elements were 257 replaced by stress elements. For the stress analysis, the elements of the steel tube, the reinforcing 258 bars and the concrete were changed to linear reduced-integration 4-node shell elements (S4R), 259 2-node truss elements (T3D2) and linear reduced-integration 8-node solid elements (C3D8R), 260 respectively.

261 The interactive behavior between the steel tube and the concrete was simulated with the contact 262 interaction algorithm in ABAQUS. The surfaces of the steel tube and the concrete were defined to be 263 a contact pair, with the inner surface of the steel tube as the slave surface and the outer surface of the 264 concrete as the master surface. The interface behavior in the normal direction was defined to be

265 "hard" contact, which means the contact pressure is fully transmitted when the surfaces are touching. 266 In the tangential direction, Coulomb friction behavior with a coefficient of friction of 0.3 was defined. 267 The embedded region constraint was used to embed the reinforcing bars within the concrete.

268 Initial imperfections were incorporated into the models in the form of the first elastic buckling mode 269 shape with an amplitude of $L / 1000$, where $L$ is the length of the column, this approach has been 270 widely used in previous studies (e.g., Espinos et al. 2011). For the STCRC columns, load was only 271 applied to the concrete core, while for the CFST column simulated for the model validation, load was 272 applied to the whole cross-section.

\section{Steel properties}

274 Steel under load at elevated temperatures experiences mechanical strain, thermal strain and creep 275 strain. The mechanical stress-strain relationship provided in EC3 (2005), which implicitly 276 incorporates the effects of creep, was found by Espinos et al. (2010) and Wang and Young (2013) to 277 yield better predictions of the fire behavior of CFST columns than the models of Lie (1994) and Poh 278 (2001). Similar findings were presented by Kodur et al. (2010), where the EC3 (2005) material 
279 model was recommended in preference to the models of ASCE (1992) and Poh (2001). It should be 280 noted that ASCE model (1992) is the same as that of Lie (1994). The EC3 (2005) model was also 281 employed in the present study, and shown to yield accurate results.

282 Espinos et al. (2010) found that the EC3 (2005) thermal expansion model produces more accurate 283 predictions than the constant thermal expansion coefficient value of $1.2 \times 10^{-5}$, proposed by Hong 284 and Varma (2009), when studying the fire performance of CFST columns. Lu et al. (2009) and Yang 285 et al. (2013a; 2013b) also gained good predictions with the thermal expansion model recommended 286 by Lie (1994).

287 The relative thermal elongation $\Delta l / l$ of steel recommended in EC3 (2005) is as follows:

$$
\Delta l / l= \begin{cases}1.2 \times 10^{-5} T+0.4 \times 10^{-8} T^{2}-2.416 \times 10^{-4} & 20^{\circ} \mathrm{C} \leq T<750^{\circ} \mathrm{C} \\ 1.1 \times 10^{-2} & 750^{\circ} \mathrm{C} \leq T \leq 860^{\circ} \mathrm{C} \\ 2 \times 10^{-5} T-6.2 \times 10^{-3} & 860^{\circ} \mathrm{C}<T \leq 1200^{\circ} \mathrm{C}\end{cases}
$$

289 where $T$ is the temperature in ${ }^{\circ} \mathrm{C}$. The corresponding thermal expansion coefficient $\alpha$ is:

$$
\alpha= \begin{cases}1.2 \times 10^{-5}+0.8 \times 10^{-8}(T-20) & 20^{\circ} \mathrm{C} \leq T<750^{\circ} \mathrm{C} \\ 0 & 750^{\circ} \mathrm{C} \leq T \leq 860^{\circ} \mathrm{C} \\ 2 \times 10^{-5} & 860^{\circ} \mathrm{C}<T \leq 1200^{\circ} \mathrm{C}\end{cases}
$$

291 The thermal expansion coefficient proposed by Lie (1994) is as follows:

$$
\alpha= \begin{cases}(0.004 T+12) \times 10^{-6} & T<1000^{\circ} \mathrm{C} \\ 16 \times 10^{-6} & T \geq 1000^{\circ} \mathrm{C}\end{cases}
$$

293 Comparisons of the thermal expansion coefficient and the relative thermal elongation between the

294 EC3 model and the Lie model are shown in Fig.13. Despite discrepancies of the thermal expansion coefficient, the relative thermal elongations are very close for these two models. However, the EC3 model accounts for the phase change that occurs in steel between about $750{ }^{\circ} \mathrm{C}$ and $860{ }^{\circ} \mathrm{C}$ by assuming a constant thermal elongation in this temperature range, which agrees well with test results

298 on steel at elevated temperatures (Cooke 1988; Outinen 2007). Therefore, the EC3 model was 299 adopted in this study.

\section{Concrete properties}

301 Strains in concrete under load at elevated temperatures include four components: the mechanical 302 strain, the thermal strain, the creep strain and the transient strain. The stress-strain relationship 
recommended by Lie (1994), which is also the ASCE model (1992), was adopted herein. It implicitly

304 incorporates creep strain and has been found to yield better predictions of the behavior of CFST columns than the EC2 model (2004) and the Li and Purkiss model (2005), by Espinos et al. (2010) and Hong and Varma (2009). The thermal expansion coefficient of concrete was taken as a constant value of $6 \times 10^{-6}$, as recommended by Espinos et al. (2010) and Hong and Varma (2009). The transient strain model proposed by Anderberg and Thelandersson (1976), which has been widely used for the structural analysis of members exposed to fire (Sadaoui and Khennane 2009; Capua and Mari 2007; Kodur and Dwaikat 2008), was employed in this study and is given as follows:

$$
\varepsilon_{\mathrm{ctr}}=k\left(\frac{\sigma}{f_{\mathrm{c}}^{\prime}}\right) \varepsilon_{\mathrm{cth}}
$$

When $T>550^{\circ} \mathrm{C}$

$$
\frac{\partial \varepsilon_{\mathrm{ctr}}}{\partial T}=-0.0001\left(\frac{\sigma}{f_{\mathrm{c}}^{\prime}}\right)
$$

315 where $\varepsilon_{\mathrm{cth}}$ is the thermal strain, $\sigma$ is the stress, $f_{\mathrm{c}}$ ' is the compressive cylinder strength of the concrete and $k$ is a factor between 1.8 and 2.35; an intermediate value of 2.0 was used herein. The transient strain was added to the mechanical strain and the stress-total strain relationship was then input into ABAQUS (Li and Purkiss 2005).

319 For the structural steel and reinforcing bars, the classical metal plasticity model with von Mises 320 yielding and the associated plastic flow rule was used, with the stress-strain relationship for both following that set out in EC3 (2005). The reduction factors for the strength and elastic modulus of the structural steel and reinforcing bars at elevated temperatures were taken from EC3 (2005) and

323 EC2 (2004), respectively. The elastic modulus of both the structural steel and reinforcing bars at 324 ambient temperature was defined to be $2.1 \times 10^{5} \mathrm{~N} / \mathrm{mm}^{2}$, according to EC3 (2005). The influence of 325 temperature on the Poisson's ratio of steel is small, hence the Poisson's ratio was set at a constant value of 0.3 for both the structural steel and reinforcing bars.

327 The concrete damage plasticity model in ABAQUS was used to represent the concrete material, 328 which requires the definition of the behavior in both compression and tension. The concrete models 
329 proposed by Lie (1994) and Hong and Varma (2009) were used to define the compressive and tensile 330 behavior of the concrete, respectively. Tests on concrete material after exposure to elevated 331 temperatures conducted by Marechal (1972) and Luccioni et al. (2003) indicate that the Poisson's 332 ratio of concrete tends to decrease with increasing temperature. Based on these post-elevated 333 temperature test results, Gernay et al. (2013) proposed an equation reflecting the relationship 334 between Poisson's ratio and temperature. The suitability of the equation was confirmed up to a 335 temperature of $300{ }^{\circ} \mathrm{C}$ by the first elevated temperature Poisson's ratio test conducted by Bahr et al. 336 (2013). However, there are some discrepancies between the equation of Gernay et al. and the test 337 results of Bahr et al. (2013) for temperatures between $300{ }^{\circ} \mathrm{C}$ and $500{ }^{\circ} \mathrm{C}$. To date, there are no 338 available test data for the Poisson's ratio of concrete at temperatures exceeding $500{ }^{\circ} \mathrm{C}$. Clearly 339 further test data are required on this topic, but for the purposes of the present study, the 340 recommendations of Gernay et al. (2013) are adopted, which are as follows:

$$
v_{\mathrm{cT}}= \begin{cases}v_{\mathrm{c}}\left(0.2+0.8 \frac{500-T}{480}\right) & T \leq 500^{\circ} \mathrm{C} \\ 0.2 v_{\mathrm{c}} & T>500^{\circ} \mathrm{C}\end{cases}
$$

342 where $v_{\mathrm{cT}}$ and $v_{\mathrm{c}}$ are the Poisson's ratio of concrete at elevated temperature and ambient temperature, 343 respectively. $v_{\mathrm{c}}$ is taken as 0.2 .

344 Ehm and Schneider (1985) found that bi-axial compressive strength displays a relative increase with 345 increasing temperature due to the restraining of thermal and load induced micro-cracking. These tests 346 were conducted at temperatures up to $600{ }^{\circ} \mathrm{C}$. Based on these test results, Gernay et al. (2013) 347 proposed an equation reflecting relationship between the ratio of the bi-axial compressive strength $348 f_{\mathrm{bi}, \mathrm{cT}}$ to the uniaxial compressive strength $f_{\mathrm{cT}}$ and temperature, as given by:

$$
f_{\mathrm{bi}, \mathrm{cT}} / f_{\mathrm{cT}}= \begin{cases}1.16 & T \leq 350^{\circ} \mathrm{C} \\ 1.16\left(1+0.6 \frac{T-350}{400}\right) & 350{ }^{\circ} \mathrm{C}<T \leq 750{ }^{\circ} \mathrm{C} \\ 1.86 & T>750^{\circ} \mathrm{C}\end{cases}
$$

350 This relationship was adopted in this study and was incorporated into ABAQUS.

351 The damage part of the concrete damage plasticity model was neglected in all studies on fire 352 performance of structural members and good predictions were obtained. This can be explained by 
two reasons: 1) there may be no obvious process of unloading and reloading, 2) there is no available model to represent concrete damage at elevated temperatures under cyclic loading. For STCRC columns, axial load is mainly sustained by inner reinforced concrete column, and there is no process of unloading and reloading. Therefore damage part of the concrete damage plasticity model also was not considered in this simulation. It should be mentioned that recently Neuenschwander et al. (2016; $2017 b$; 2018) validated the suitability of concrete damage plastic model for concrete at elevated temperatures for the first time experimentally and studied the damage evolution of elastic modulus at elevated temperatures. It will be very beneficial for simulation of composite structures exposed fire, especially for indeterminate structures.

\section{Validation of FE model and parametric studies}

\section{Validation of FE model}

364 The temperature history (temperature-time response) in the tested circular STCRC columns was 365 simulated using the developed FE model, as shown in Fig.14. The cross-section of STCRC columns resembles that of CFST columns; the thermal analysis model was therefore also validated against tests on CFST columns. Typical comparisons of the predicted and test temperatures of plain concrete-filled steel tubular columns (Lie and Chabot 1992) and reinforced concrete-filled steel tubular columns (Chabot and Lie 1992) are illustrated in Fig.15 and Fig.16, respectively, where $d$ is the distance of the thermocouple to the outer surface of the concrete. The geometrical details of these CFST columns are provided in Table 5; note that the furnace temperature for these columns was increased following the ASTM-E119 fire curve (1990). The predicted temperatures may be seen to generally accord well with the test temperatures, for both the STCRC columns and CFST columns. There are some discrepancies between the predicted and test temperatures in the concrete when the temperature is around $100{ }^{\circ} \mathrm{C}$, due to the complexities in simulating of the effect of moisture. However, these discrepancies have an insignificant influence on the prediction of fire resistance since there is no reduction in the concrete strength at that temperature level.

378 The deformation-time responses of the STCRC columns in fire were also predicted using the 379 developed FE model, as depicted in Fig.17. Fire tests on STCRC columns are limited, and since the composition of CFST columns is similar to that of STCRC columns, other than the outer steel 
tube in CFST columns is subjected to direct axial loading, test results on CFST columns were also employed to validate the FE model. The plain concrete-filled steel tubular columns tested by Lie and 383 Chabot (1992) and Han et al. (2003a) and the reinforced concrete-filled steel tubular columns tested 384 by Chabot and Lie (1992) and Espinos et al. (2015), were simulated using the developed FE model. 385 Typical comparisons between the FE and test results are presented in Fig.18 and Fig.19. The details of these columns are given in Table 6 and Table 7, respectively, in which $D$ is the outer diameter of the steel tube, $t_{\mathrm{s}}$ is the wall thickness of the steel tube, $L$ is the length of the specimen, $e$ is the load eccentricity, $f_{\mathrm{c}}$ ' is the concrete cylinder strength, $f_{\mathrm{y}}$ is the yield strength of the structural steel, $N_{\mathrm{f}}$ is the applied axial load and $a$ is the thickness of the fire protection. The predicted and test fire resistances of the STCRC columns, plain concrete-filled steel tubular columns and reinforced concrete-filled steel tubular columns are shown in Fig.20. The mean and standard deviation of the ratio of the predicted-to-test fire resistance are 1.072 and 0.237 , respectively. The discrepancies may be attributed to: (i) the complexity of fire resistance testing and possible inaccuracies in the measurements and (ii) the assumptions made in the FE model, for example, the stress-strain relationships of the steel and concrete were not taken directly from tests. Despite these potential uncertainties, the predicted fire resistances generally agree well with the test results.

After validation of the FE model, parametric studies were carried out to extend ranges of studied parameters, including load ratio $(n)$, cross-section dimension $(D)$, slenderness ratio $(\lambda=L / i$, where $L$ is column length and $i$ is the radius of gyration), concrete strength $\left(f_{\mathrm{c}}\right.$ '), yield strength of steel $\left(f_{\mathrm{y}}\right)$, yield strength of reinforcement $\left(f_{\mathrm{b}}\right)$, steel tube to concrete area ratio $\left(\alpha_{\mathrm{s}}\right)$ and reinforcement ratio $\left(\alpha_{\mathrm{b}}\right)$.

403 Ranges of these parameters are as follows: $n=0.3-0.7, D=200 \mathrm{~mm}-1500 \mathrm{~mm}, f_{\mathrm{c}}{ }^{\prime}=24 \mathrm{~N} / \mathrm{mm}^{2}-50$ $404 \mathrm{~N} / \mathrm{mm}^{2}, f_{\mathrm{y}}=235 \mathrm{~N} / \mathrm{mm}^{2}-420 \mathrm{~N} / \mathrm{mm}^{2}, f_{\mathrm{b}}=335 \mathrm{~N} / \mathrm{mm}^{2}-500 \mathrm{~N} / \mathrm{mm}^{2}, \alpha_{\mathrm{s}}=2 \%-4 \%, \alpha_{\mathrm{b}}=2 \%-5 \%$. The 405 default condition is taken as: $D=600 \mathrm{~mm}, f_{\mathrm{c}}{ }^{\prime}=40 \mathrm{~N} / \mathrm{mm}^{2}, f_{\mathrm{y}}=345 \mathrm{~N} / \mathrm{mm}^{2}, f_{\mathrm{b}}=335 \mathrm{~N} / \mathrm{mm}^{2}, \alpha_{\mathrm{s}}=3 \%$, $406 \quad \alpha_{b}=4 \%$.

407 Influences of these parameters on fire resistance are presented in Fig.21. Fire resistance decreases 408 significantly with the increase of load ratio, as shown in Fig.21 (a). Take the column with a diameter 
409 of $600 \mathrm{~mm}$ for example, its fire resistance decreases from $157.7 \mathrm{~min}$ to $30.3 \mathrm{~min}$ when load ratio

410 increases from 0.4 to 0.6 . Higher load ratio means higher load is applied, and then the load-bearing

411 capacity declines to the level of applied load in a shorter time.

412 Fire resistance increases with increase of cross-section dimension, concrete strength, yield strength

413 of reinforcement and reinforcement ratio, while it decreases with increase of slenderness ratio, yield

414 strength of steel and steel tube to concrete area ratio (Fig.21 (b)-(h)). Influences of these parameters

415 on fire resistance of circular STCRC columns resemble to that of CFST columns. When the load

416 ratio is within 0.5 , influences of these parameters on fire resistance are obvious, whereas influences

417 of these parameters are limited while the load ratio exceeds 0.5. Han et al. (2013a) and Yang et al.

418 (2013b) found steel tube to concrete area ratio and strengths of concrete and steel have limited

419 influence on the fire resistance of CFST columns, since load ratio exceeds 0.5 in their studies.

\section{Simplified design methods}

421 All above parameters have some influence on the fire resistance of circular STCRC columns, 422 especially for columns with a load ratio of less than 0.5. It is infeasible to propose equations for 423 predicting fire resistance directly from parametric study results by regression analysis. Since the 424 load-bearing capacity of columns degrades with increasing temperature, once the load-bearing 425 capacity declines to the level of applied load, the column fails and the corresponding time is the fire 426 resistance of the column. Simplified design methods for predicting the temperature and load-bearing 427 capacity of STCRC columns are sought in this section, which can be used to determine fire 428 resistance.

\section{Design method for predicting temperatures}

430 The cross-section of STCRC columns resembles that of CFST columns. The Chinese code GB50936 431 (2014) and the Japanese code AIJ (2008) provide simplified methods for calculating the temperature 432 of the steel tube in CFST columns exposed to the standard fire. The equation given in the Chinese 433 code GB50936 (2014) is as follows:

$$
T_{\mathrm{s}}=A\left(1-\frac{1}{1+\left(\frac{t}{B}\right)^{C}}\right)+20
$$


435 where $A=1200, B=0.337+8.5 t_{\mathrm{s}}$ and $C=0.996+14.0 t_{\mathrm{s}}, t_{\mathrm{s}}$ is the wall thickness of the steel tube in meters, 436 and $t$ is the heating time in hours.

437 The equation provided by the Japanese code AIJ (2008) is as follows:

$$
T_{\mathrm{s}}=1080-450 \exp (-0.8 t)-630 \exp (-3 t)+20
$$

439 where $t$ is the heating time in hours.

440 The predicted temperatures using these equations and those obtained from the FE models are 441 compared in Fig.22, revealing good agreement. Therefore the temperature of the steel tube in 442 STCRC columns may be approximated using either Eq.(7) or Eq.(8).

443 Similar to reinforced concrete columns, the temperatures of the reinforcing bars in STCRC columns 444 can be represented by the temperature of the concrete at the location of the center of the bar section. 445 The Japanese code AIJ (2008) provides a method for calculating the concrete temperature, given as 446 follows:

$$
T_{\mathrm{c}}=\left(T_{\mathrm{s}}-20\right) \exp \left(\frac{10\left(2 x / D_{\mathrm{c}}-1\right)}{\left(t / D_{\mathrm{c}}^{2}\right)^{3 / 4}}\right)+20
$$

448 where $x$ is the distance to the center of the concrete in centimeters, $D_{\mathrm{c}}$ is the diameter of the core 449 concrete in centimeters, and $t$ is the heating time in seconds. In Eq.(9), when $x$ equals $0.5 D_{\mathrm{c}}, T_{\mathrm{c}}$ 450 equals $T_{\mathrm{s}}$, which means that the thermal resistance at the interface between the steel tube and the 451 concrete is not accounted for in this equation. The influence of the thermal resistance at the interface 452 on the temperature of the concrete was investigated with the FE model, as shown in Fig.23. The 453 thermal resistance may be seen to have a significant influence on the temperature near the concrete 454 surface (i.e. $d=0$ ). However, the influence degrades quickly as the distance to the concrete surface $d$ 455 increases. The concrete cover to the reinforcing bars usually exceeds $20 \mathrm{~mm}$, so the distance of the 456 center of the bar section to the concrete surface would typically be more than $30 \mathrm{~mm}$. Therefore the 457 thermal resistance has little influence on the temperatures of the reinforcing bars, and Eq.(9) may be 458 used to approximate the temperatures of the reinforcing bars. When the units used in Eq.(9) are 459 replaced by SI units, the equation becomes: 


$$
T_{\mathrm{b}}=\left(T_{\mathrm{s}}-20\right) \exp \left(-43.03 \frac{d \sqrt{D_{\mathrm{c}}}}{t^{3 / 4}}\right)+20
$$

461 where $d$ is the distance to the concrete surface in meters, $D_{\mathrm{c}}$ is the diameter of the core concrete in 462 meters, and $t$ is the heating time in hours.

463 The temperature of the concrete is non-uniform across the section due to the high thermal capacity 464 and low thermal conductivity. The concrete cross-section can be subdivided into a number of layers, 465 and the temperature of each layer can be calculated from Eq.(9). However, this method is often not 466 practical for use in engineering design. An alternative approach is to determine an equivalent 467 uniform temperature for the whole cross-section, which yields the same cross-section capacity as the 468 real non-uniform temperature distribution. The equivalent compressive strength of concrete can be 469

$$
f_{\mathrm{c}, \mathrm{eq}}(T)=\frac{\sum_{i=1}^{n} f_{\mathrm{ci}}(T) A_{\mathrm{ci}}}{A_{\mathrm{c}}}
$$

471 where $i$ is the element number, $f_{\mathrm{ci}}(T)$ is the compressive strength of the element $i, A_{\mathrm{ci}}$ is the area of 472 element $i, n$ is the total number of elements across the section and $A_{\mathrm{c}}$ is the area of the full concrete 473 core.

474 The reduction factor for the compressive strength of concrete at elevated temperatures is as follows:

$$
k_{\mathrm{cT}}=\frac{f_{\mathrm{c}, \mathrm{eq}}(T)}{f_{\mathrm{c}}}
$$

476 According to the compressive strength versus temperature relationship proposed by Lie (1994), the 477 equivalent temperature of concrete is:

$$
T_{\mathrm{c}, \mathrm{eq}}=\frac{\left(2.011-k_{\mathrm{cT}}\right) \times 10^{3}}{2.353}+20
$$

479 When $k_{\mathrm{cT}}=1.0, T_{\mathrm{c}, \mathrm{eq}}=449.7^{\circ} \mathrm{C}$, and when $k_{\mathrm{cT}}=0, T_{\mathrm{c}, \mathrm{eq}}=874.7^{\circ} \mathrm{C}$.

480 A total of 91 parametric FE results for STCRC columns with varying diameters (from $200 \mathrm{~mm}$ to $4811500 \mathrm{~mm}$ ) and subjected to a range of heating times ( 0 to 3 hours) were obtained to assess the 482 temperature development in the cross-sections, and hence, by means of Eqs (12) and (13), the 483 reduction factors for the compressive strength of concrete at elevated temperatures. A predictive 
484 equation for the reduction factor $k_{\mathrm{cT}}$ was then established based on the parametric results, which is 485 given as follows:

$$
k_{\mathrm{cT}}=1-\left(\frac{0.045}{D_{\mathrm{c}}}-0.016\right) t
$$

487 where $D_{\mathrm{c}}$ is the diameter of the concrete core in meters and $t$ is the heating time in hours.

488 Comparisons of the predicted reduction factor from Eq.(14) and the FE model are depicted in Fig.24, 489 which shows good agreement. Based on this reduction factor, the following simplified equation is 490 proposed for calculating the equivalent temperature of concrete:

$$
T_{\mathrm{c}, \mathrm{eq}}=449.7+425\left(\frac{0.045}{D_{\mathrm{c}}}-0.016\right) t
$$

\section{Design method for predicting load-bearing capacity}

493 Liu and Zhou (2010) proposed a design method for predicting the cross-sectional capacity of STCRC 494 columns at ambient temperature, which is given as follows:

$$
N_{0}=f_{\mathrm{cc}} A_{\mathrm{c}}+f_{\mathrm{b}} A_{\mathrm{b}}
$$

where $A_{\mathrm{c}}$ and $A_{\mathrm{b}}$ are the cross-sectional area of the concrete and longitudinal reinforcement, respectively, $f_{\mathrm{b}}$ is the yield strength of the reinforcement and $f_{\mathrm{cc}}$ is the compressive strength of the confined concrete, which can be determined as follows (Mander et al. 1988):

$$
f_{\mathrm{cc}}=\left(-1.254+2.254 \sqrt{1+7.94 \frac{f_{\mathrm{r}}}{f_{\mathrm{c}}^{\prime}}}-2 \frac{f_{\mathrm{r}}}{f_{\mathrm{c}}^{\prime}}\right) f_{\mathrm{c}}^{\prime}
$$

500 where $f_{\mathrm{c}}$ ' is the concrete cylinder strength and $f_{\mathrm{r}}$ is the confining stress imposed by the steel tube on 501 the concrete, which can be calculated as follows:

$$
f_{\mathrm{r}}=\frac{2 t_{\mathrm{s}} f_{\mathrm{y}}}{D-2 t_{\mathrm{s}}}
$$

503 where $f_{\mathrm{y}}$ is the yield strength of the steel tube, and $D$ and $t_{\mathrm{s}}$ are the cross-sectional diameter and 504 thickness of the steel tube, respectively.

505 Consistent with the above method for STCRC columns at ambient temperature, a design method is 506 proposed herein for predicting the cross-sectional capacity of STCRC columns subjected to the ISO 507834 standard fire. 


$$
N_{0}(T)=f_{\mathrm{cc}}(T) A_{\mathrm{c}}+f_{\mathrm{b}}(T) A_{\mathrm{b}}
$$

509 where

513 where $f_{\text {ceq }}(T)$ can be obtained by substituting the equivalent temperature $T_{\text {c,eq }}$ from Eq. (16) into the 514 model proposed by Lie (1994):

$$
f_{\mathrm{c}, \mathrm{eq}}^{\prime}(T)= \begin{cases}f_{\mathrm{c}}^{\prime} & 0{ }^{\circ} \mathrm{C}<T_{\mathrm{c}, \mathrm{eq}}<450{ }^{\circ} \mathrm{C} \\ \left(2.011-2.353\left(\frac{T_{\mathrm{c}, \mathrm{eq}}-20}{1000}\right)\right) \beta f_{\mathrm{c}}^{\prime} & 450{ }^{\circ} \mathrm{C} \leq T_{\mathrm{c}, \mathrm{eq}} \leq 874^{\circ} \mathrm{C} \\ 0 & T_{\mathrm{c}, \mathrm{eq}}>874^{\circ} \mathrm{C}\end{cases}
$$

516 where $\beta$ is a factor proposed herein to account for the effect of the differential stresses within the

517 cross-section under the same strain, due to the large thermal gradient within sections under the ISO 518834 standard fire; the factor $\beta$ can be calculated as follows based on the results of the thermal 519 parametric study.

$$
\beta=\frac{1}{1+(0.005 t+0.2) \sqrt{\frac{t}{D_{c}}}}
$$

521 For columns at ambient temperature or having a uniform cross-section temperature (e.g. $200{ }^{\circ} \mathrm{C}$ ), the 522 factor $\beta$ equals 1.0 since there is no thermal gradient. Comparisons of the predicted load-bearing 523 capacities using the simplified design method with those obtained from the FE models are shown in 524 Fig.25 (a) for the case of uniform temperature and Fig.25 (b) for the case of exposure to the ISO 834 525 standard fire. It may be seen that the thermal gradients in the concrete have a significant influence on 526 the cross-sectional capacity of circular STCRC columns exposed to the ISO 834 standard fire and 527 that this influence is accurately captured by the simplified model through the application of Eq.(23).

528 The strength reduction factors for the structural steel $k_{\mathrm{yT}}$ and reinforcing bars $k_{\mathrm{bT}}$ can be determined 529 according to the temperatures of these respective parts. The reduction factors for structural steel at 
530 elevated temperatures provided in EC3 (2005) are in fact the same as those specified for reinforcing 531 bar in EC2 (2004). Similar values are given in CECS200 (2006), and presented below:

$$
k_{\mathrm{bT}}=k_{\mathrm{yT}}= \begin{cases}1.0 & 20^{\circ} \mathrm{C} \leq T \leq 300^{\circ} \mathrm{C} \\ 1.24 \times 10^{-8} T^{3}-2.096 \times 10^{-5} T^{2}+9.228 \times 10^{-3} T-0.2168 & 300^{\circ} \mathrm{C}<T<800^{\circ} \mathrm{C} \\ 0.5-T / 2000 & 800^{\circ} \mathrm{C} \leq T \leq 1000^{\circ} \mathrm{C}\end{cases}
$$

533 For axially loaded STCRC slender columns, the load-bearing capacity can be obtained as follows:

$$
N_{\mathrm{u}}(T)=\chi N_{0}(T)
$$

535 where $\chi$ is the buckling reduction factor. Parametric studies were conducted to identify the influences 536 of slenderness ratio, heating time and cross-sectional dimensions on the buckling capacity of STCRC 537 columns; a total of 294 numerical parametric results were generated, based upon which the following 538 equation is proposed for the prediction of the buckling reduction factor $\chi$ :

$$
\chi=\left\{\begin{array}{cc}
1 & \lambda \leq 12 \\
1-0.006(\lambda-12)\left(1.0+\frac{0.16 t}{D}\right) & \lambda>12
\end{array}\right.
$$

540 where $t$ is the heating time in hours, $D$ is the cross-sectional diameter in meters, $\lambda=4 L / D$ is the 541 slenderness ratio and $L$ is the effective column length.

542 The load-bearing capacity of STCRC columns subjected to the ISO 834 standard fire can hence be 543 predicted using Eqs (24) and (28). The fire resistance and failure temperature of the STCRC columns 544 were predicted using the proposed method; the test and predicted values are compared in Table1, 545 confirming the accuracy of the proposals. Comparisons of the predicted load-bearing capacities 546 between the simplified method and the FE parametric results are shown in Fig.26. The mean and 547 standard deviation of the ratio of the simplified design method-to-FE model predicted cross-section 548 capacity are 0.997 and 0.136 , respectively, whereas the mean and standard deviation of the ratio of 549 the simplified design method-to-FE model predicted buckling capacity are 0.994 and 0.106 , 550 respectively.

551 The limits of the validity of the above design method are as follows: $D=0.2-1.5 \mathrm{~m}, \lambda \leq 60, f_{\mathrm{c}}^{\prime}=24$ $552 \mathrm{~N} / \mathrm{mm}^{2}-50 \mathrm{~N} / \mathrm{mm}^{2}, f_{\mathrm{y}}=235 \mathrm{~N} / \mathrm{mm}^{2}-420 \mathrm{~N} / \mathrm{mm}^{2}, f_{\mathrm{b}}=335 \mathrm{~N} / \mathrm{mm}^{2}-500 \mathrm{~N} / \mathrm{mm}^{2}, \alpha_{\mathrm{s}}=2 \%-4 \%, \alpha_{\mathrm{b}}=2 \%$ $553-5 \%$. 


\section{Conclusions}

555 An experimental study was first conducted to investigate the fire performance of circular STCRC 556 columns subjected to the ISO 834 standard fire. Full-scale fire tests were carried out on four STCRC 557 columns and one CFST column to determine the fundamental behavior of these columns. The

558 furnace and specimen temperatures, displacement versus time curves and fire resistances were 559 presented and discussed. It was found that the temperatures across the cross-sections of the STCRC 560 and CFST columns decrease from the outer steel tube to the center of the concrete, and that the 561 temperature of the concrete remains at around $100{ }^{\circ} \mathrm{C}$ for some time, due to the energy absorption 562 associated with the moisture evaporation and migration. The development of the deformation of the 563 STCRC columns resembled that of the CFST column. The STCRC columns under combined thermal 564 and structural loading failed by global buckling, accompanied by local buckling. The inner concrete 565 remained largely intact due to the presence of the outer steel tube, despite some crushing of the 566 concrete. The load ratio had a significant influence on the fire resistance of the STCRC columns, but 567 compared to the CFST column, the STCRC columns provided much higher fire resistance, owing to 568 the contribution of the embedded reinforcing bars.

569 Complementary to the experimental study, a nonlinear finite element (FE) study was conducted to 570 investigate the behavior of reinforced concrete columns confined by circular steel tubes subjected to 571 the ISO 834 standard fire. The main input parameters for the FE model were discussed, carefully 572 selected and shown to result in good predictions of observed physical behavior; these chosen 573 parameters will serve as useful reference values for others in future work. The fire behavior of a 574 series of tested STCRC columns and CFST columns exposed to fire were predicted by the means of 575 the developed FE model. Good agreement was achieved between the FE model and the test results in 576 terms of the specimen temperatures, deformation-time responses and fire resistance. Parametric 577 studies were then performed using the validated FE model to generate data over a wide range of 578 STCRC column cross-section geometries, heating times and slenderness ratios. A simplified design 579 method was proposed for predicting the equivalent temperature, load-bearing capacity and fire 580 resistance of STCRC columns. The accuracy of the proposals was verified through comparisons with 581 the test and numerical results. 
582 The limits of this study are as follows: $D=0.2-1.5 \mathrm{~m}, \lambda \leqslant 60, f_{\mathrm{c}}{ }^{\prime}=24 \mathrm{~N} / \mathrm{mm}^{2}-50 \mathrm{~N} / \mathrm{mm}^{2}, f_{\mathrm{y}}=235$

$583 \mathrm{~N} / \mathrm{mm}^{2}-420 \mathrm{~N} / \mathrm{mm}^{2}, f_{\mathrm{b}}=335 \mathrm{~N} / \mathrm{mm}^{2}-500 \mathrm{~N} / \mathrm{mm}^{2}, \alpha_{\mathrm{s}}=2 \%-4 \%, \alpha_{\mathrm{b}}=2 \%-5 \%$.

\section{Acknowledgement}

585 The research presented in this paper was sponsored by the National key research and development 586 program (2016YFC0701203) and the National Natural Science Foundation (51878220); their 587 financial support is highly appreciated.

\section{Notation}

589 The following symbols are used in this paper:

$a=$ thickness of fire protection

$A_{\mathrm{b}}=$ cross-sectional area of reinforcing bars

$A_{\mathrm{c}}=$ cross-sectional area of concrete core

$A_{\mathrm{s}}=$ cross-sectional area of steel tube

$A=$ cross-sectional area of composite section, $A=A_{\mathrm{s}}+A_{\mathrm{c}}+A_{\mathrm{b}}$

$d_{\mathrm{b}}=$ diameter of reinforcing bars

$D=$ outer diameter of cross-section

$D_{\mathrm{c}}=$ outer diameter of concrete core

$e=$ load eccentricity

$E_{\mathrm{b}}=$ Young's modulus of reinforcing bars

$E_{\mathrm{c}}=$ Young's modulus of concrete

$E_{\mathrm{s}}=$ Young's modulus of structural steel

$f_{\mathrm{bi}, \mathrm{cT}}=$ bi-axial compressive strength of concrete at elevated temperature

$f_{\text {by }}=$ yield strength of reinforcing bars

$f_{\text {bu }}=$ ultimate tensile strength of reinforcing bars

$f_{\mathrm{c}}=$ concrete compressive strength

$f_{\mathrm{c}}{ }^{\prime}=$ concrete cylinder strength

$f_{\text {cu }}=$ concrete cube strength

$f_{\mathrm{s} y}=$ yield strength of structural steel 
$f_{\mathrm{su}}=$ ultimate tensile strength of structural steel

$L=$ length of column

$n=$ load ratio

$N_{0}=$ cross-section capacity of composite column at ambient temperature

$N_{0}(T)=$ cross-section capacity of composite column at elevated temperature

$N_{\mathrm{f}}=$ applied axial load

$N_{\mathrm{u}}=$ ultimate capacity of composite column at ambient temperature

$N_{\mathrm{u}}(T)=$ ultimate capacity of composite column at elevated temperature

$t_{\mathrm{s}}=$ wall thickness of steel tube

$T=$ temperature

$T_{\mathrm{c}, \mathrm{eq}}=$ equivalent temperature of concrete

$T_{\mathrm{b}}=$ temperature of reinforcing bar

$T_{\mathrm{s}}=$ temperature of steel tube

$\alpha=$ thermal expansion coefficient

$\alpha_{\mathrm{b}}=$ ratio of reinforcement, $\alpha_{\mathrm{b}}=A_{\mathrm{b}} /\left(A_{\mathrm{c}}+A_{\mathrm{b}}\right)$

$\alpha_{\mathrm{s}}=$ steel tube to concrete area ratio, $\alpha_{\mathrm{s}}=A_{\mathrm{s}} / A_{\mathrm{c}}$

$\varepsilon_{\mathrm{cth}}=$ thermal strain of concrete

$\varepsilon_{\mathrm{ctr}}=$ transient strain of concrete

$v_{\mathrm{c}}=$ Poisson's ratio of concrete at ambient temperature

$v_{\mathrm{cT}}=$ Poisson's ratio of concrete at elevated temperature

$v_{s}=$ Poisson's ratio

$\chi=$ buckling reduction factor

\section{References}

591 Aboutaha, R. S., and Machado, R. (1998). "Seismic resistance of steel confined reinforced concrete 592 (SCRC) columns." Struct. Des. Tall Buil., 7(3): 251-260.

593 Aboutaha, R. S., and Machado, R. I. (1999). "Seismic resistance of steel-tubed high-strength 594 reinforced-concrete columns." J. Struct. Eng.-ASCE, 125(5): 485-494.

595 AIJ (Architectural Institute of Japan) (2008). "Recommendations for design and construction of 
concrete-filled steel tubular structures." Tokyo (in Japanese)

Anderberg, Y., Thelandersson, S. (1976). "Stress and deformation characteristics of concrete at high temperatures: 2 experimental investigation and material behaviour model." Bulletin 54, Lund Institute of Technology, Sweden.

ASCE (American Society of Civil Engineers). (1992). "Structural fire protection." ASCE Committee on Fire Protection, Structural Division, Manual of Practice No. 78.

ASTM (American Society for Testing and Materials). (1990). "Standard methods of fire tests on building construction and materials." E119, Philadelphia.

Bahr, O., Schaumann, P., Bollen, B., and Bracke, J. (2013). "Young's modulus and Poisson's ratio of concrete at high temperatures: Experimental investigations." Mater. Des., 45: 421-429.

Capua, D. D., and Mari, A. R. (2007). "Nonlinear analysis of reinforced concrete cross-sections exposed to fire." Fire Safety J., 42(2): 139-149.

CECS200. (China Association for Engineering Construction Standardization). (2006). "Technical code for fire safety of steel structures in building." Beijing (in Chinese)

CEN (European Committee for Standardization). (2004). "Eurocode 2: Design of concrete structures-Part 1-2: General rules -Structural fire safety.” EN 1992-1-2, Brussels.

CEN (European Committee for Standardization). (2005). "Eurocode 3: Design of steel structures-Part 1-2: General rules -Structural fire safety.” EN 1993-1-2, Brussels.

Chabot, M., Lie, T. T. "Experimental studies on the fire resistance of hollow steel columns filled with bar-reinforced concrete. " NRC-CNRC Internal Report, 1992, No.628.

Cooke, G. M. E. (1988). "An introduction to the mechanical properties of structural steel at elevated temperatures." Fire Safety J., 13(1): 45-54.

Ding, J., and Wang, Y. C. (2008). "Realistic modelling of thermal and structural behaviour of unprotected concrete filled tubular columns in fire." J. Constr. Steel Res., 64(10): 1086-1102.

Ehm, C., and Schneider, U. (1985). "The high temperature behaviour of concrete under biaxial conditions." Cem. Concr. Res., 15(1): 27-34.

Espinos, A., Romero, M. L., and Hospitaler, A. (2010). "Advanced model for predicting the fire response of concrete filled tubular columns." J. Constr. Steel Res., 66(8-9): 1030-1046. 
624 Espinos, A., Gardner, L., Romero, M. L., and Hospitaler, A. (2011). "Fire behaviour of concrete filled elliptical steel columns." Thin Walled Struct., 49(2): 239-255.

626 Espinos, A., Romero, M. L., Serra, E., and Hospitaler, A. (2015). "Circular and square slender concrete-filled tubular columns under large eccentricities and fire." J. Constr. Steel Res., 110: 90-100.

GB50936. (Ministry of Housing and Urban-Rural Development, China )(2014). "Technical code for concrete filled steel tubular structures." Beijing (in Chinese)

Gernay, T., Millard, A., and Franssen, J.-M. (2013). "A multiaxial constitutive model for concrete in the fire situation: Theoretical formulation." Int. J. Solids Struct., 50(22): 3659-3673.

Han, L. H., Zhao, X. L., Yang, Y. F., Feng, J. B. (2003a). "Experimental study and calculation of fire resistance of concrete-filled hollow steel columns." J. Struct. Eng.-ASCE, 129(3): 346-356.

Han, L. H., Yang, Y. F., and Xu, L. (2003b). "An experimental study and calculation on the fire resistance of concrete-filled SHS and RHS columns." J. Constr. Steel Res., 59(4): 427-452.

Han, L. H., and Huo, J. S. (2003c). "Concrete-filled hollow structural steel columns after exposure to ISO834 fire standard." J. Struct. Eng.-ASCE, 129(1): 68-78.

Han, L. H., Yao, G. H., Chen, Z. B., and Yu, Q. (2005a). "Experimental behaviours of steel tube confined concrete (STCC) columns." Steel Compos. Struct., 5(6): 459-484.

Han, L. H., Huo, J. S., and Wang, Y. C. (2005b). "Compressive and flexural behaviour of concrete filled steel tubes after exposure to standard fire." J. Constr. Steel Res., 61(7): 882-901.

Han, L. H. (2007). "Concrete filled steel tubular structures-theory and practice. (2nd edition)" Science Press.(in Chinese)

Han, L. H., Qu, H., Tao, Z., and Wang, Z. F. (2009). "Experimental behaviour of thin-walled steel tube confined concrete column to RC beam joints under cyclic loading." Thin Walled Struct., 47(8): 847-857.

Han, L. H., Wang, W. H., and Yu, H. X. (2012). "Analytical behaviour of RC beam to CFST column frames subjected to fire." Eng. Struct., 36: 394-410.

Hong, S., and Varma, A. H. (2009). "Analytical modeling of the standard fire behavior of loaded CFT columns." J. Constr. Steel Res., 65(1): 54-69. 
652 Ibáñez, C., Romero, M. L., and Hospitaler, A. (2013). "Fiber beam model for fire response simulation of axially loaded concrete filled tubular columns." Eng. Struct., 56: 182-193.

654 Imani, R., Mosqueda, G., and Bruneau, M. (2015). "Finite element simulation of concrete-filled 655 double-skin tube columns subjected to postearthquake fires." J. Struct. Eng.-ASCE, 141(12),

ISO 834-1. (Switzerland: International Organization for Standardization). (1999). "Fire resistance tests - elements of building construction-part 1: general requirements." Geneva, Switzerland.

ISO 6892-1. (Switzerland: International Organization for Standardization). (2009). "Metallic materials-Tensile testing-Part 1: Method of test at room temperature." Geneva, Switzerland.

Kodur, V. K. R., and Lie, T. T. (1996). "Fire resistance of circular steel columns filled with fiber-reinforced concrete." J. Struct. Eng.-ASCE, 122(7), 776-782.

Kodur, V. K. R. (1999). "Performance-based fire resistance design of concrete-filled steel columns." J. Constr. Steel Res., 51(1): 21-36.

Kodur, V. K. R., and Dwaikat, M. (2008). "A numerical model for predicting the fire resistance of reinforced concrete beams." Cem. Concr. Compos., 30(5): 431-443.

Kodur, V., Dwaikat, M., and Fike, R. (2010). "High-temperature properties of steel for fire resistance modeling of structures." J. Mater. Civ. Eng., 22(5): 423-434.

Li, L. Y., and Purkiss, J. (2005). "Stress-strain constitutive equations of concrete material at elevated temperatures." Fire Safety J., 40(7): 669-686.

Lie, T. T., Chabot, M. (1992). "Experimental studies on the fire resistance of hollow steel columns filled with plain concrete." NRC-CNRC Internal Report, No.611.

Lie, T. T. (1994). "Fire resistance of circular steel columns filled with bar-reinforced concrete." $J$. Struct. Eng.-ASCE, 120(5): 1489-1509.

Lie, T. T., and Kodur, V. K. R. (1996). "Fire resistance of steel columns filled with bar-reinforced concrete." J. Struct. Eng.-ASCE, 122(1): 30-36.

Liu, J., and Zhou, X. (2010). "Behavior and strength of tubed RC stub columns under axial compression." J. Constr. Steel Res., 66(1): 28-36.

Liu, F., Gardner, L., and Yang, H. (2014). "Post-fire behaviour of reinforced concrete stub columns 

confined by circular steel tubes." J. Constr. Steel Res., 102: 82-103.

681 Liu, J., Wang, X., and Zhang, S. (2015). "Behavior of square tubed reinforced-concrete short 682

Liu, F., Yang, H., and Gardner, L. (2016). "Post-fire behaviour of eccentrically loaded reinforced concrete columns confined by circular steel tubes." J. Constr. Steel Res., 122: 495-510.

Liu, F., Yang, H., Yang, D., and Zhang, S. (2017). "Fire safety design method of circular steel tube confined reinforced concrete columns." J. Building Struct., 38(s1): 150-156. (in Chinese)

Lu, H., Zhao, X. L., and Han, L. H. (2009). "Fire behaviour of high strength self-consolidating concrete filled steel tubular stub columns." J. Constr. Steel Res., 65(10): 1995-2010.

Luccioni, B. M., Figueroa, M. I., and Danesi, R. F. (2003). "Thermo-mechanic model for concrete exposed to elevated temperatures." Eng. Struct., 25(6): 729-742.

Lv, X. T., Yang, H., Zhang, S. M. (2011). "Effect of contact thermal resistance on temperature distributions of concrete-filled steel tubes in fire." Journal of Harbin Institute of Technology, 18(1): $81-88$.

Mander, J. B., Priestley, M. J. N., and Park, R. (1988). "Theoretical stress - strain model for confined concrete." J. Struct. Eng.-ASCE, 114(8): 1804-1826.

Marechal, J. C. (1972). "Variations in the modulus of elasticity and Poisson's Ratio with temperature." ACI Special Publication, SP34: 495-503.

Neuenschwander, M., Knobloch, M., and Fontana, M. (2016). "Suitability of the damage-plasticity modelling concept for concrete at elevated temperatures: Experimental validation with uniaxial cyclic compression tests." Cem. Concr. Res., 79(1): 57-75.

Neuenschwander, M., Knobloch, M., and Fontana, M. (2017a). "Modeling thermo-mechanical behavior of concrete-filled steel tube columns with solid steel core subjected to fire." Eng. Struct., 136: 180-193.

Neuenschwander, M., Knobloch, M., and Fontana, M. (2017b). "Generic model stress-strain relationship for concrete in compression at elevated temperatures." ACI Mater. J., 114(1): 3-14.

Neuenschwander, M., Scandella, C., Knobloch, M., and Fontana, M. (2018). "Experimental validation of the damage-plasticity modeling concept for normal strength concrete in fire." $J$. 
Outinen, J. (2007). "Mechanical properties of structural steels at high temperatures and after cooling down." Helsinki University of Technology, Helsinki, Finland.

Poh, K. (2001). "Stress-Strain-Temperature Relationship for Structural Steel." J. Mater. Civil Eng., 13(5): 371-379.

Sadaoui, A., and Khennane, A. (2009). "Effect of transient creep on the behaviour of reinforced

Sakino, K., Tomii, M., and Watanabe, K. (1985). "Sustaining load capacity of plain concrete stub columns by circular steel tubes." In Proc., International Special Conf. on Concrete-filled Steel Tubular Structure, Harbin, China, 112-118.

Schaumann, P., Kodur V., and Bahr O. (2009). "Fire behaviour of hollow structural section steel columns filled with high strength concrete." J. Constr. Steel Res., 65(8-9): 1794-1802.

Song, T. Y., Han, L. H., and Yu, H. X. (2010a). "Concrete filled steel tube stub columns under combined temperature and loading." J. Constr. Steel Res., 66(3): 369-384.

Song, T. Y., Han, L. H., and Uy, B. (2010b). "Performance of CFST column to steel beam joints subjected to simulated fire including the cooling phase." J. Constr. Steel Res., 66(4): 591-604.

Sun, Y., and Sakino, K. (2000). "Simplified design method for ultimate capacities of circularly confined high-strength concrete columns." ACI Special Publication, 193: 571-586.

Sun, Y., and Fukuhara, T. (2005). "Development of high seismic performance concrete frames." ACI Special Publication, 228: 615-632.

Tan, Q. H., Han, L. H., and Yu, H. X. (2012). "Fire performance of concrete filled steel tubular (CFST) column to RC beam joints." Fire Safety J., 51(7): 68-84.

Tao, Z., Ghannam, M. (2012). "Refined FE model to predict the temperature field within concrete-filled steel tubes." In Proceedings of 7th International Conference on Advances in Steel Structures, Nanjing, China, 781-789.

Tao, Z., Ghannam, M., Song, T. Y., and Han, L. H. (2016). "Experimental and numerical investigation of concrete-filled stainless steel columns exposed to fire." J. Constr. Steel Res., 118: $120-134$. 
736 Tomii, M., Sakino, K., Watanabe, K., and Xiao, Y. (1985a). "Lateral load capacity of reinforced concrete short columns confined by steel tube." In Proc., International Special Conf. on Concrete-filled Steel Tubular Structure, Harbin, China, 19-26.

739 Tomii, M., Sakino, K., Xiao, Y., and Watanabe, K. (1985b). "Earthquake resisting hysteretic behavior Conf. on Concrete-filled Steel Tubular Structure, Harbin, China, 119-125.

Wang, K., and Young, B. (2013). "Fire resistance of concrete-filled high strength steel tubular columns." Thin Walled Struct., 71: 46-56.

Wang, X., Liu, J., and Zhang, S. (2015). "Behavior of short circular tubed-reinforced-concrete columns subjected to eccentric compression." Eng. Struct., 105: 77-86.

Wang X, Liu J. (2017). "Behavior and design of slender square tubed-reinforced-concrete columns subjected to eccentric compression." Thin Walled Struct., 120: 153-160.

Xiong, M. X., and Liew, J. R. (2016). "Mechanical behaviour of ultra-high strength concrete at elevated temperatures and fire resistance of ultra-high strength concrete filled steel tubes." Mater. Des., 104: 414-427.

Yang, H., Han, L. H., and Wang, Y. C. (2008). "Effects of heating and loading histories on post-fire cooling behaviour of concrete-filled steel tubular columns." J. Constr. Steel Res., 64(5): 556-570.

Yang, H., Liu, F., Zhang, S., and Lv, X. (2013a). "Experimental investigation of concrete-filled square hollow section columns subjected to non-uniform exposure." Eng. Struct., 48: 292-312.

Yang, H., Liu, F., and Gardner, L. (2013b). "Performance of concrete-filled RHS columns exposed to fire on 3 sides." Eng. Struct., 56: 1986-2004.

Yang, H., Liu, F., and Gardner, L. (2015). "Post-fire behaviour of slender reinforced concrete columns confined by circular steel tubes." Thin Walled Struct., 87: 12-29.

Yu, M., Xu, H., Ye, J., and Chi, Y. (2018). "A unified interaction equation for strength and global stability of solid and hollow concrete-filled steel tube columns under room and elevated temperatures." J. Constr. Steel Res., 148: 304-313.

Yu, Q., Tao, Z., Liu, W., and Chen, Z. B. (2010). "Analysis and calculations of steel tube confined 
764 concrete (STCC) stub columns." J. Constr. Steel Res., 66(1): 53-64.

765 Zhou, X., and Liu, J. (2010). "Seismic behavior and shear strength of tubed RC short columns." J. $766 \quad$ Constr. Steel Res., 66(3): 385-397.

767 Zhou X, Liu J, Wang X, and Chen Y.F. (2016). "Behavior and design of slender circular 768 tubed-reinforced-concrete columns subjected to eccentric compression." Eng. Struct., 124: $769 \quad 17-28$.

770 Wang X, Liu J. (2017). "Behavior and design of slender square tubed-reinforced-concrete columns $771 \quad$ subjected to eccentric compression." Thin Walled Struct., 120: 153-160. 


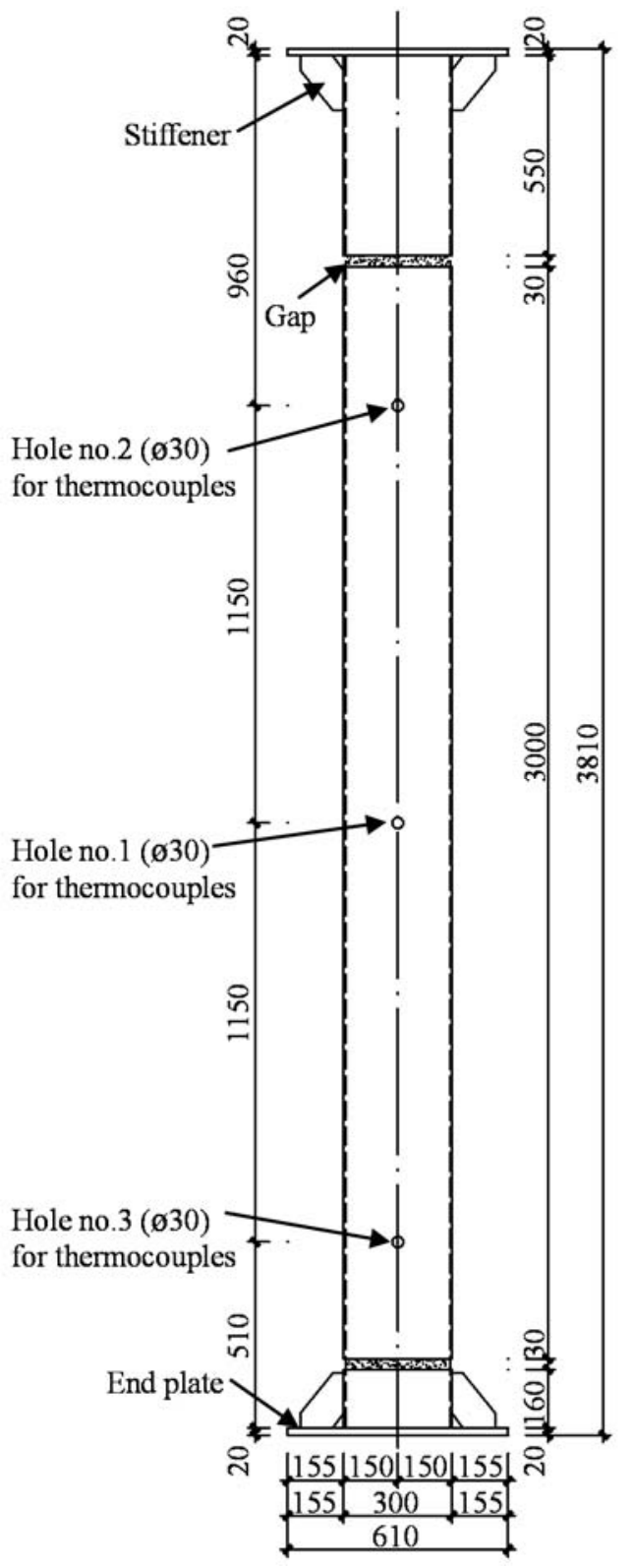

(a)

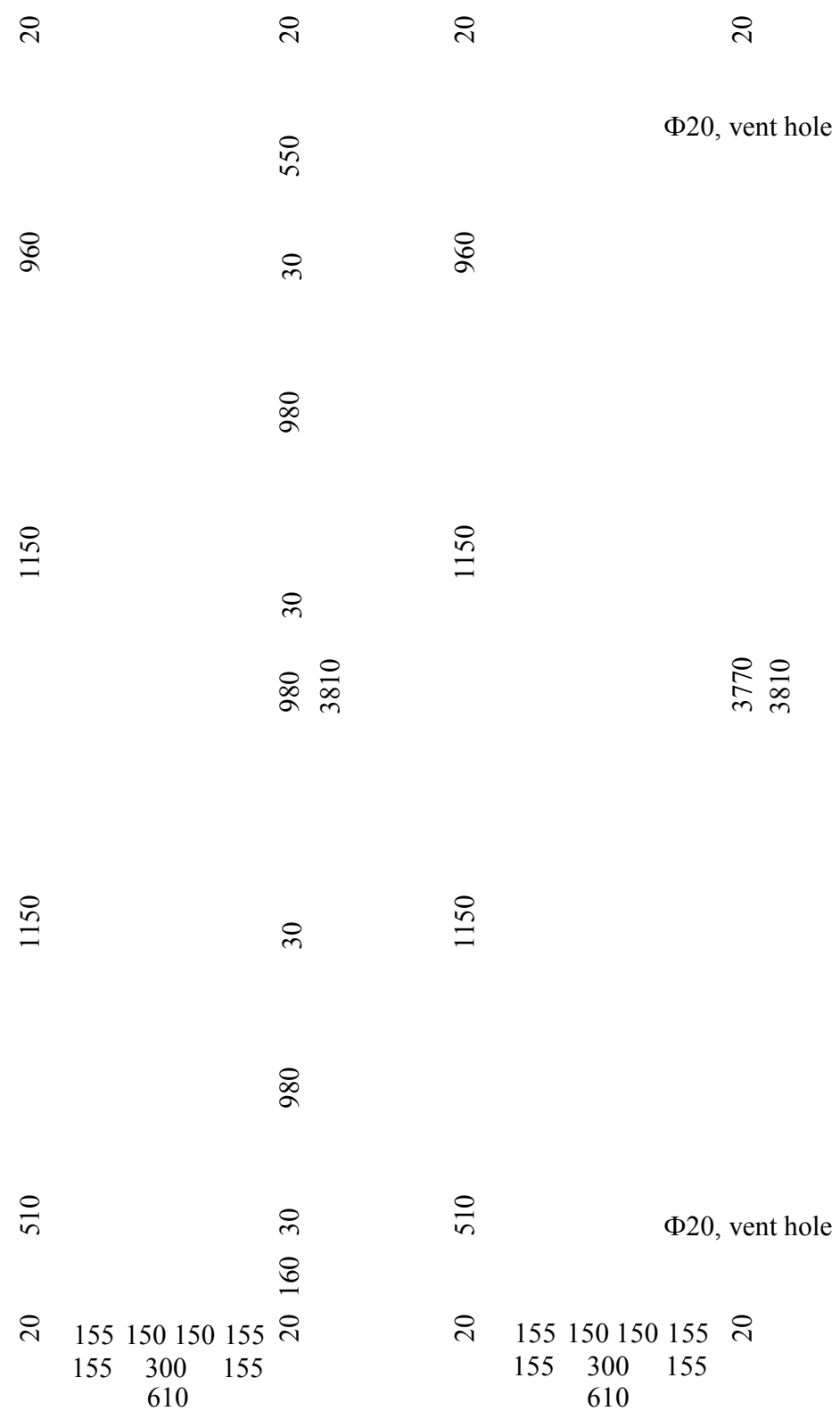

(b)

(c)

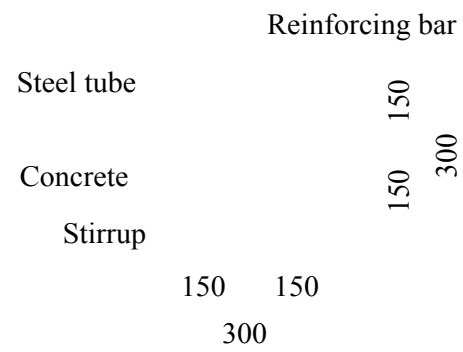

(d)
Steel tube

요

ह
Concrete

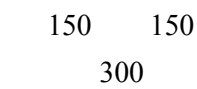

(e)

Fig.1 Details of the test specimens: (a) STCRC-1 to STCRC-3 (case a); (b) STCRC-4 (case b); (c) CFST; (d) cross-section of the STCRC columns; and (e) cross-section of the CFST column (unit: mm). 


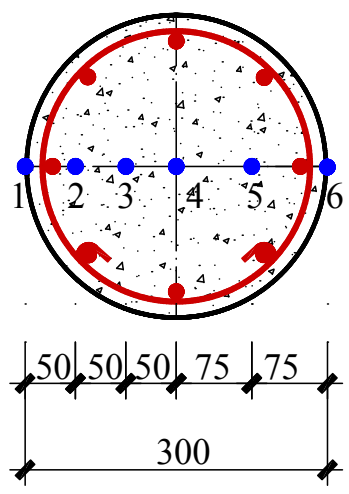

(a)
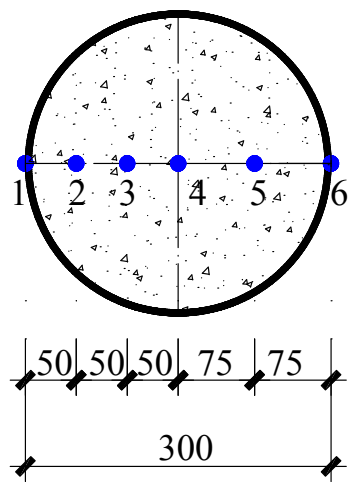

(d)
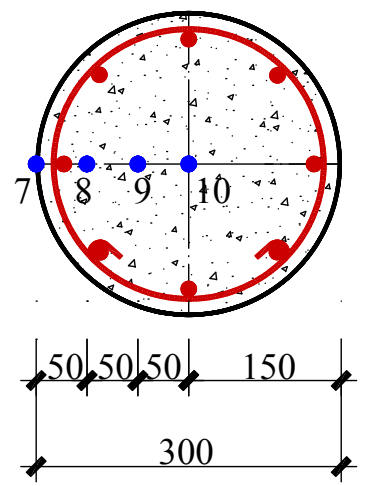

(b)

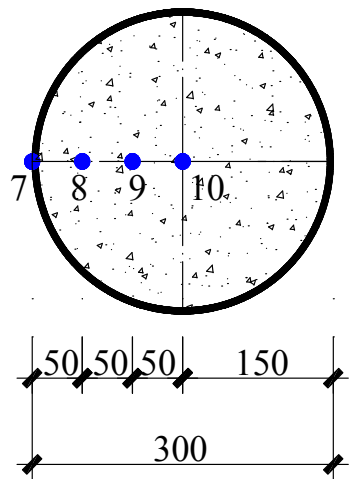

(e)

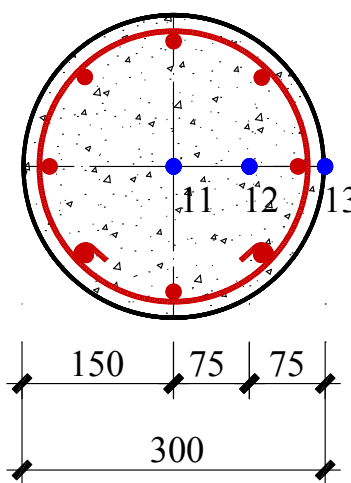

(c)

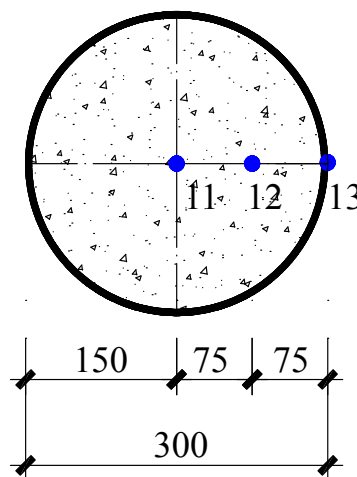

(f)

Fig.2 Layout of thermocouples in the test specimens: STCRC1-STCRC4: (a) at hole no. 1; (b) at hole no. 2; (c) at hole no. 3; and CFST: (d) at hole no. 1; (e) at hole no. 2; (f) at hole no. 3 (unit: mm). 


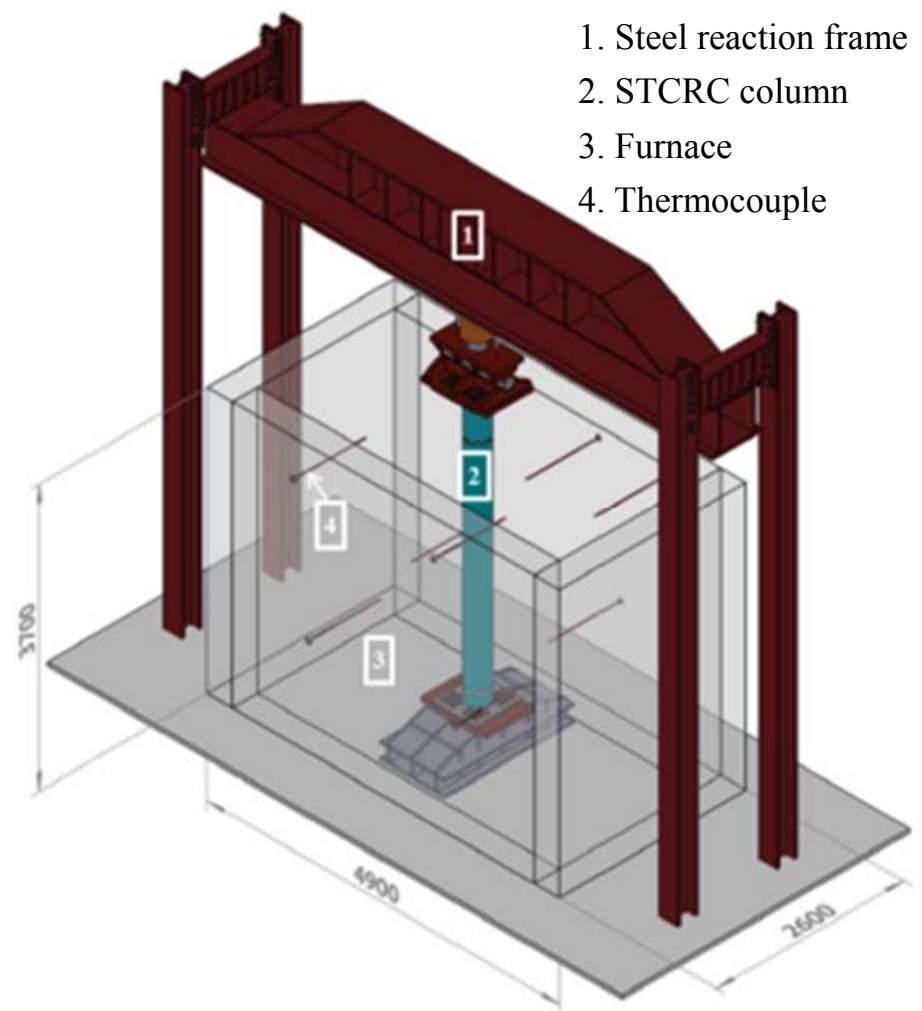

(a)

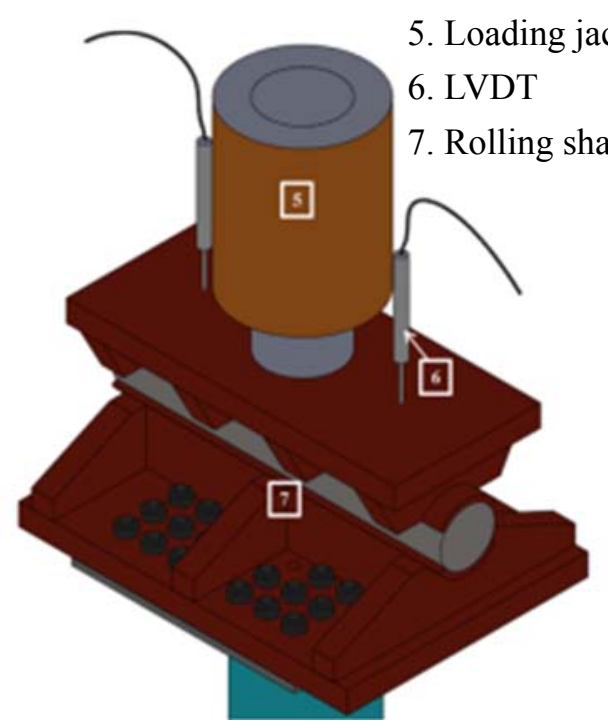

(c)

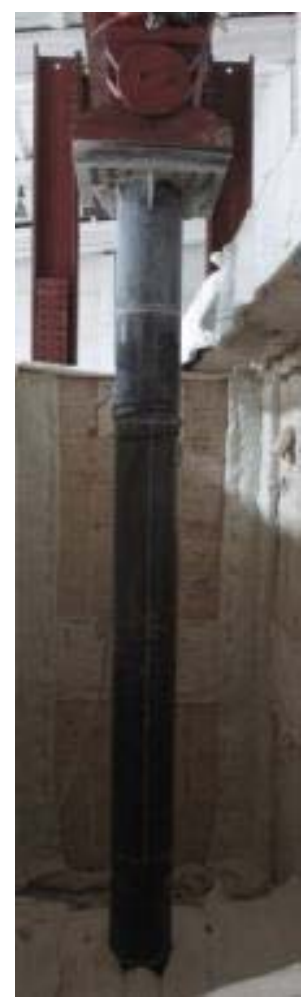

(b)

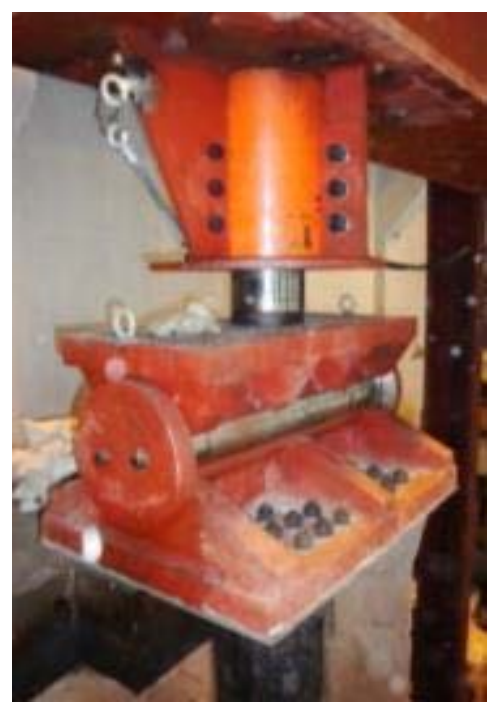

(d)

Fig. 3 General view of test rig and specimen: (a) overview of the test rig with dimensions in mm; (b) specimen prior to testing; (c) schematic view of top boundary condition; and (d) real top boundary condition. 


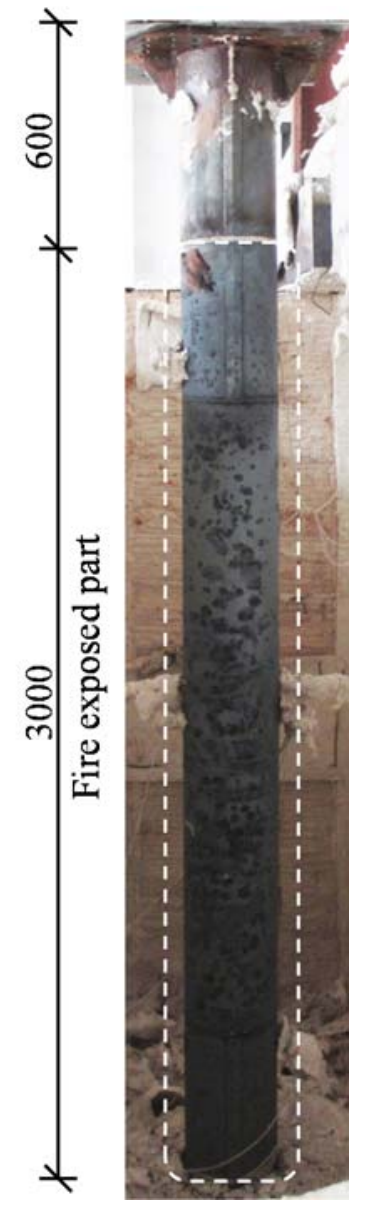

(a)

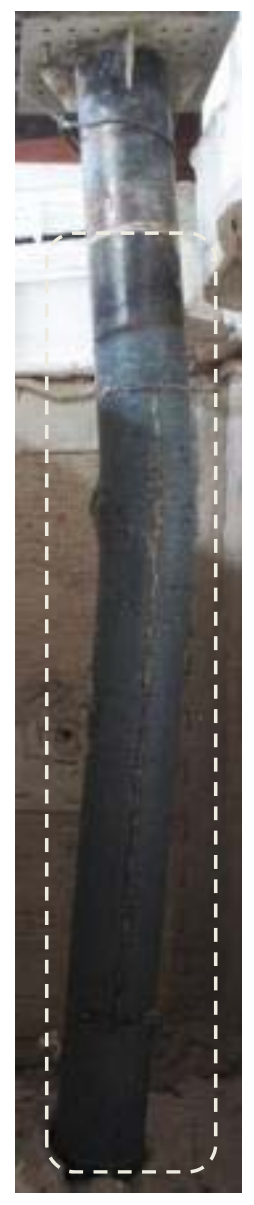

(b)

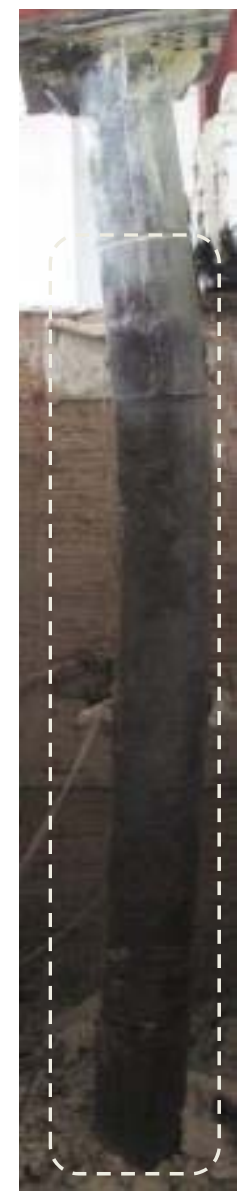

(c)

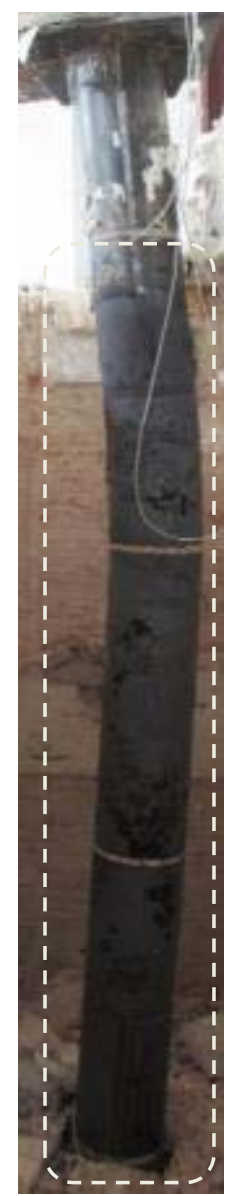

(d)

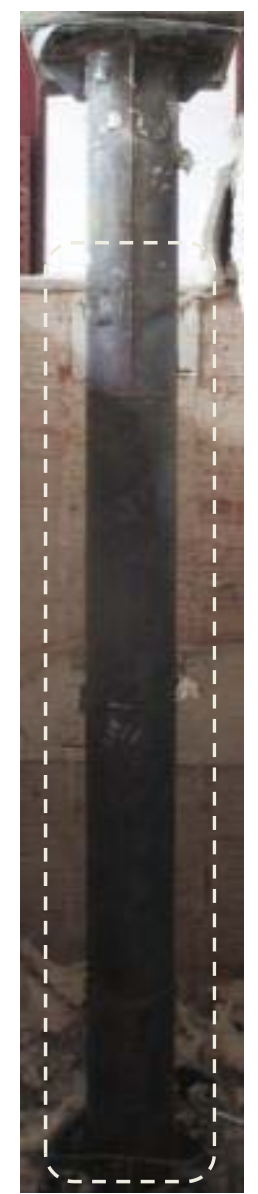

(e)

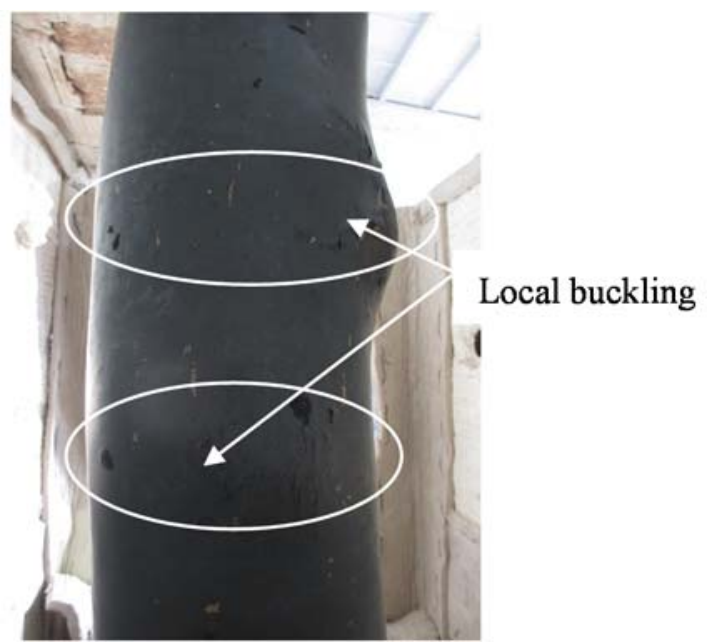

(f)

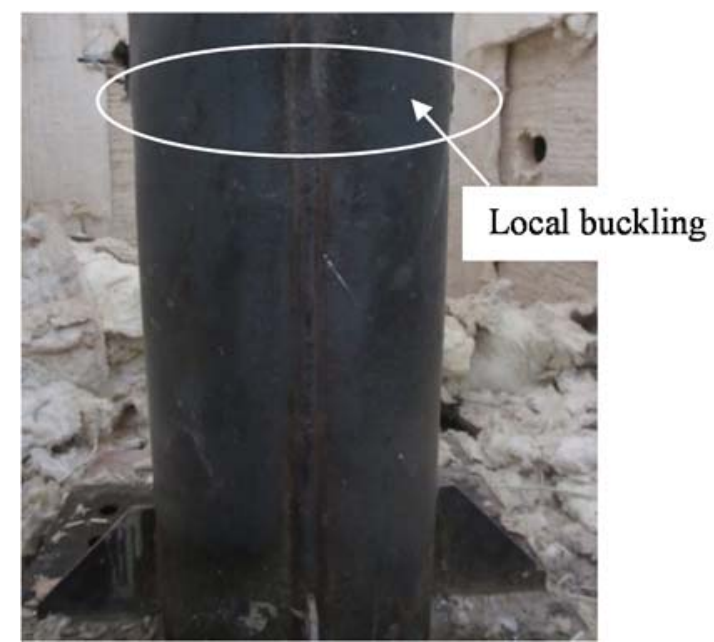

(g)

Fig.4 Failure modes of test specimens: general view: (a) STCRC-1; (b) STCRC-2; (c) STCRC-3; (d) STCRC-4; and (e) CFST; and typical local buckling: (f) STCRC and (g) CFST. 


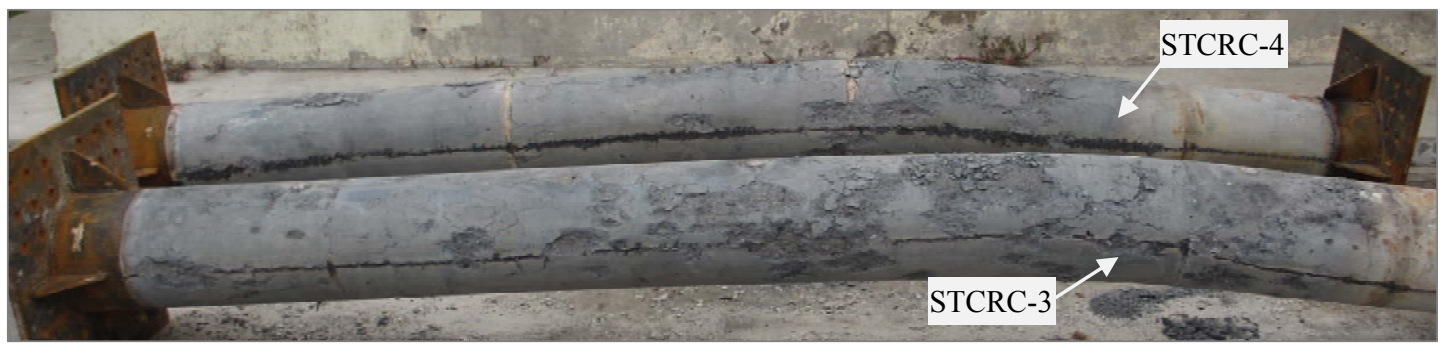

Fig.5 Failed specimens upon removal of steel tube. 


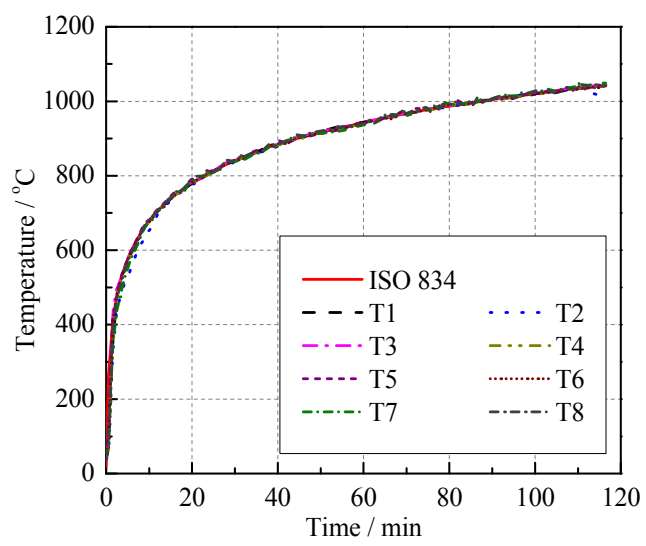

Fig.6 Furnace temperature versus time curves at different locations. 


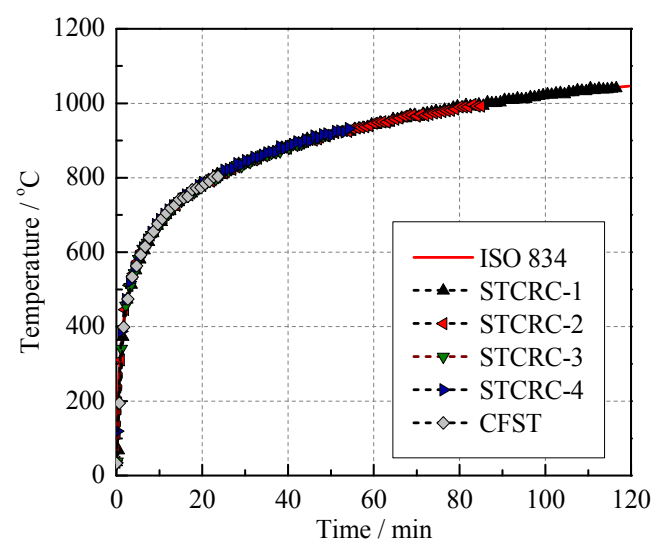

(a)

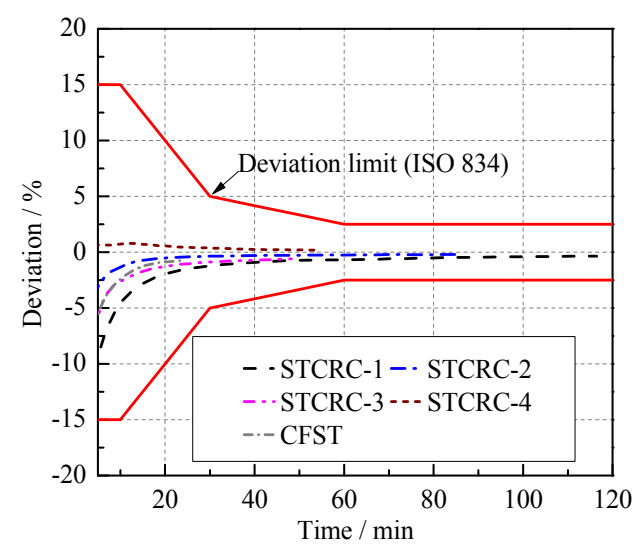

(b)

Fig.7 Average furnace temperature versus time curves: (a) comparison to standard fire curve; and (b) deviation from standard fire curve. 


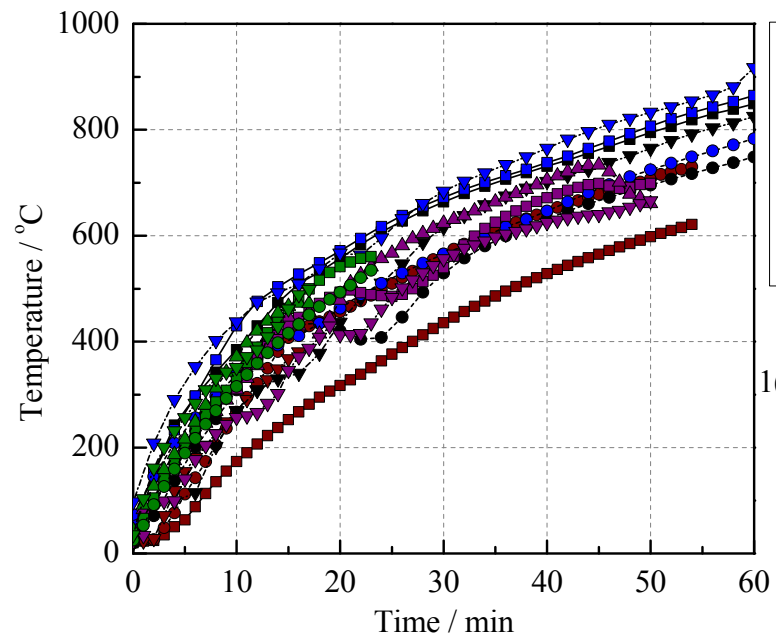

STCRC-1: - 1 - $-\cdots \bullet-13$

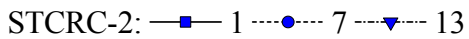

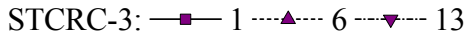

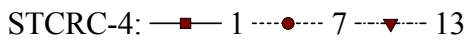

CFST: $\square 1 \cdots$

$\cdots-\cdots 13$

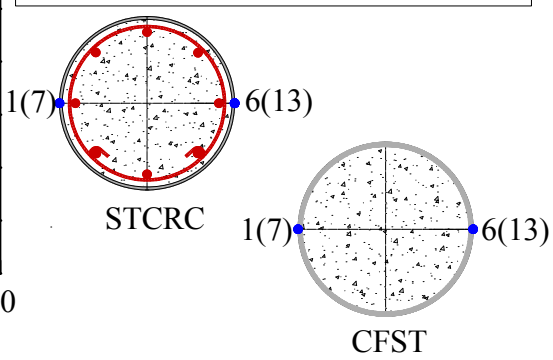

(a)

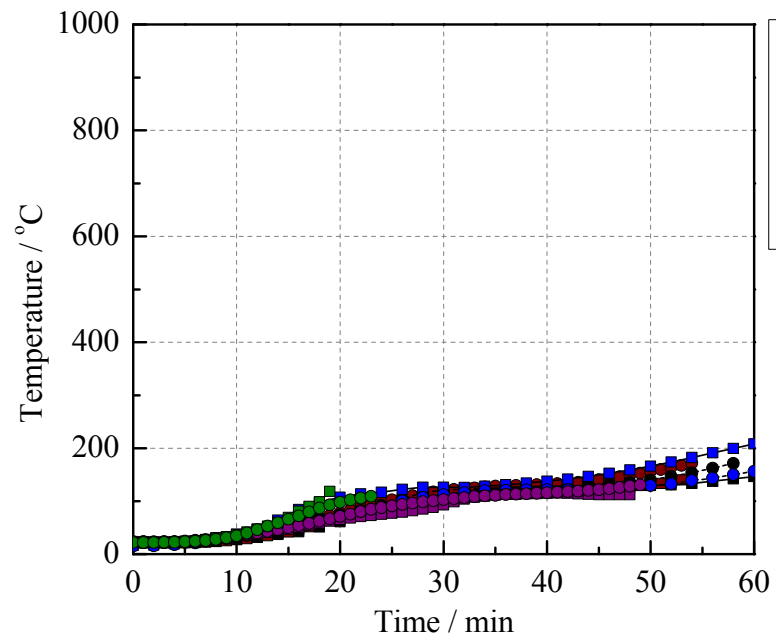

STCRC-1: $\longrightarrow 2-\cdots \cdot \bullet 8$

STCRC-2: $\square 2-\cdots$

STCRC-3: - $2-\cdots \bullet$

STCRC-4: $\longrightarrow-2 \cdots \bullet$

CFST: $\longrightarrow 2 \cdots$

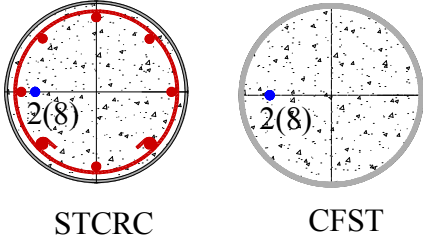

(b)

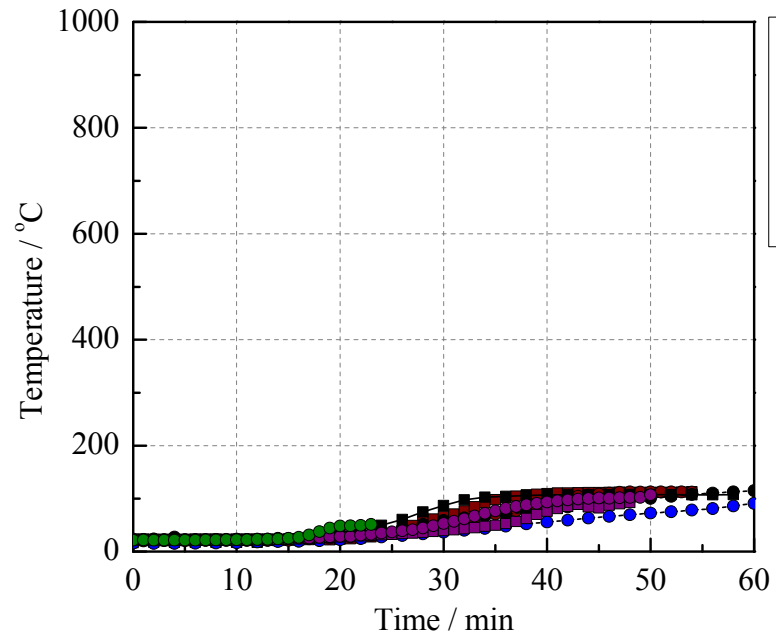

STCRC-1: - $3-\cdots \bullet$

STCRC-2: $\longrightarrow 3$-..--.. 9

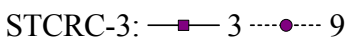

STCRC-4: $\longrightarrow-3$-.-•-.. 9

CFST: $\longrightarrow 3-\cdots$

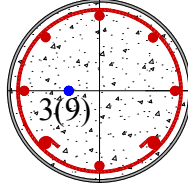

STCRC

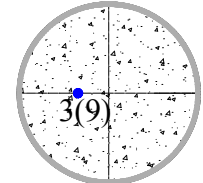

CFST

(c) 


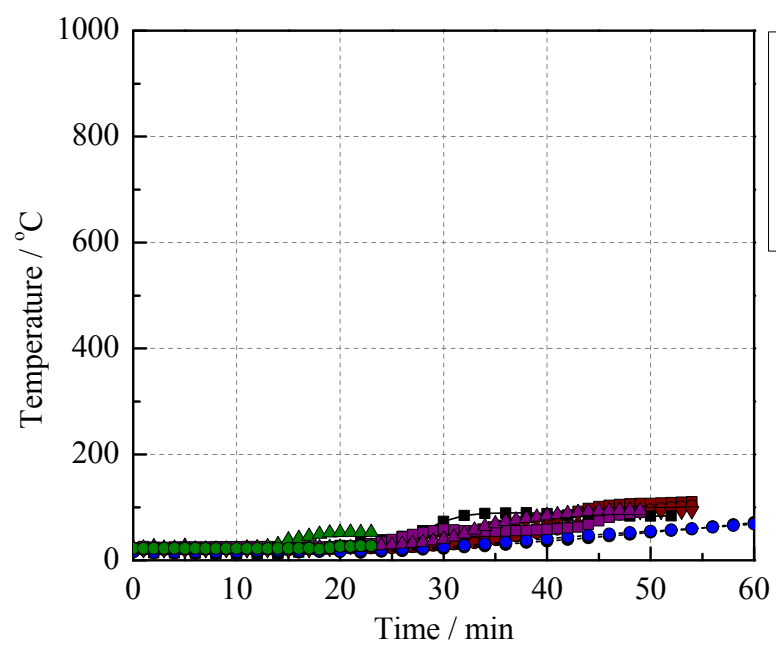

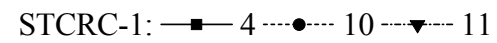

STCRC-2: $\longrightarrow-4-\cdots \cdot \cdots 10-\cdots 11$

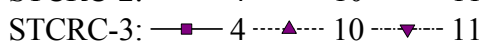

STCRC-4: $\because 4-4 \cdot-\cdots 10-\cdots-\cdots 1$

CFST: $\longrightarrow 4-410-\cdots 11$

(d)

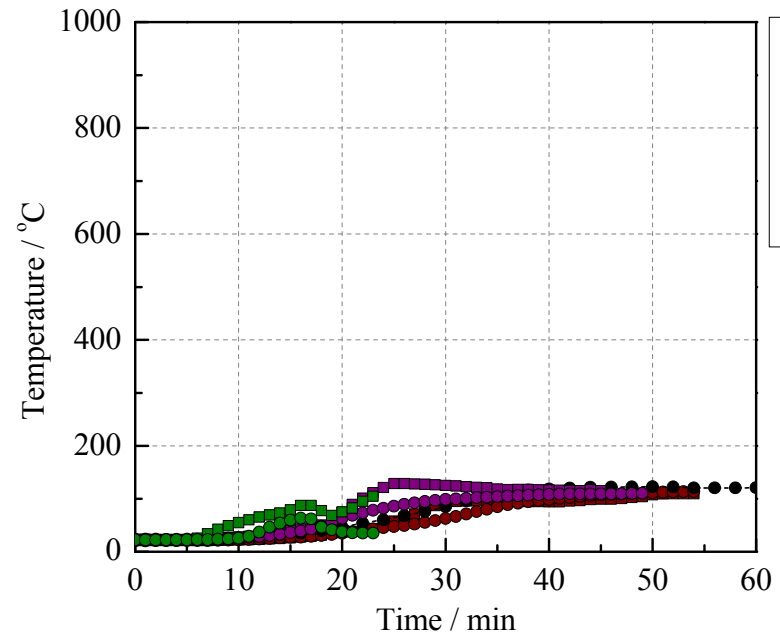

STCRC-1: $\longrightarrow 5-5 \cdot \cdots \cdot 12$

STCRC-2: $\longrightarrow 5-5 \cdots \cdot-\cdots 12$

STCRC-3: $\longrightarrow 5-5-\cdots \cdot \cdots \cdot 12$

STCRC-4: $\square-5-\cdots \cdot 12$

CFST: $\longrightarrow 5-\cdots-\cdots 12$

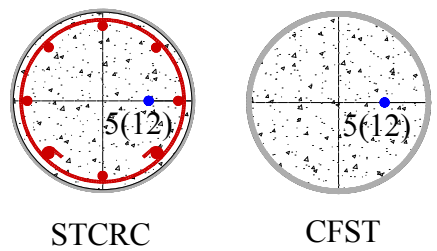

(e)

Fig.8 Temperatures of specimen at different heights (STCRC-4): (a) steel tube; and (b) - (e) concrete. 


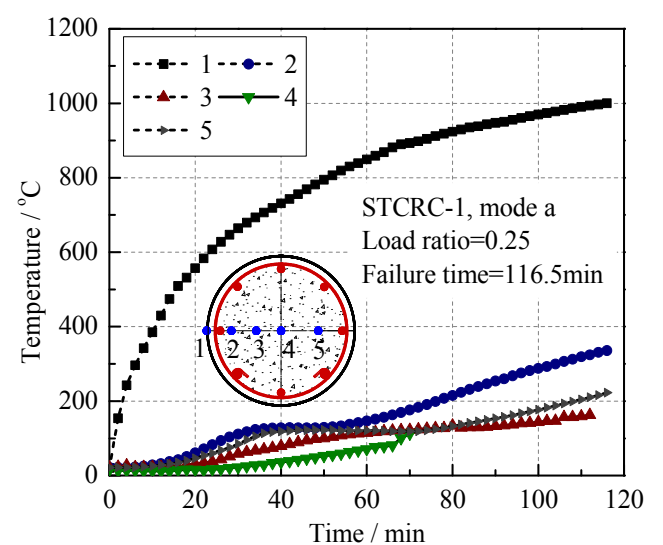

(a)

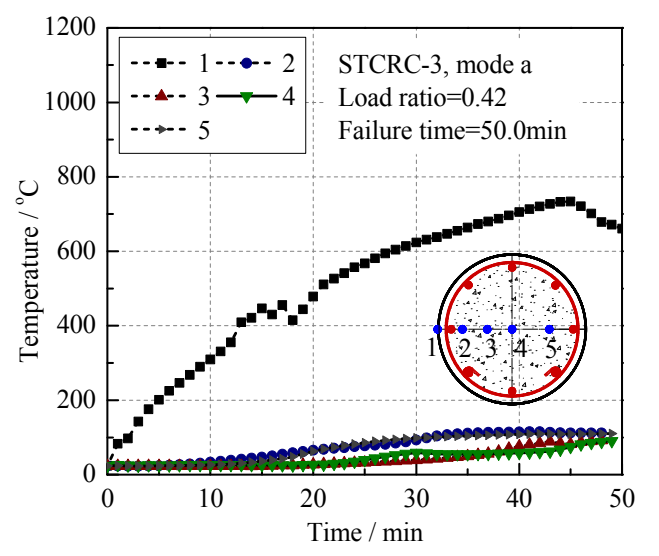

(c)

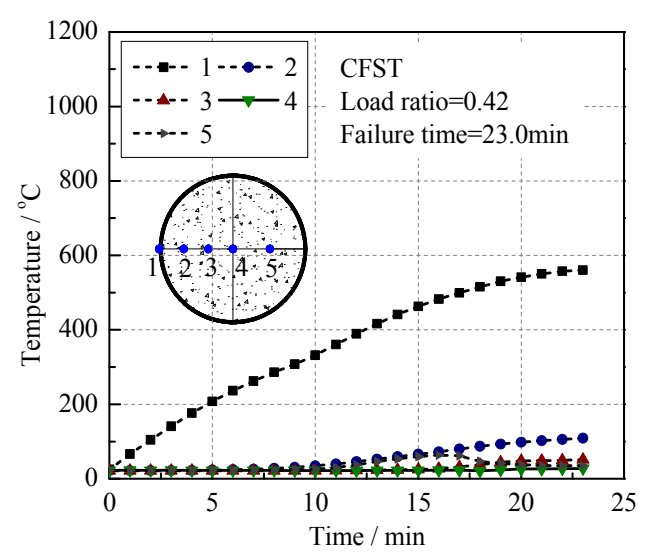

(e)

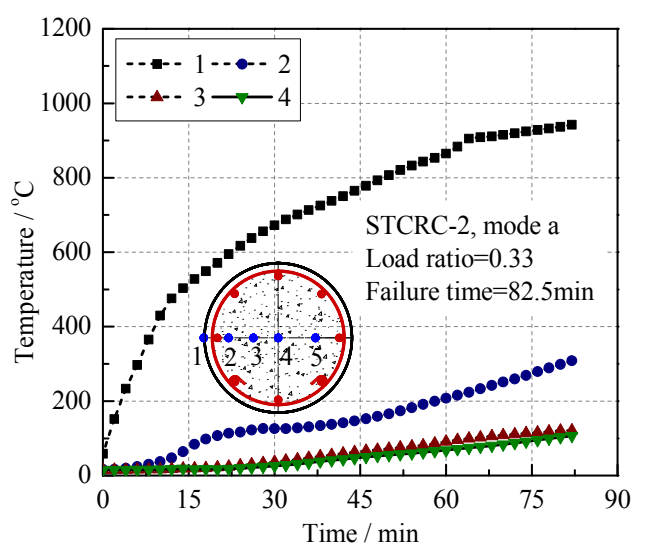

(b)

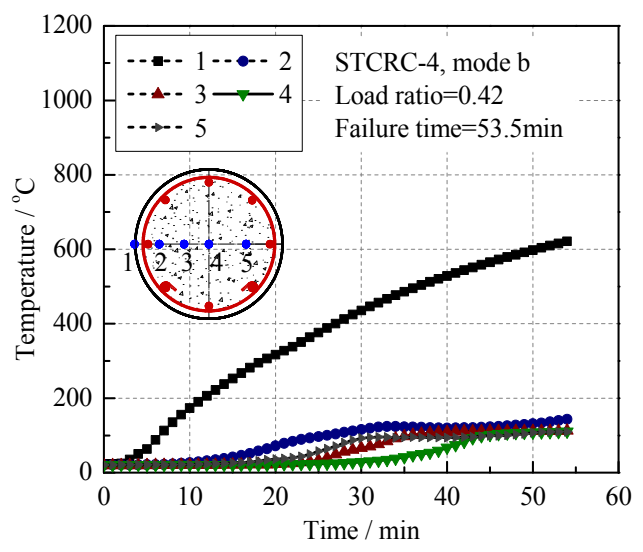

(d)

Fig.9 Measured temperatures of specimens through cross-sections: (a) STCRC-1; (b) STCRC-2; (c) STCRC-3; (d) STCRC-4 and (e) CFST. 


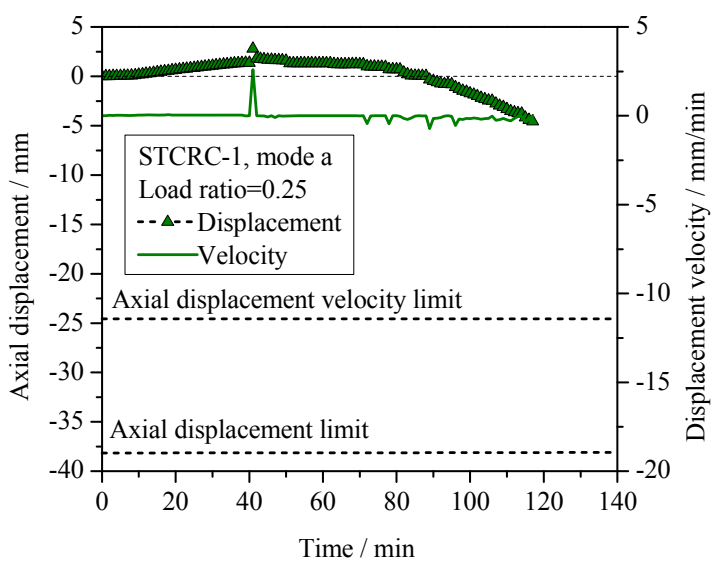

(a)

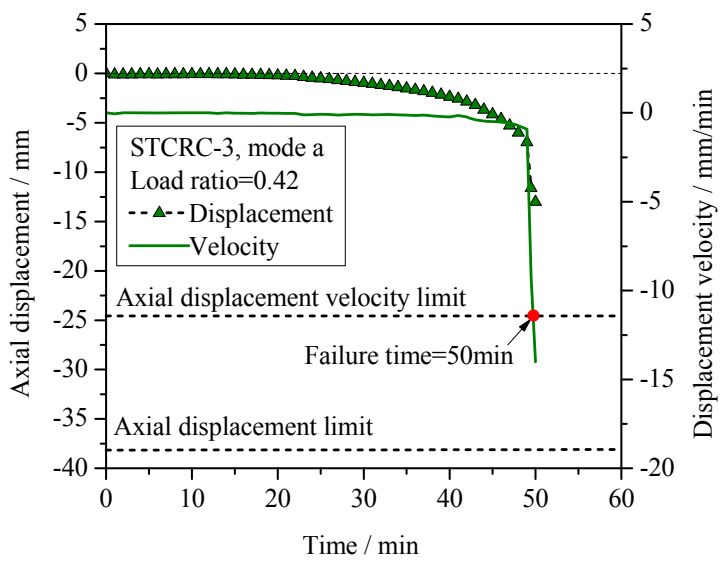

(c)

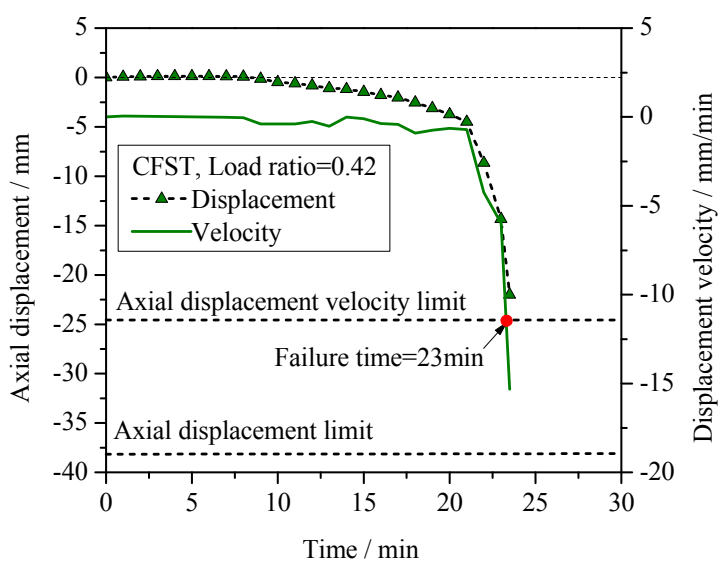

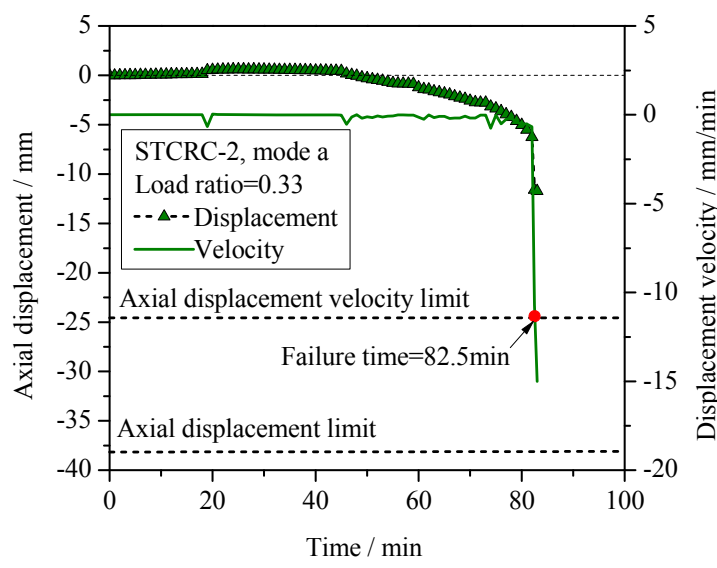

(b)

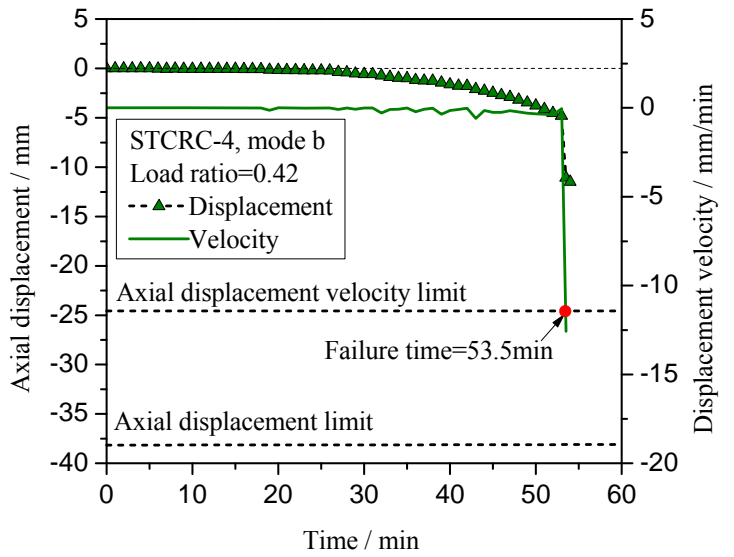

(d)

(e)

Fig.10 Displacement versus time curves of specimens during fire: (a) STCRC-1; (b) STCRC-2; (c) STCRC-3; (d) STCRC-4; and (e) CFST. 


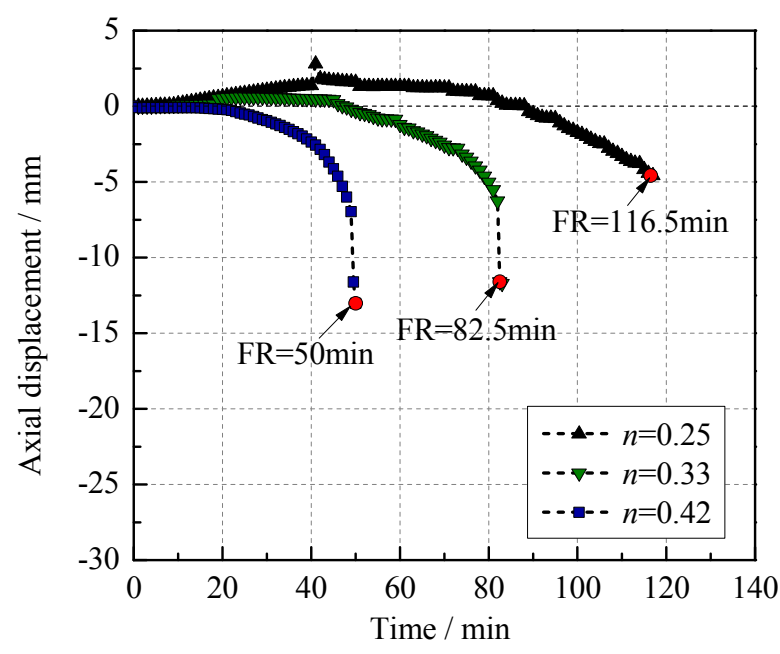

(a)

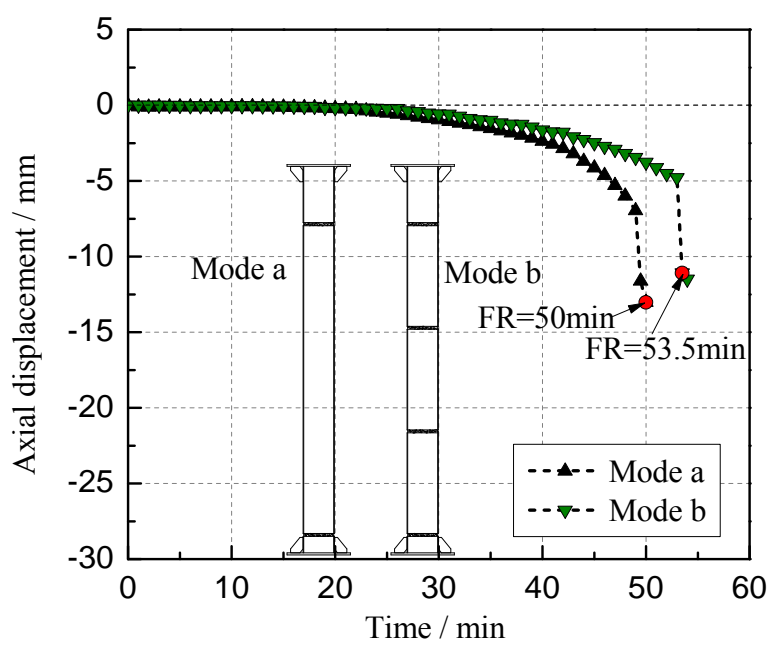

(b)

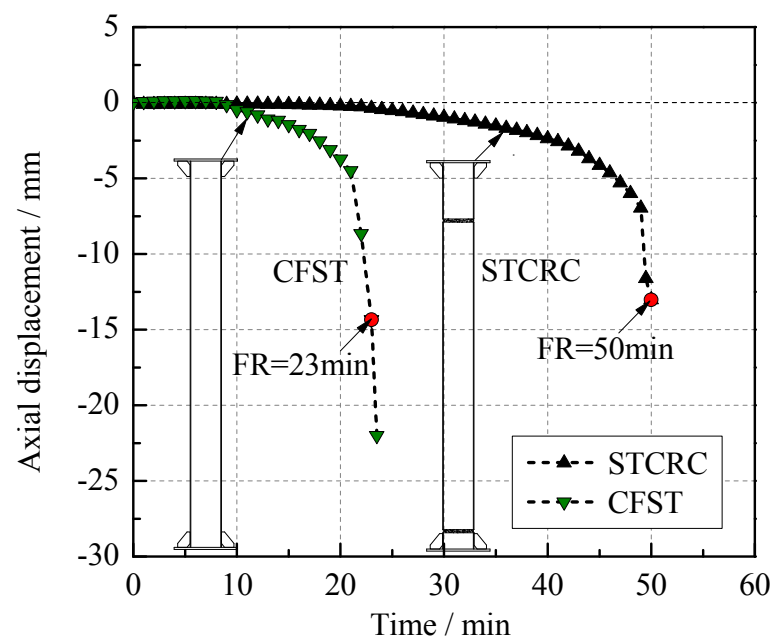

Fig.11 Influences of parameters on displacement-time response: (a) load ratio; (b) frequency of breaks to the longitudinal continuity of the steel tube; and (c) member type. 


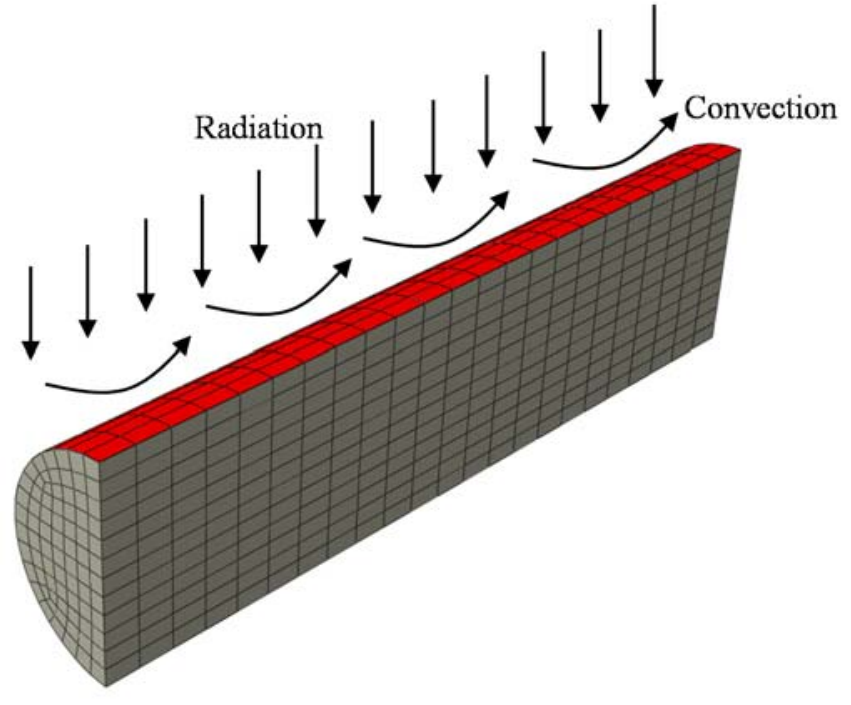

(a)

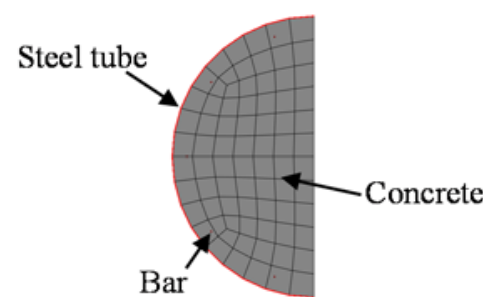

(b)

Fig.12 Finite element model of STCRC columns: (a) schematic view and (b) cross-section. 


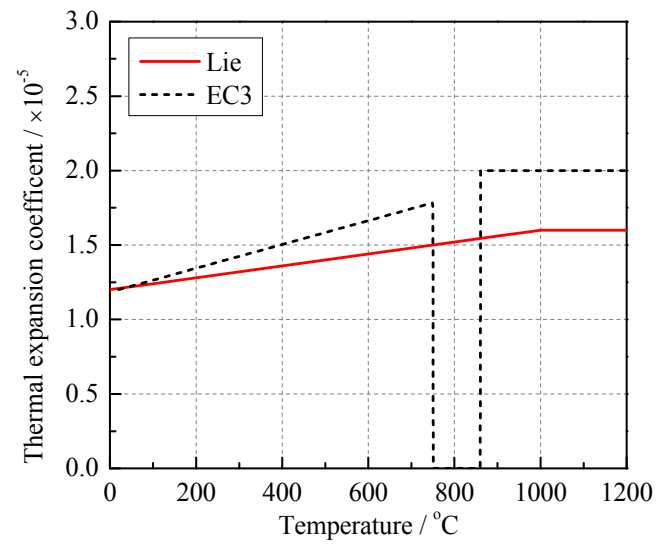

(a)

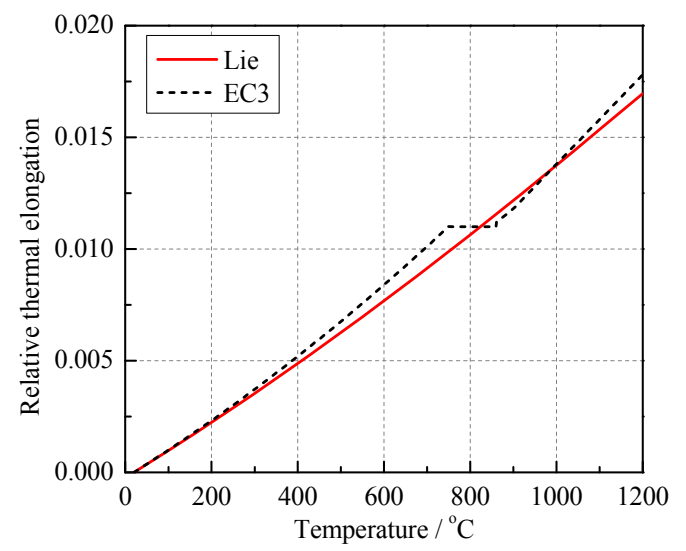

(b)

Fig.13 Comparisons between the EC3 model and Lie model: (a) thermal expansion coefficient; and (b) relative thermal elongation. 


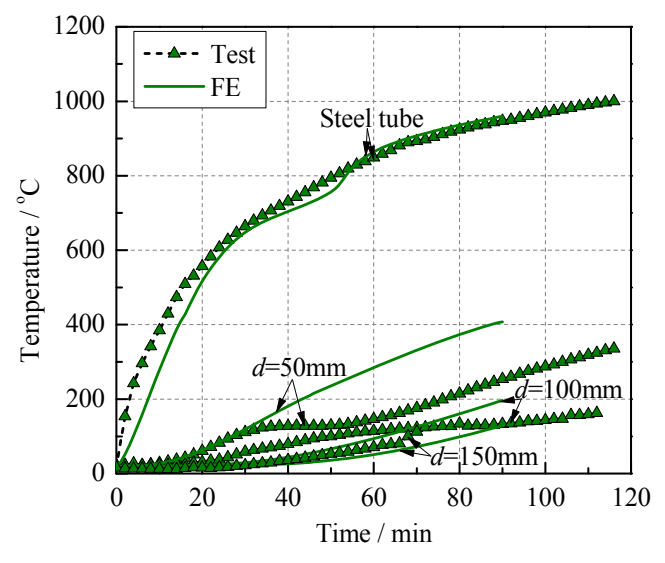

(a)

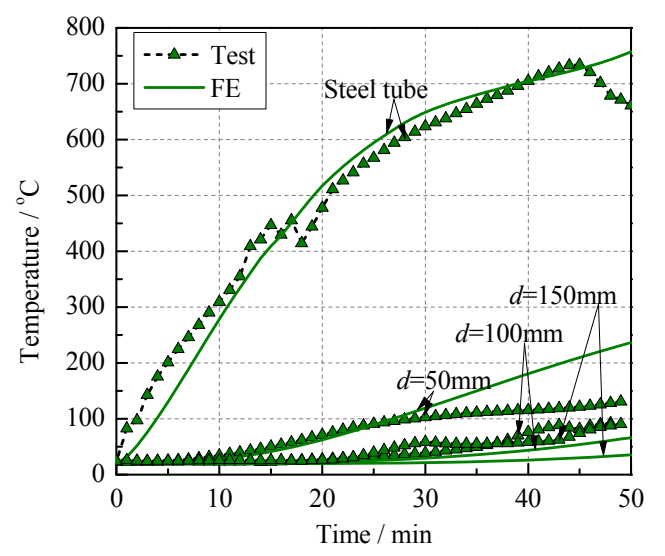

(c)

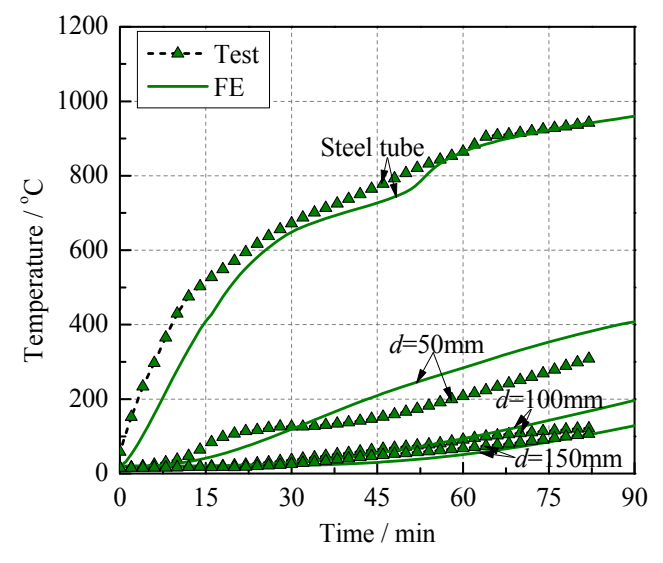

(b)

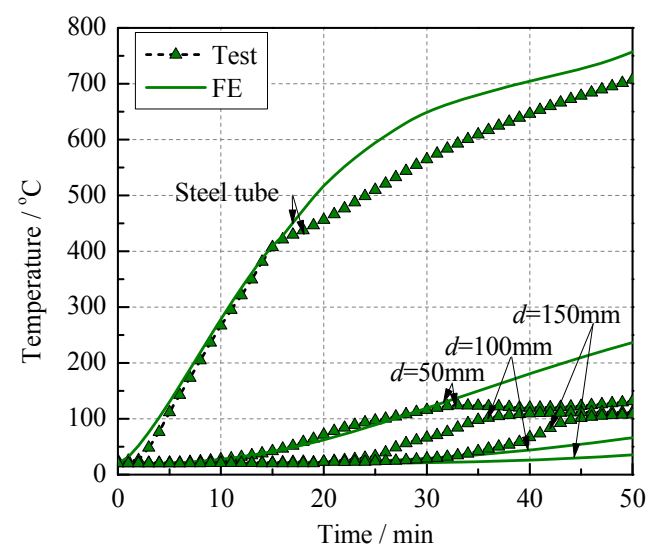

(d)

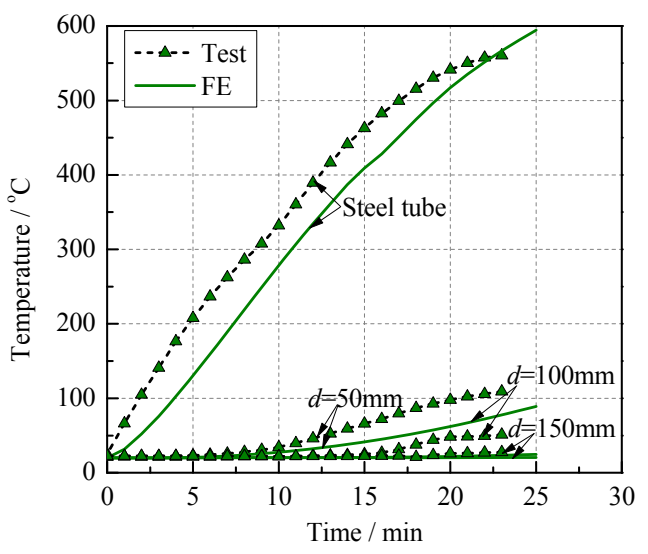

(e)

Fig. 14 Comparisons between the FE predicted and test temperatures of STCRC columns: (a) STCRC-1; (b) STCRC-2; (c) STCRC-3; (d) STCRC-4; and (e) CFST. 


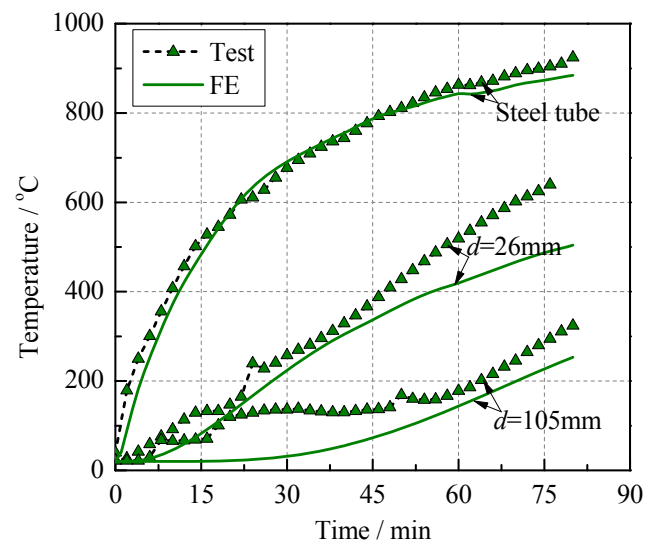

(a)

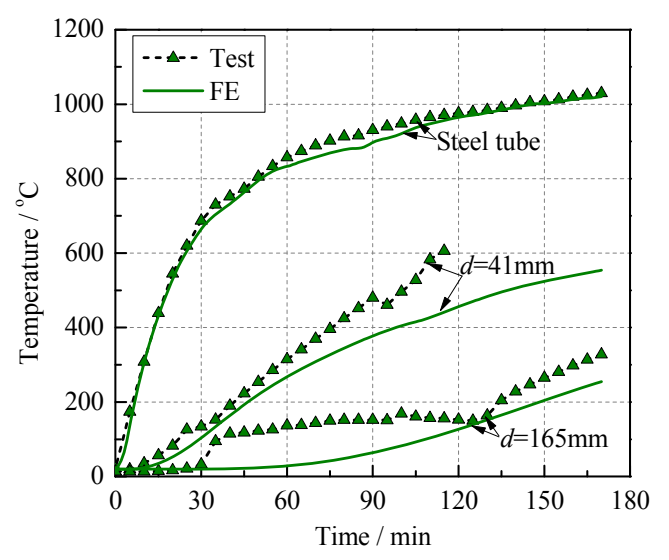

(c)

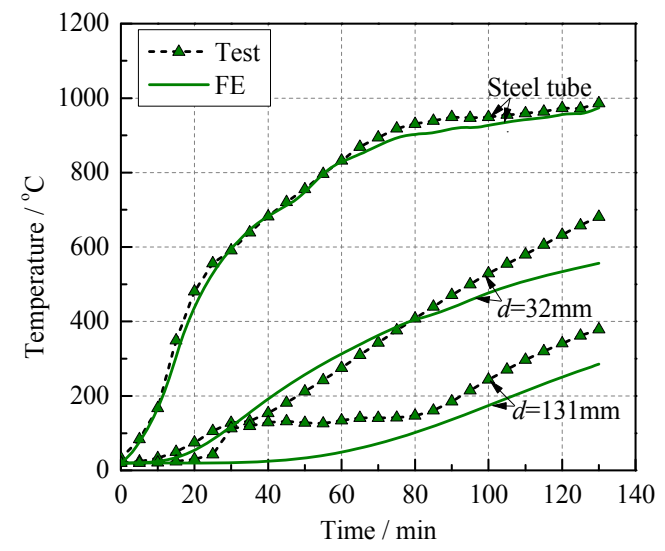

(b)

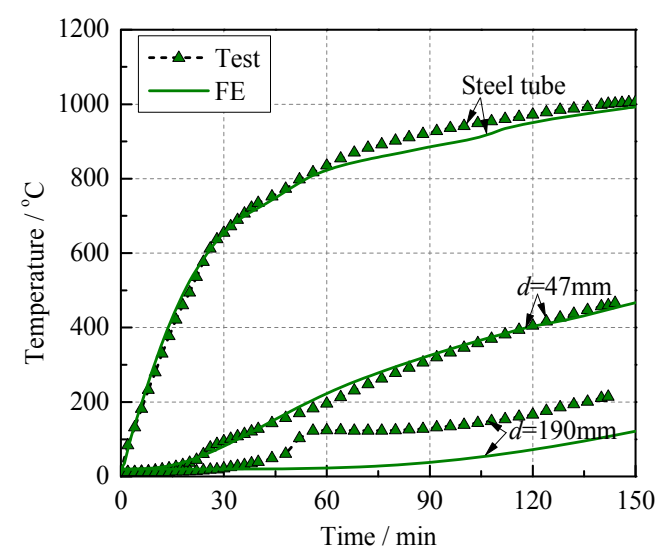

(d)

Fig. 15 Comparisons between the FE predicted and test temperatures of plain concrete-filled steel tubular columns (Lie and Chabot 1992): (a) C11; (b) C21; (c) C29; and (d) C60.

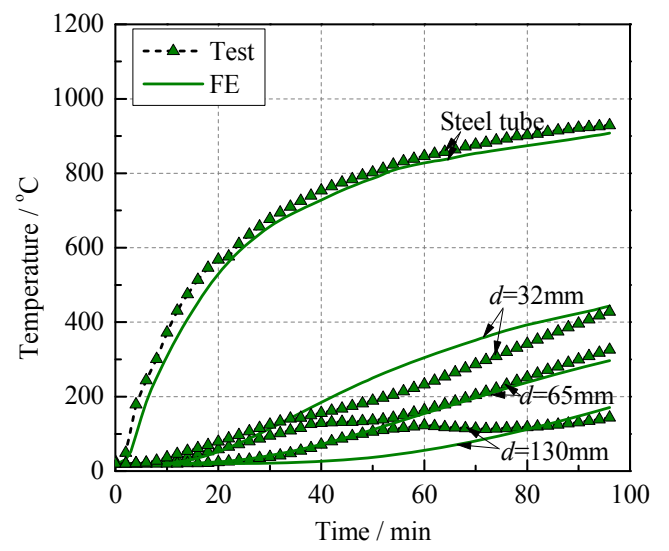

(a)

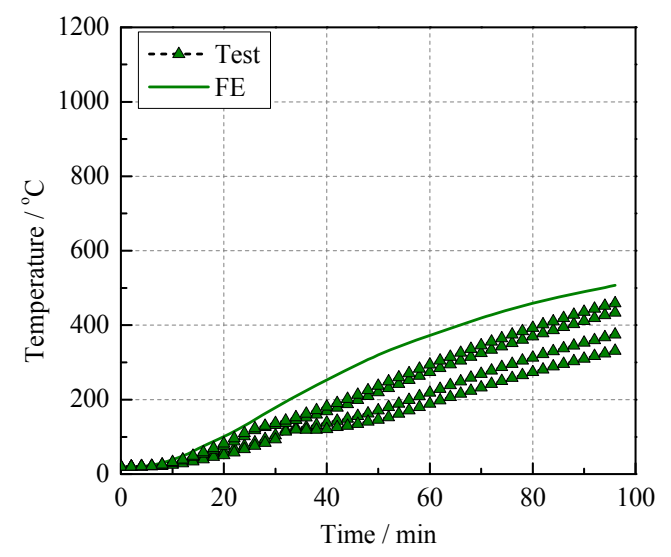

(b)

Fig.16 Comparisons between the FE predicted and test temperatures of reinforced concrete-filled steel tubular columns (Chabot and Lie 1992): C49: (a) steel tube and concrete; and (b) reinforcing bar. 


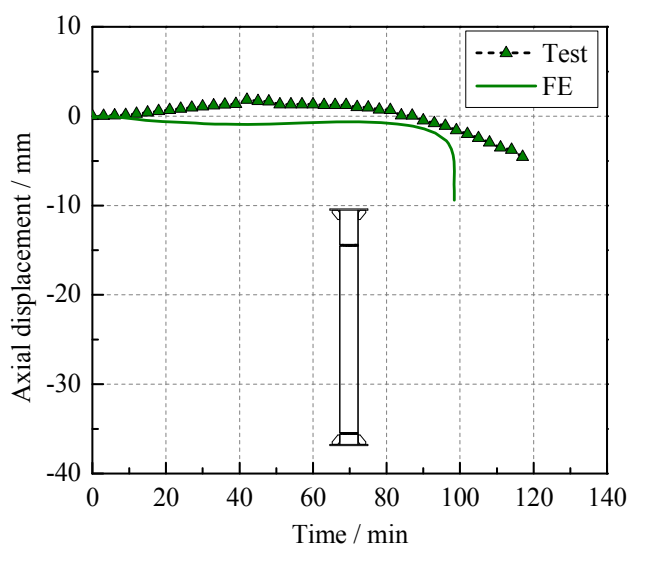

(a)

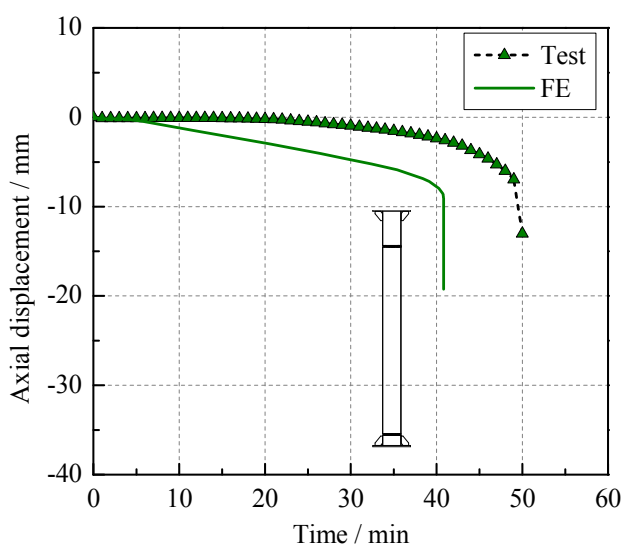

(c)

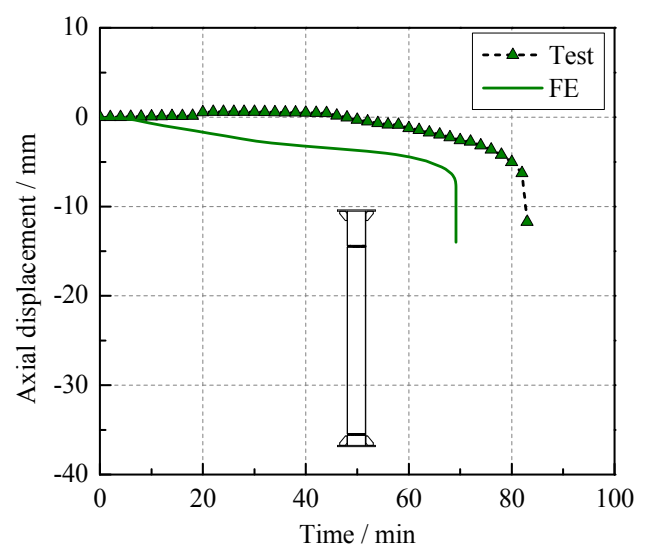

(b)

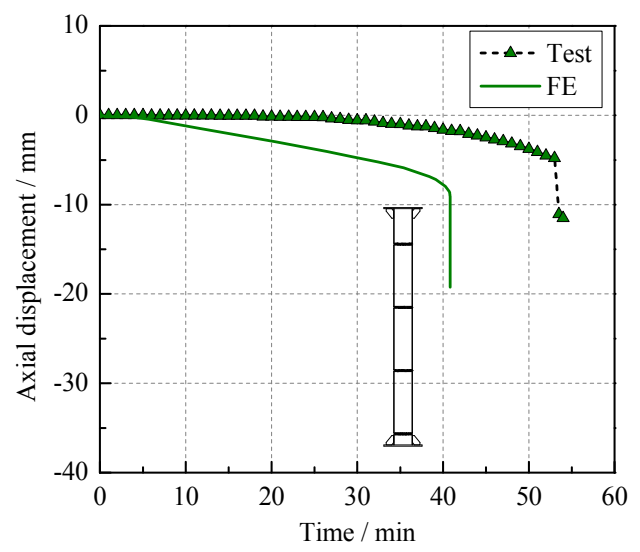

(d)

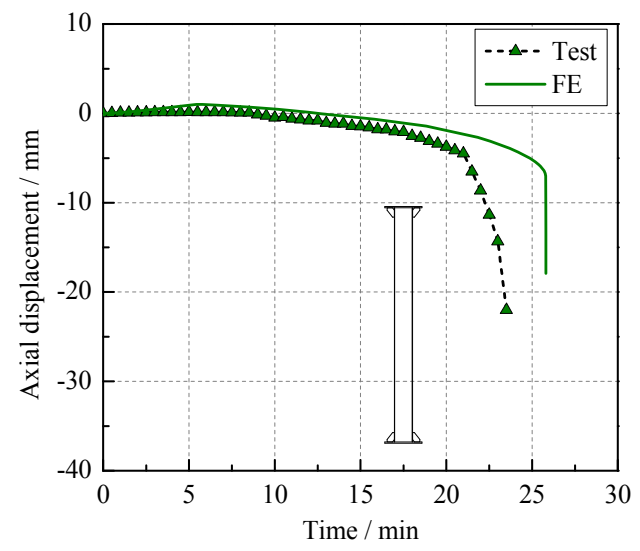

Fig.17 Comparisons between the FE predicted and test deformation-time curves of STCRC columns: (a) STCRC-1; (b) STCRC-2; (c) STCRC-3; (d) STCRC-4; and (e) CFST. 


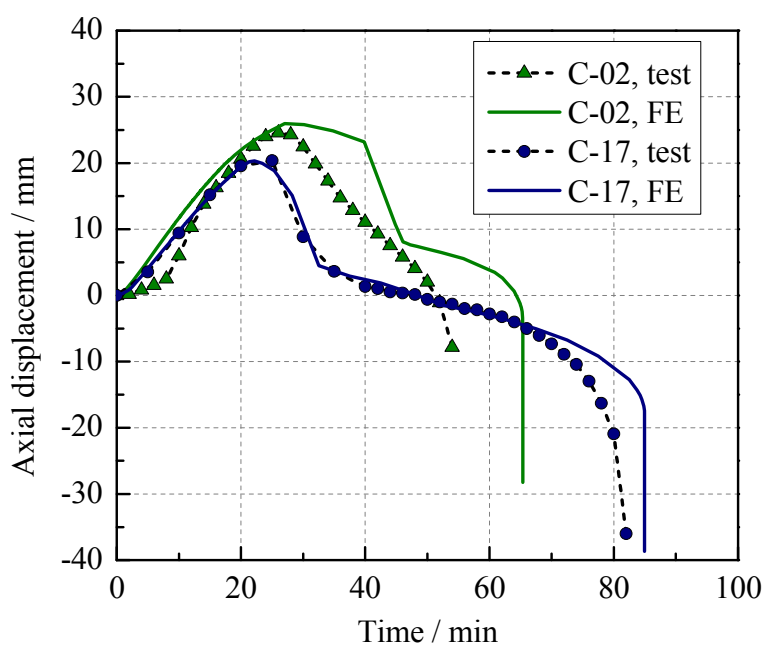

(a)

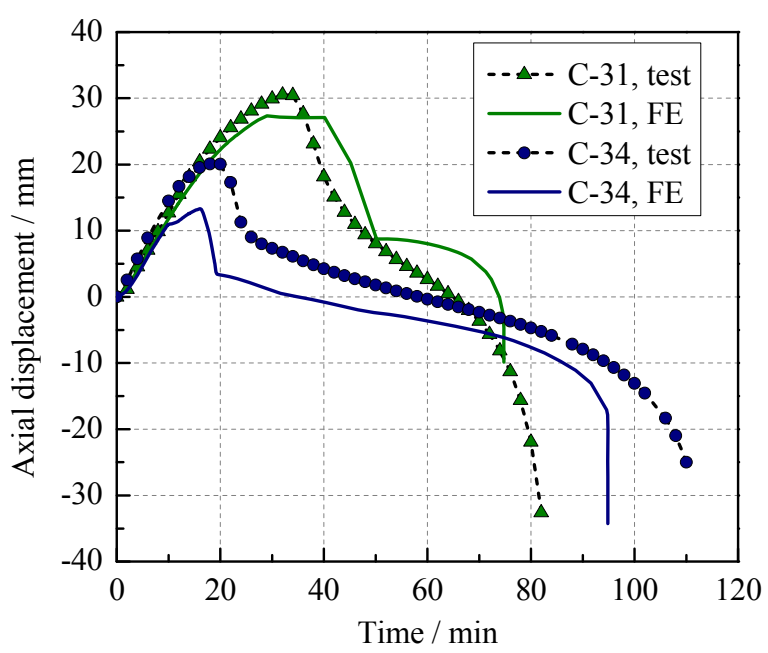

(c)

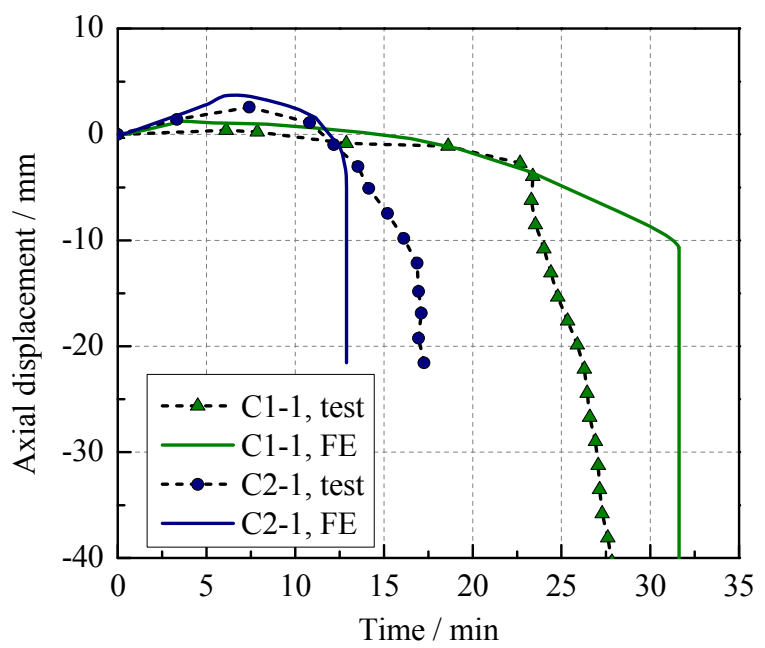

(e)

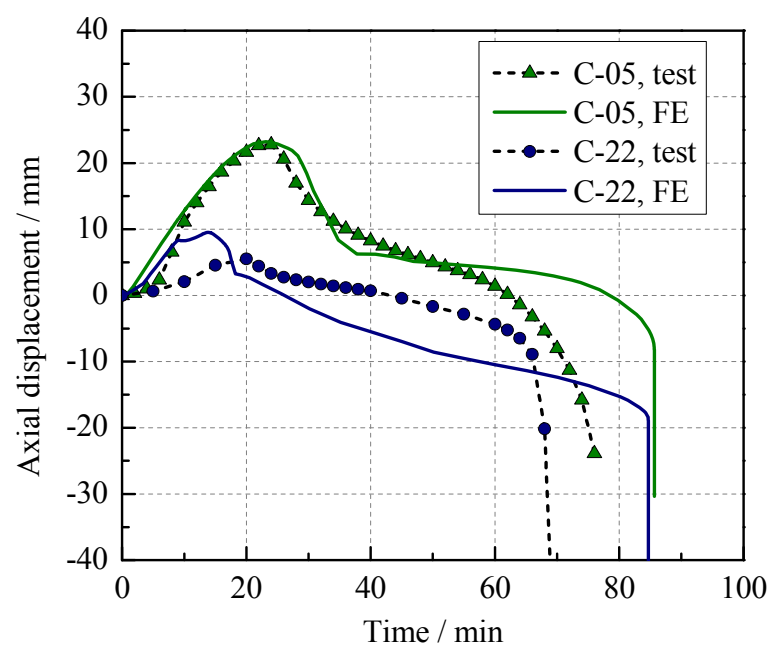

(b)

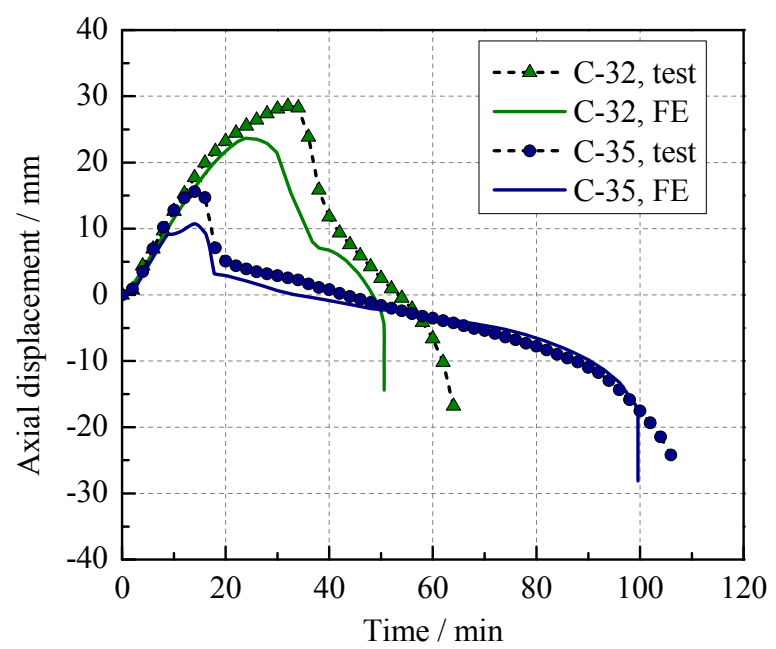

(d)

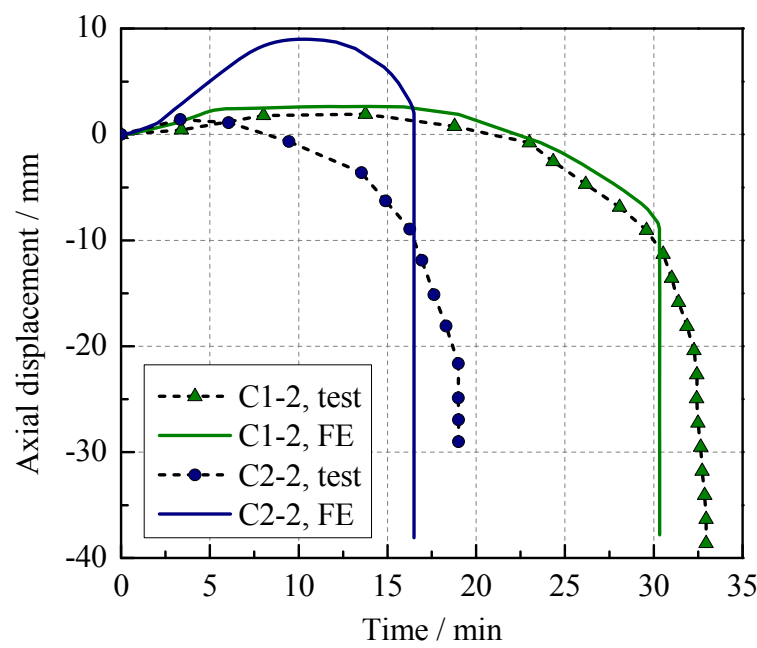

(f)

Fig. 18 Comparisons between the FE predicted and test deformation-time curves of plain concrete-filled steel tubular columns (Lie and Chabot 1992; Han et al. 2013): (a) C-02 and C-17; (b) C-05 and C-22; (c) C-31 and C-34; (d) C-32 and C-35; (e) C1-1 and C2-1; and (f) C1-2 and C2-2. 


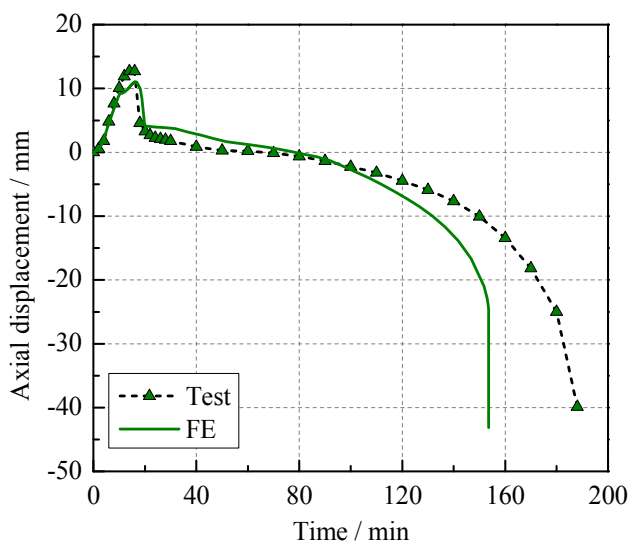

(a)

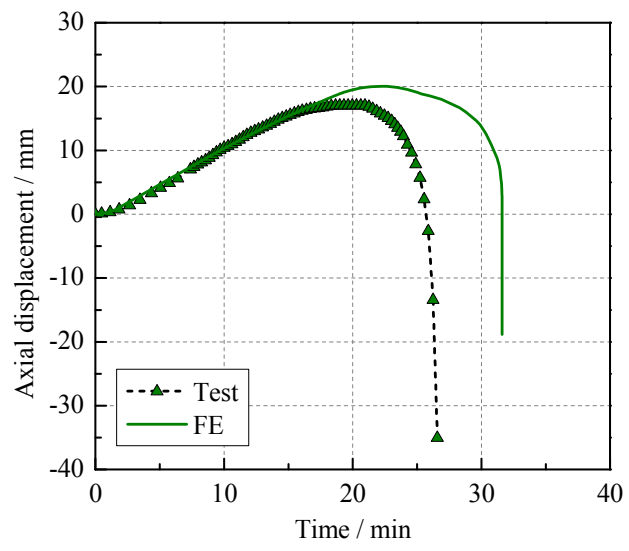

(c)

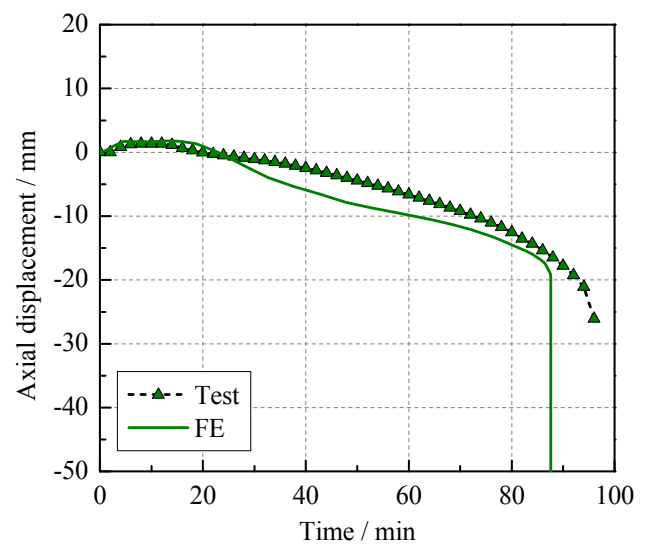

(b)

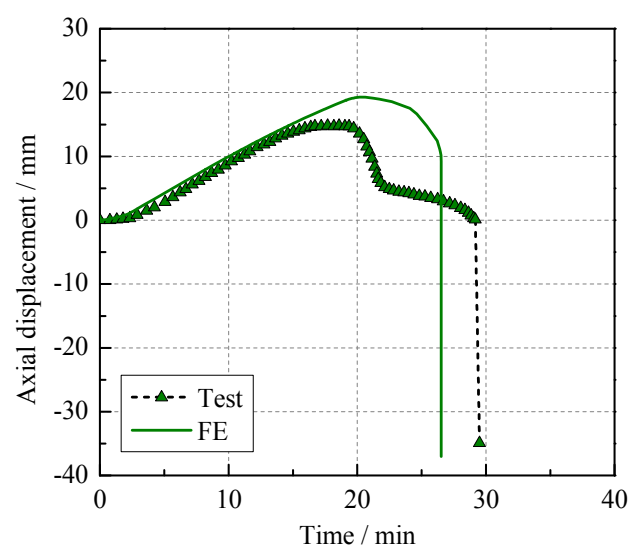

(d)

Fig.19 Comparisons between the FE predicted and test deformation-time curves of reinforced concrete-filled steel tubular columns (Chabot and Lie 1992; Espinos et al. 2015): (a) C48; (b) C49; (c) C1; and (d) C3. 


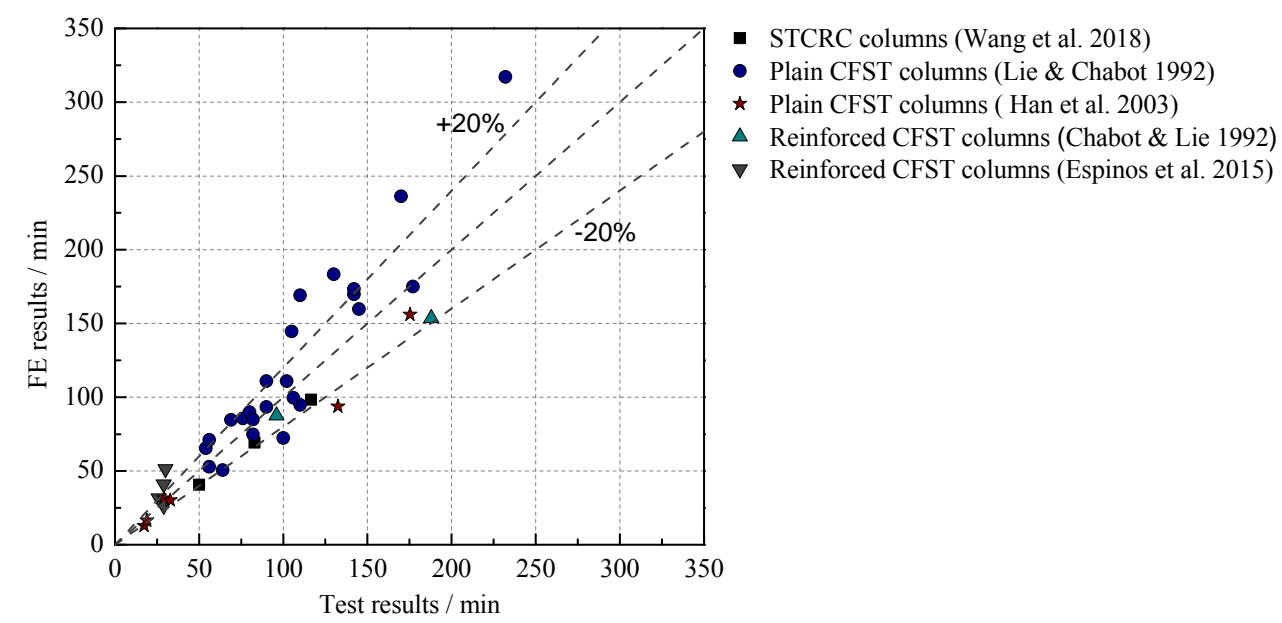

Fig.20 Comparison between FE predicted and test fire resistances. 


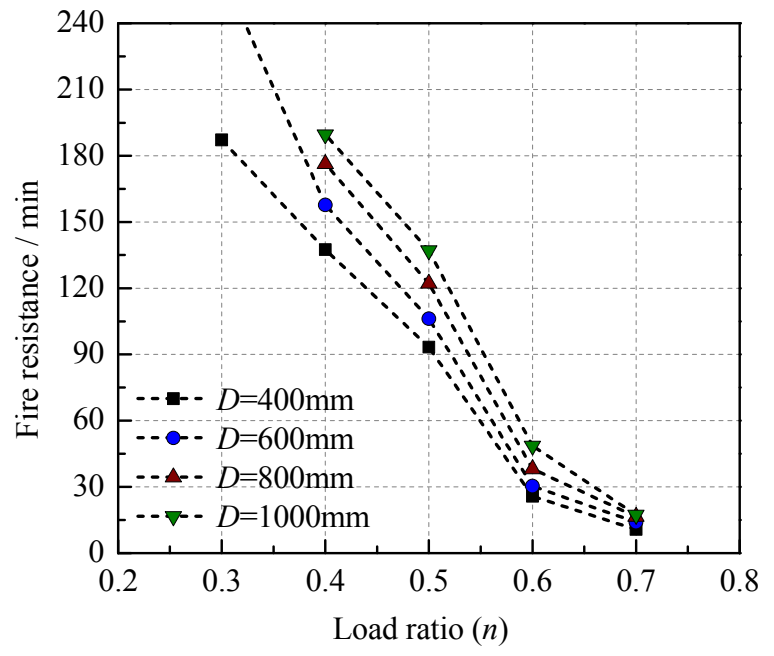

(a)

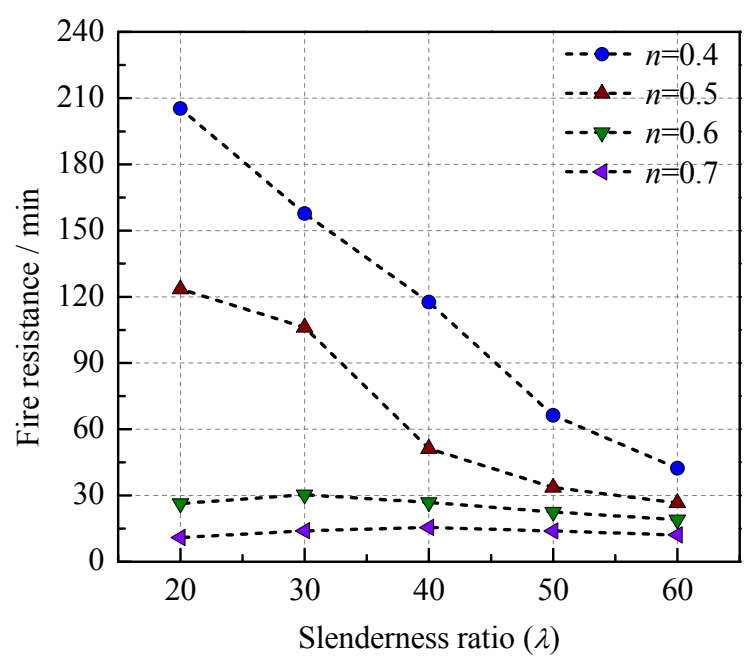

(c)

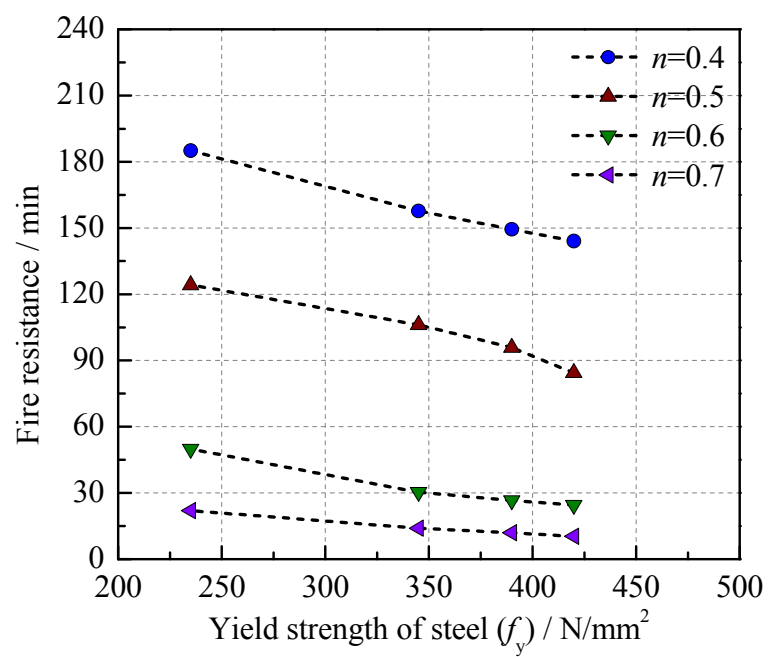

(e)

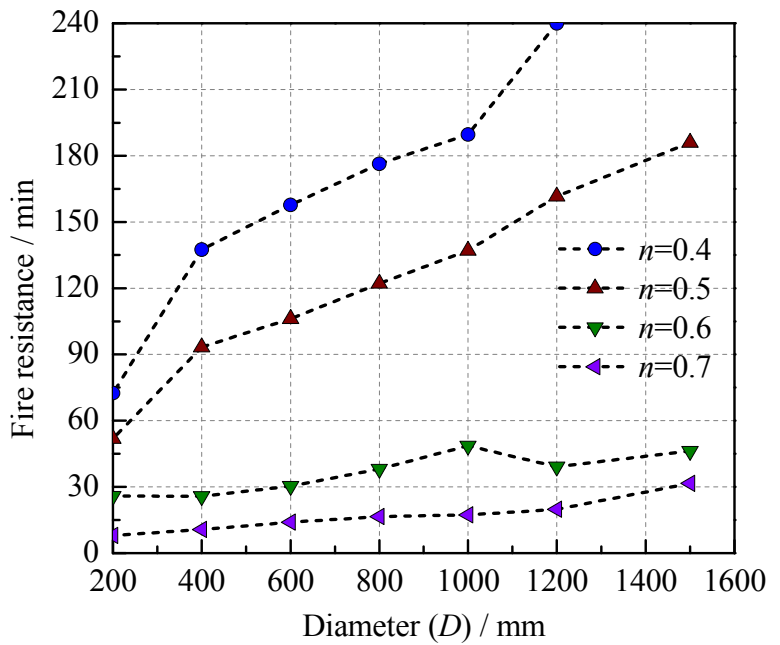

(b)

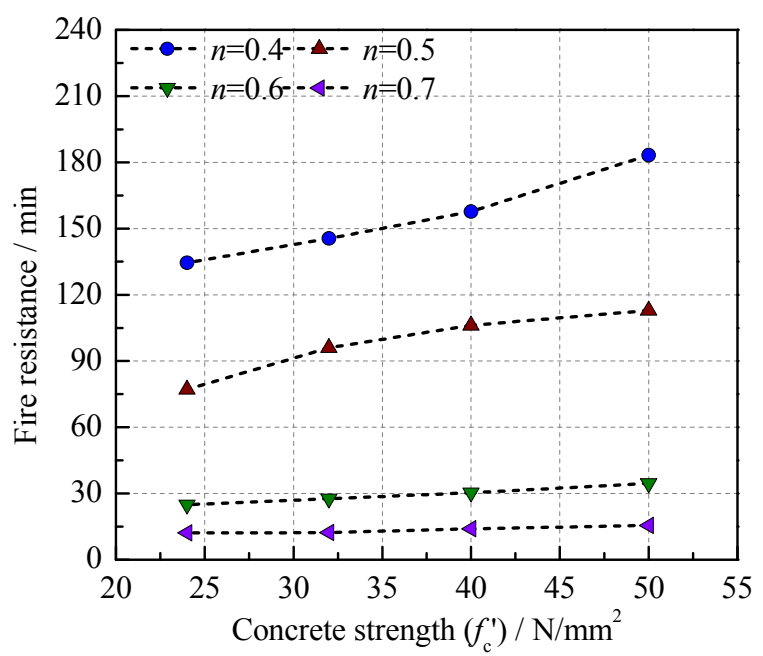

(d)

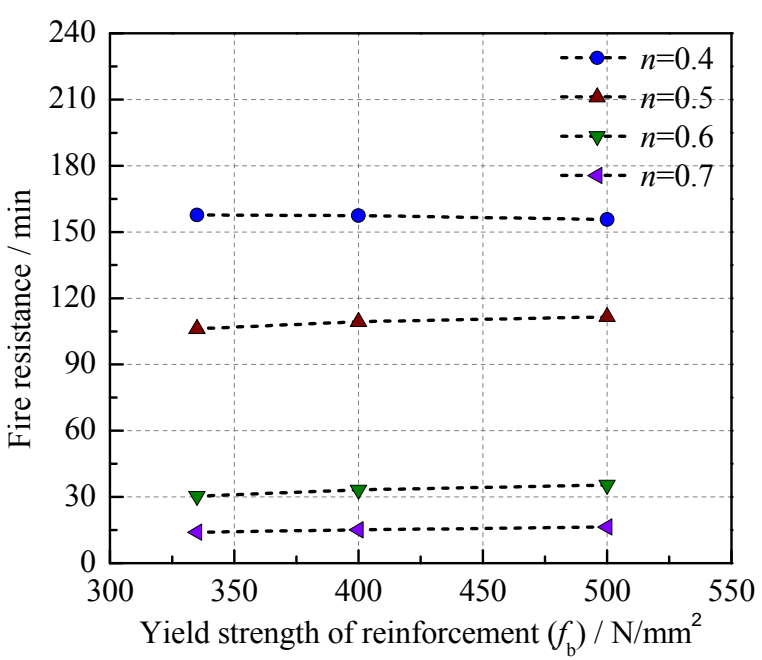

(f) 


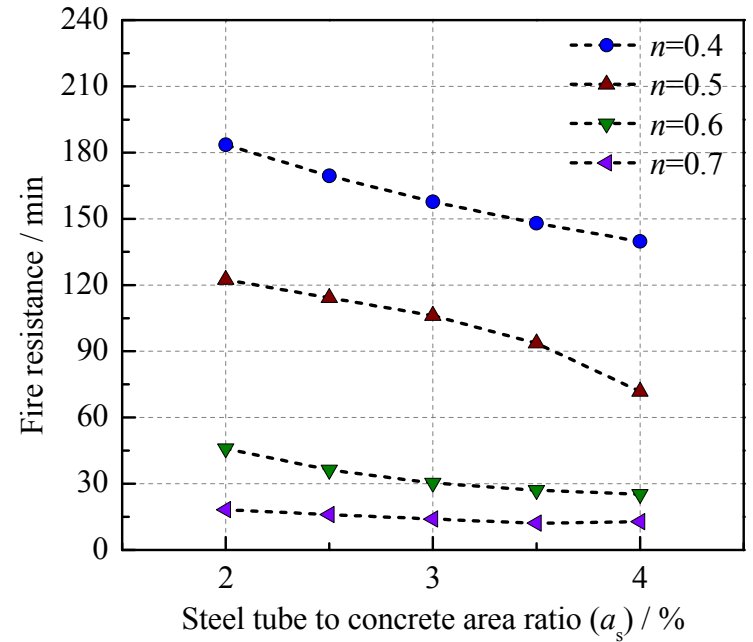

(g)

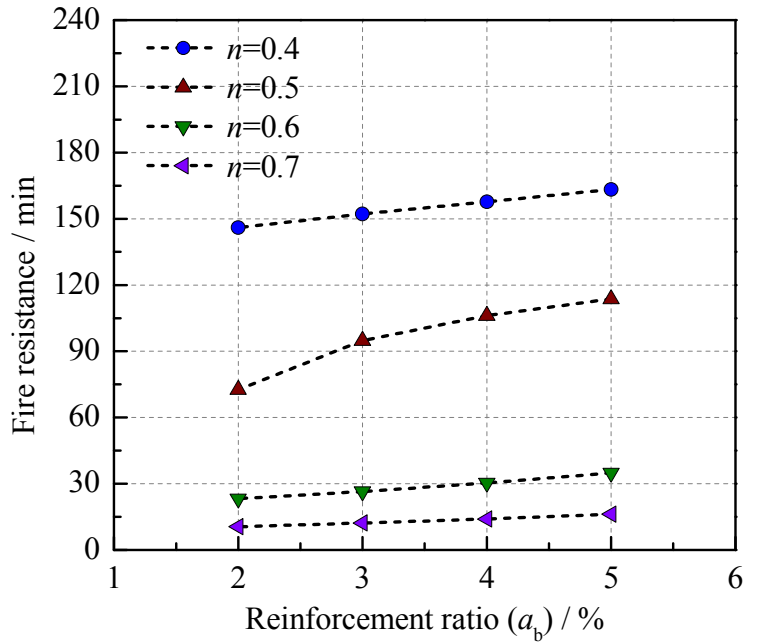

(h)

Fig.21 Influences of parameters on the fire resistance: (a) load ratio; (b) cross-section dimension; (c) slenderness ratio; (d) concrete strength; (e) yield strength of steel; (f) yield strength of reinforcement; (g) steel tube to concrete area ratio; and (h) reinforcement ratio. 


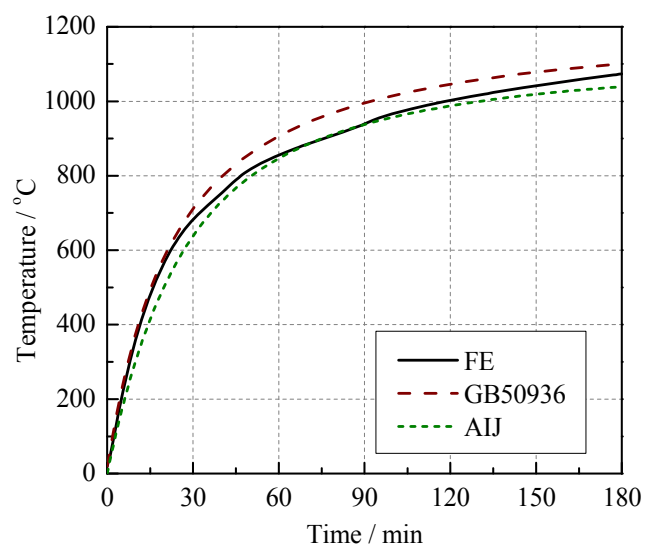

Fig.22 Comparison of predicted temperatures of steel tube between simplified methods and FE model $(D=600$ $\left.\mathrm{mm}, \alpha_{\mathrm{s}}=3.0 \%\right)$. 


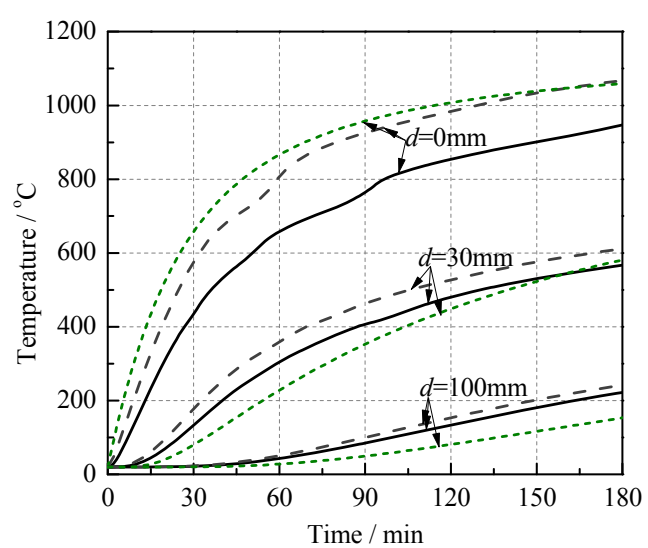

— With TR - - - Without TR -...- AIJ

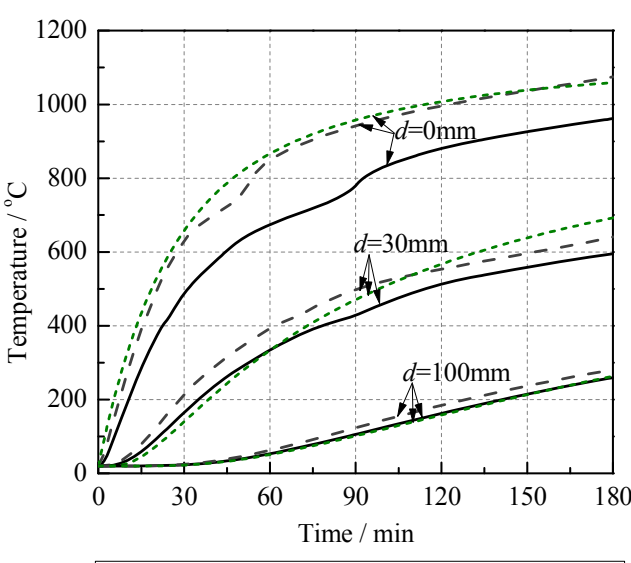

— With TR - - - Without TR - - - - AIJ

(a)

(b)

Fig.23 Influence of thermal resistance (TR) on the concrete temperature ( $\alpha_{\mathrm{s}}=3 \%$ ): (a) $D=600 \mathrm{~mm}$; and (b) $D=1200$ $\mathrm{mm}$. 


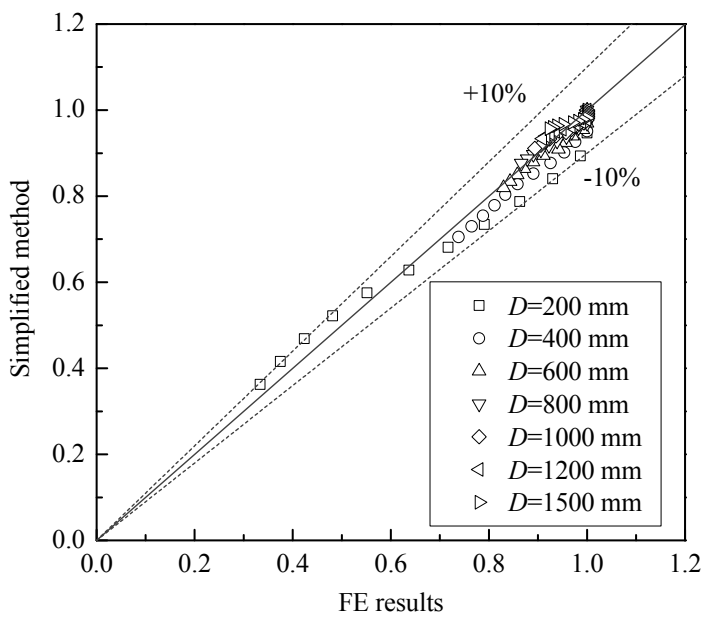

Fig.24 Comparison of predicted reduction factor for the concrete strength between simplified method and FE model. 


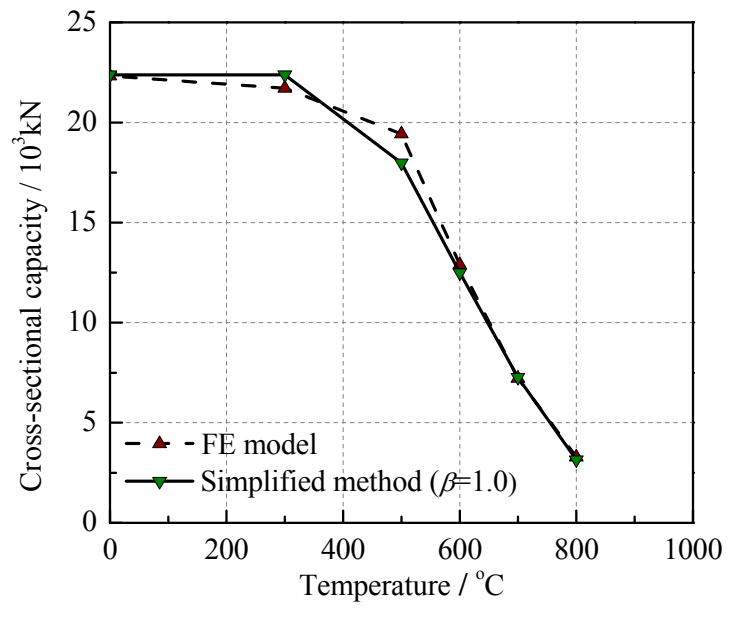

(a)

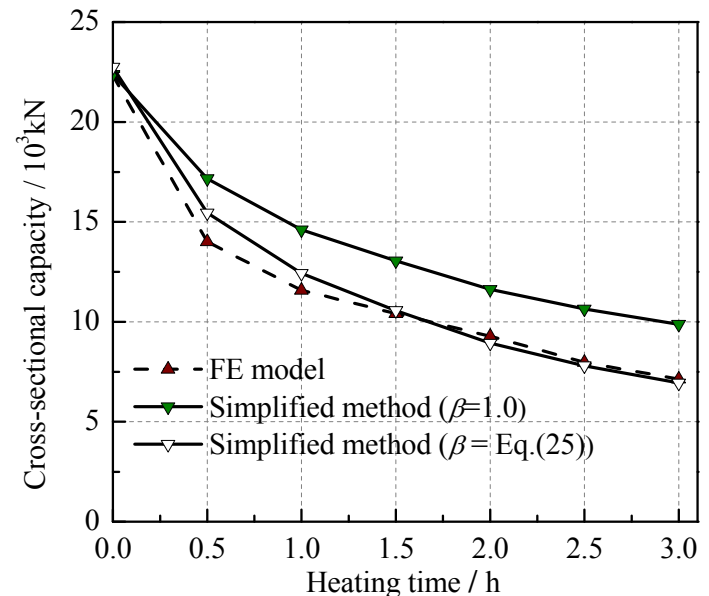

(b)

Fig.25 Influences of thermal gradient on the load-bearing capacities of circular STCRC columns under: (a) uniform temperature and (b) ISO 834 standard fire. 


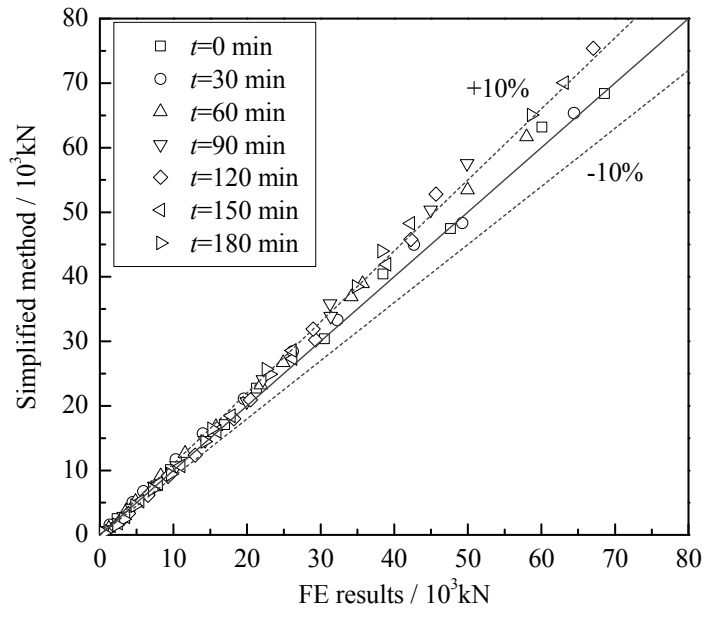

(a)

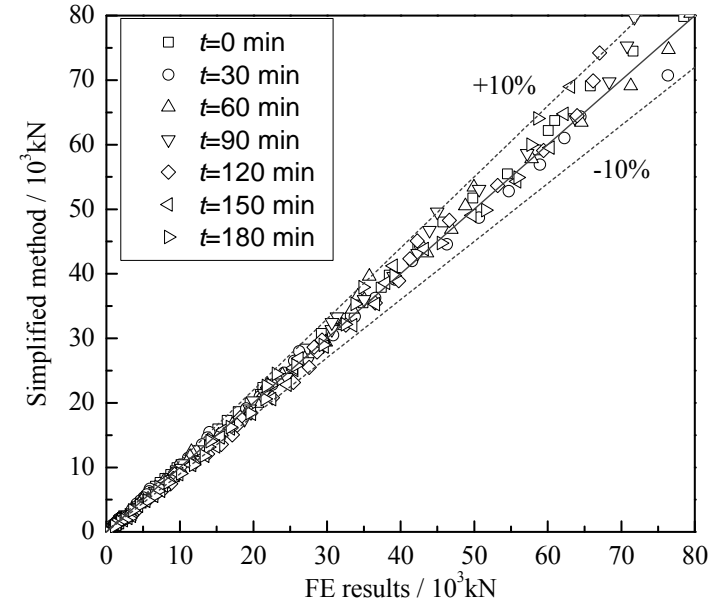

(b)

Fig.26 Comparison between predicted load-bearing capacities using the simplified design method and the FE model: (a) cross-section capacity; and (b) buckling capacity. 
Table 1 Details of test specimens

\begin{tabular}{|c|c|c|c|c|c|c|c|c|c|c|c|c|c|c|}
\hline \multirow{2}{*}{$\begin{array}{c}\text { Column } \\
\text { no. }\end{array}$} & \multicolumn{2}{|c|}{$D(\mathrm{~mm})$} & \multicolumn{2}{|c|}{$t_{\mathrm{s}}(\mathrm{mm})$} & \multirow{2}{*}{$\begin{array}{c}L \\
(\mathrm{~mm})\end{array}$} & \multirow{2}{*}{$\begin{array}{c}\alpha_{\mathrm{S}} \\
(\%)\end{array}$} & \multirow{2}{*}{$\begin{array}{c}\text { Reinforcing } \\
\text { bars }\end{array}$} & \multirow{2}{*}{$\begin{array}{c}\alpha_{\mathrm{b}} \\
(\%)\end{array}$} & \multirow{2}{*}{$\begin{array}{c}N_{\mathrm{f}} \\
(\mathrm{kN})\end{array}$} & \multirow[t]{2}{*}{$n$} & \multirow[t]{2}{*}{ Case } & \multicolumn{3}{|c|}{$\begin{array}{c}\text { Fire } \\
\text { Resistance } \\
\text { (min) }\end{array}$} \\
\hline & Nominal & Measured & Nominal & Measured & & & & & & & & Test & $\mathrm{FE}$ & Eq. \\
\hline STCRC-1 & 300 & 299.2 & 2.75 & 2.53 & 3810 & 3.38 & $8 ø 20$ & 3.68 & 1340 & 0.25 & $\mathrm{a}$ & 117 & 98 & 104 \\
\hline STCRC-2 & 300 & 299.5 & 2.75 & 2.53 & 3810 & 3.38 & $8 ø 20$ & 3.68 & 1800 & 0.33 & $\mathrm{a}$ & 83 & 69 & 79 \\
\hline STCRC-3 & 300 & 298.9 & 2.75 & 2.53 & 3810 & 3.39 & $8 ø 20$ & 3.68 & 2240 & 0.42 & $\mathrm{a}$ & 50 & 41 & 60 \\
\hline STCRC-4 & 300 & 299.1 & 2.75 & 2.53 & 3810 & 3.38 & $8 ø 20$ & 3.68 & 2240 & 0.42 & b & 54 & 41 & 60 \\
\hline CFST & 300 & 299.3 & 6.00 & 5.67 & 3810 & 7.58 & - & - & 2168 & 0.42 & - & 23 & 26 & - \\
\hline
\end{tabular}


Table 2 Measured properties of the structural steel

\begin{tabular}{cccccc}
\hline Column no. & $t_{\mathrm{s}}(\mathrm{mm})$ & $f_{\text {sy }}\left(\mathrm{N} / \mathrm{mm}^{2}\right)$ & $f_{\text {su }}\left(\mathrm{N} / \mathrm{mm}^{2}\right)$ & $E_{\mathrm{s}}\left(\times 10^{5} \mathrm{~N} / \mathrm{mm}^{2}\right)$ & $v_{\mathrm{s}}$ \\
\hline STCRC1-STCRC4 & 2.53 & 291.3 & 409.5 & 1.955 & 0.24 \\
CFST & 5.67 & 264.6 & 435.3 & 1.795 & 0.26 \\
\hline
\end{tabular}


Table 3 Measured properties of the reinforcing bars

\begin{tabular}{ccccc}
\hline Steel type & $d_{\mathrm{b}}(\mathrm{mm})$ & $f_{\text {by }}\left(\mathrm{N} / \mathrm{mm}^{2}\right)$ & $f_{\text {bu }}\left(\mathrm{N} / \mathrm{mm}^{2}\right)$ & $E_{\mathrm{b}}\left(\times 10^{5} \mathrm{~N} / \mathrm{mm}^{2}\right)$ \\
\hline Hot-rolled plain & 6.8 & 435.4 & 668.8 & 1.930 \\
Hot-rolled ribbed & 20.0 & 357.4 & 570.5 & 1.838 \\
\hline
\end{tabular}


Table 4 Measured properties of the concrete

\begin{tabular}{ccc}
\hline$f_{\text {cu }}\left(\mathrm{N} / \mathrm{mm}^{2}\right)$ & $E_{\mathrm{c}}\left(\times 10^{4} \mathrm{~N} / \mathrm{mm}^{2}\right)$ & Ages of concrete (days) \\
\hline 33.7 & 2.518 & 28 \\
73.2 & 3.850 & 518 \\
\hline
\end{tabular}




\begin{tabular}{cccccc}
\hline Column no. & Sources & $D(\mathrm{~mm})$ & $t_{\mathrm{s}}(\mathrm{mm})$ & Reinforcing bars & $\begin{array}{c}\text { Concrete } \\
\text { cover } \\
(\mathrm{mm})\end{array}$ \\
\hline C02 & & 141.3 & 6.55 & - & - \\
C11 & 219.1 & 4.78 & - & - \\
C21 & Lie and & 273.1 & 5.56 & - & - \\
C25 & Chabot (1992) & 323.9 & 6.35 & - & - \\
C29 & & 355.6 & 12.7 & - & - \\
C60 & & 406.4 & 12.7 & - & - \\
\hline C48 & Chabot and & 273.1 & 6.35 & $4 \varnothing 19.5 \mathrm{~mm}$ & 23 \\
C49 & Lie (1992) & 273.1 & 6.35 & $4 \varnothing 19.5 \mathrm{~mm}$ & 23 \\
\hline
\end{tabular}


Table 6 Details of plain concrete-filled steel tubular columns

\begin{tabular}{|c|c|c|c|c|c|c|c|c|c|c|c|c|}
\hline \multirow[t]{2}{*}{$\begin{array}{c}\text { Column } \\
\text { no. }\end{array}$} & \multirow[t]{2}{*}{ Sources } & \multirow[t]{2}{*}{$\begin{array}{c}D \\
(\mathrm{~mm})\end{array}$} & \multirow[t]{2}{*}{$\begin{array}{c}t_{\mathrm{s}} \\
(\mathrm{mm})\end{array}$} & \multirow[t]{2}{*}{$\begin{array}{c}L \\
(\mathrm{~mm})\end{array}$} & \multirow[t]{2}{*}{$\begin{array}{c}e \\
(\mathrm{~mm})\end{array}$} & \multirow[t]{2}{*}{$\begin{array}{l}\text { Boundary } \\
\text { conditions }\end{array}$} & \multirow[t]{2}{*}{$\begin{array}{c}f_{\mathrm{c}}^{\prime} \\
(\mathrm{MPa})\end{array}$} & \multirow[t]{2}{*}{$\begin{array}{c}f_{\mathrm{y}} \\
(\mathrm{MPa})\end{array}$} & \multirow[t]{2}{*}{$\begin{array}{c}N_{\mathrm{f}} \\
(\mathrm{kN})\end{array}$} & \multirow[t]{2}{*}{$\begin{array}{c}a \\
(\mathrm{~mm})\end{array}$} & \multicolumn{2}{|c|}{$\begin{array}{c}\text { Fire } \\
\text { resistance } \\
\text { (min) }\end{array}$} \\
\hline & & & & & & & & & & & Test & $\mathrm{FE}$ \\
\hline C-02 & & 141.3 & 6.55 & 3810 & 0 & & 33.1 & 350 & 110 & 0 & 55 & 65 \\
\hline C-04 & & 141.3 & 6.55 & 3810 & 0 & & 31.0 & 350 & 131 & 0 & 57 & 53 \\
\hline C-05 & & 168.3 & 4.78 & 3810 & 0 & & 32.7 & 350 & 150 & 0 & 76 & 86 \\
\hline C-08 & & 168.3 & 4.78 & 3810 & 0 & & 35.5 & 350 & 218 & 0 & 56 & 71 \\
\hline C-09 & & 168.3 & 6.35 & 3810 & 0 & & 35.4 & 350 & 150 & 0 & 81 & 90 \\
\hline C-13 & & 219.1 & 4.78 & 3810 & 0 & & 32.3 & 350 & 384 & 0 & 102 & 111 \\
\hline C-17 & & 219.1 & 8.18 & 3810 & 0 & & 31.7 & 350 & 525 & 0 & 82 & 85 \\
\hline C-20 & & 273.1 & 5.56 & 3810 & 0 & & 28.6 & 350 & 574 & 0 & 112 & 169 \\
\hline C-21 & & 273.1 & 5.56 & 3810 & 0 & & 29.0 & 350 & 525 & 0 & 130 & 183 \\
\hline C-22 & & 273.1 & 5.56 & 3810 & 0 & & 27.2 & 350 & 1000 & 0 & 70 & 85 \\
\hline C-23 & & 273.1 & 12.7 & 3810 & 0 & & 27.4 & 350 & 525 & 0 & 143 & 170 \\
\hline C-25 & Lie and & 323.9 & 6.35 & 3810 & 0 & & 27.6 & 350 & 699 & 0 & 145 & 160 \\
\hline C-26 & Chabot & 323.9 & 6.35 & 3810 & 0 & Fixed & 24.3 & 350 & 1050 & 0 & 93 & 93 \\
\hline C-29 & (1992) & 355.6 & 12.7 & 3810 & 0 & -fixed & 25.4 & 350 & 1050 & 0 & 170 & 236 \\
\hline C-31 & & 141.3 & 6.55 & 3810 & 0 & & 30.2 & 300 & 80 & 0 & 82 & 75 \\
\hline C-32 & & 141.3 & 6.55 & 3810 & 0 & & 34.8 & 300 & 143 & 0 & 64 & 51 \\
\hline C-34 & & 219.1 & 4.78 & 3810 & 0 & & 35.4 & 300 & 500 & 0 & 111 & 95 \\
\hline C-35 & & 219.1 & 4.78 & 3810 & 0 & & 42.7 & 300 & 560 & 0 & 108 & 100 \\
\hline C-37 & & 219.1 & 8.18 & 3810 & 0 & & 28.7 & 350 & 560 & 0 & 102 & 72 \\
\hline C-40 & & 273.1 & 6.35 & 3810 & 0 & & 46.5 & 350 & 1050 & 0 & 106 & 145 \\
\hline C-42 & & 273.1 & 6.35 & 3810 & 0 & & 55.4 & 350 & 1050 & 0 & 90 & 111 \\
\hline C-44 & & 273.1 & 6.35 & 3810 & 0 & & 38.7 & 350 & 715 & 0 & 178 & 175 \\
\hline C-45 & & 273.1 & 6.35 & 3810 & 0 & & 38.2 & 350 & 712 & 0 & 144 & 173 \\
\hline C-50 & & 323.9 & 6.35 & 3810 & 0 & & 42.4 & 300 & 820 & 0 & 234 & 317 \\
\hline C-55 & & 355.6 & 12.7 & 3810 & 0 & & 40.7 & 300 & 965 & 0 & 274 & 361 \\
\hline C1-1 & & 478 & 8 & 3810 & 0 & & 39.6 & 293 & 4700 & 0 & 29 & 32 \\
\hline C1-2 & & 478 & 8 & 3810 & 71.7 & & 39.6 & 293 & 2200 & 0 & 32 & 30 \\
\hline C2-1 & Han & 219 & 5 & 3810 & 32.9 & Pinned & 39.6 & 293 & 450 & 0 & 17 & 13 \\
\hline C2-2 & (2013) & 219 & 5 & 3810 & 65.7 & -pinned & 39.6 & 293 & 300 & 0 & 18 & 17 \\
\hline C2-3 & & 219 & 5 & 3810 & 0 & & 39.6 & 293 & 960 & 15 & 132 & 94 \\
\hline C2-4 & & 219 & 5 & 3810 & 0 & & 39.6 & 293 & 960 & 25 & 175 & 156 \\
\hline
\end{tabular}




\begin{tabular}{cccccccccccccccc}
\hline $\begin{array}{c}\text { Column } \\
\text { no. }\end{array}$ & Sources & $\begin{array}{c}D \\
(\mathrm{~mm})\end{array}$ & $\begin{array}{c}t_{\mathrm{s}} \\
(\mathrm{mm})\end{array}$ & Reinf. & $\mathrm{e} / \mathrm{D}$ & $\begin{array}{c}L \\
(\mathrm{~mm})\end{array}$ & $\begin{array}{c}\text { Boundary } \\
\text { conditions }\end{array}$ & $\begin{array}{c}f_{\mathrm{c}}^{\prime} \\
(\mathrm{MPa})\end{array}$ & $\begin{array}{c}f_{\mathrm{y}} \\
(\mathrm{MPa})\end{array}$ & $\begin{array}{c}f_{\mathrm{b}} \\
(\mathrm{MPa})\end{array}$ & $\begin{array}{c}N_{\mathrm{f}} \\
(\mathrm{kN})\end{array}$ & $\begin{array}{c}\text { Fire } \\
\text { resistance } \\
(\mathrm{min})\end{array}$ \\
\hline C48 & Chabot & 273.1 & 6.35 & $4 ø 19.5$ & 0 & 3810 & Fixed & 46.7 & 350.0 & 400.0 & 1050.0 & 188 & 154 \\
C49 & and Lie & 273.1 & 6.35 & $4 ø 19.5$ & 0 & 3810 & -fixed & 47.0 & 350.0 & 400.0 & 1900.0 & 96 & 88 \\
C1 & (1992) & & 193.7 & 8 & $6 ø 12$ & 0.5 & 3210 & & 36.4 & 359.1 & 512.4 & 186.7 & 26 & 32 \\
C2 & Espinos & 273.0 & 10 & $6 ø 16$ & 0.5 & 3210 & Pinned & 37.6 & 369.7 & 553.5 & 387.5 & 30 & 51 \\
C3 & et al. & 193.7 & 8 & $6 ø 12$ & 0 & 3210 & -pinned & 43.2 & 359.1 & 512.4 & 535.6 & 29 & 27 \\
C5 & (2015) & 193.7 & 8 & $6 ø 16$ & 0.75 & 3210 & & 35.8 & 359.1 & 553.5 & 152.4 & 29 & 41 \\
\hline
\end{tabular}

